\title{
LA HUELLA DE CARBONO EN LAS INFRAESTRUCTURAS HIDRÁULICAS DE LAS ISLAS BALEARES
}

\author{
Noelia Cruz Pérez \\ Juan Carlos Santamarta Cerezal \\ Celso García \\ Pablo Rodríguez-Lozano \\ Dolores Tirado
}

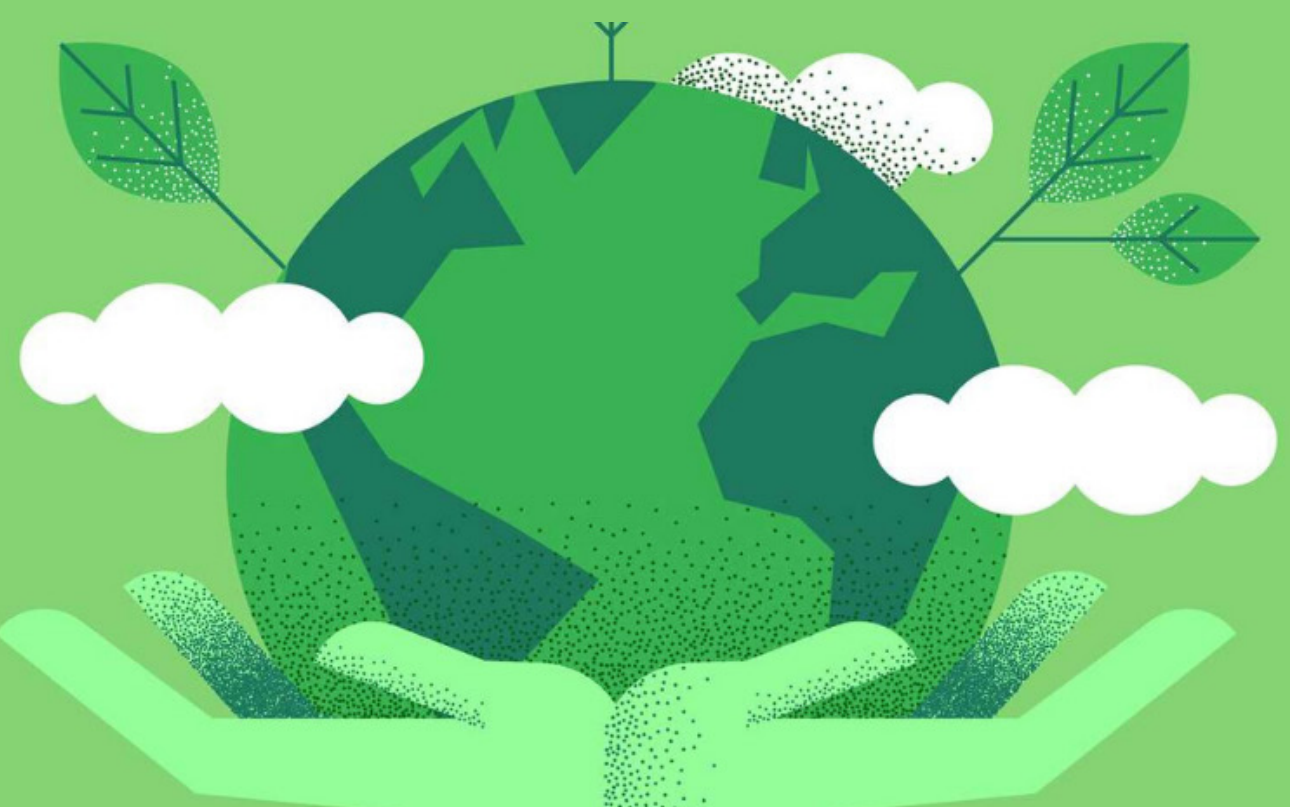




\section{䍀}

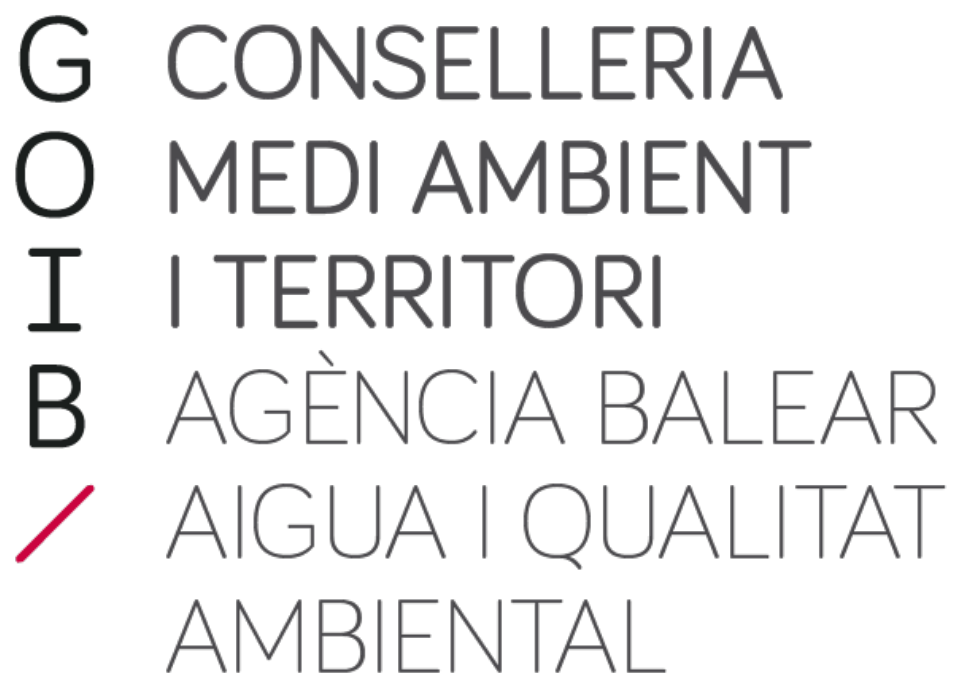

\section{LA HUELLA DE CARBONO EN LAS INFRAESTRUCTURAS HIDRÁULICAS DE LAS ISLAS BALEARES}

Noelia Cruz Pérez Juan Carlos Santamarta Cerezal

Celso García Pablo Rodríguez-Lozano Dolores Tirado 
Edita: Consejería de Medio Ambiente y Territorio de las Illes Balears con la colaboración de la Universidad de La Laguna y la Universitat de les Illes Balears.

(c) Noelia Cruz Pérez, Juan Carlos Santamarta Cerezal, Celso García García.

Director científico del proyecto: Dr. Juan Carlos Santamarta Cerezal. jcsanta@ull.es. Universidad de La Laguna.

Dirección del proyecto de parte de la Administración: Juan Antonio García Martínez, Agencia Balear del Agua y la Calidad Ambiental

Financiación: Este estudio se ha financiado a través del "Asesoramiento técnico y transferencia de conocimiento en materia de sostenibilidad y de estimación de la huella de carbono en las instalaciones vinculadas al ciclo integral del agua en las Islas Baleares, como punto de partida en la reducción de emisiones de gases de efecto invernadero» de la Agencia Balear del Agua y la Calidad Ambiental (ABAQUA).

1a Edición: noviembre 2021

ISBN: 978-84-09-34448-2

Depósito legal: TF 621-2021

DOI: https://doi.org/10.25145/b.CarbonoBaleares.2021

Cómo citar este libro:

Cruz-Pérez, N., Santamarta, J.C., García, C., Rodríguez-Lozano, P., Tirado, D. (2021). La Huella de Carbono en las infraestructuras hidráulicas de las Islas Baleares. Universidad de La Laguna, Universitat de les Illes Balears y Consejería de Medio Ambiente y Territorio. https://doi.org/10.25145/b.CarbonoBaleares.2021

Ninguna parte de este libro puede ser reproducida o transmitida en cualquier forma o por cualquier medio, electrónico o mecánico, incluido fotografías, grabación o por cualquier sistema de almacenar información sin el permiso escrito del autor y editores. 


\section{ÍNDICE DE CONTENIDOS}

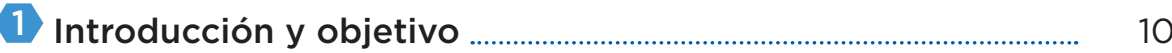

1.1. Efecto invernadero y cambio climático y cambio climático

1.2. Sostenibilidad y cambio climático …………............................. 13

1.3. Energías renovables ................................................................... 15

1.4. El ciclo urbano del agua en las Islas Baleares ..................... 16

1.4.1. Las masas de agua subterráneas ................................... 16

1.4.2. Las masas de agua superficiales .................................. 19

1.4.3. La desalación .......................................................................... 20

1.5. El caso de Mallorca .................................................................. 23

1.6. El caso de Menorca ............................................................ 25

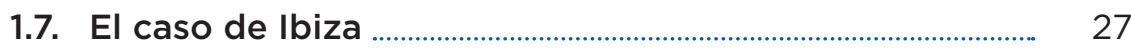

1.8. El caso de Formentera ................................................................. 28

2 Metodología _....................................................................................... 30

2.1. Huella de carbono ..................................................................... 30

2.1.1. Aplicación de la huella de carbono al caso de

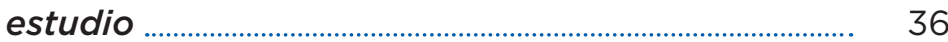

2.2. Huella hídrica ............................................................ 39

2.2.1. Aplicación de la huella hídrica al caso de estudio .. 41

3 Caracterización de la huella ambiental en las EDAR gestionadas por ABAQUA ........................................................ 42

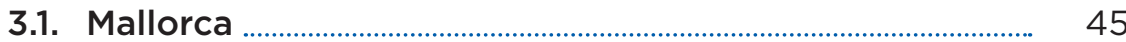

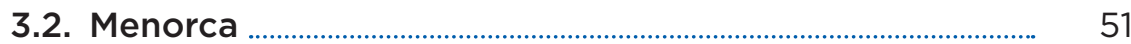

3.3. Ibiza ……………………………………………………………... 55

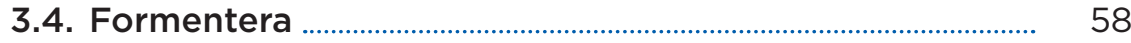


4 Caracterización de la huella ambiental en las IDAM gestionadas por ABAQUA

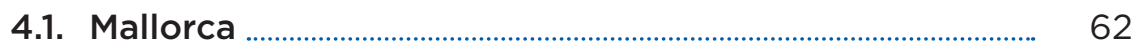

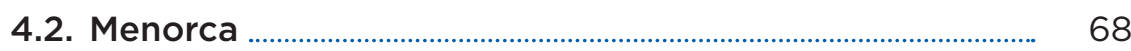

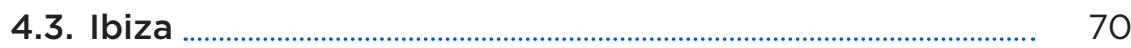

4.4. Formentera …………………………………………………….... 76

5 Caracterización de la huella ambiental en el resto de las instalaciones del ciclo del agua gestionadas por ABAQUA . 81

5.1. Captaciones de agua potable mediante bombeo ............. 81

5.1.1. Mallorca ....................................................................................... 82

5.2. Red de distribución en alta ................................................. 87

5.2.1.. Mallorca ........................................................................... 89

6 Conclusiones del estudio .......................................................................... 91

7 Recomendaciones ........................................................................................... 95

8 Referencias y bibliografía recomendada ....................................... 99

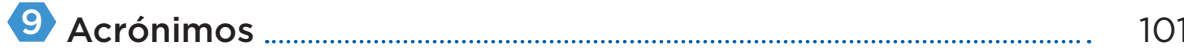




\section{ÍNDICE DE TABLAS}

Tabla 1. Presiones agrícolas, ganaderas y de abastecimiento público que afectan las masas de agua subterránea de las Islas Baleares

Tabla 2. Número de EDAR en el archipiélago balear

Tabla 3. Huella de carbono de la depuradora de Andratx en 2019 y 2020

Tabla 4. Huella de carbono de la depuradora Banyalbufar en 2019 y 2020

Tabla 5. Huella de carbono de la depuradora Camp de Mar en 2019 y 2020

Tabla 6. Huella de carbono de la depuradora Deia en 2019 y 2020

Tabla 7. Huella de carbono de la depuradora de Estellencs en 2019 y 2020

Tabla 8. Huella de carbono de la depuradora de Puigpunyent en 2019 y 2020

Tabla 9. Huella de carbono de la depuradora de Soller en 2019 y 2020

Tabla 10. Huella de carbono de la depuradora Cala Galdana en 2019 y 2020

Tabla 11. Huella de carbono de la depuradora Es Migjorn en 2019 y 2020

Tabla 12. Huella de carbono de la depuradora Ferreries en 2019 y 2020

Tabla 13. Huella de carbono de la depuradora Ciutadella Nord en 2019 y 2020 
Tabla 14. Huella de carbono de la depuradora Ciutadella Sud en 2019 y 2020

Tabla 15. Huella de carbono de la depuradora Ibiza en 2019 y 2020

Tabla 16. Huella de carbono de la depuradora de San Antonio en 2019 y 2020

56

Tabla 17. Huella de carbono de la depuradora de Cala Tarida en 2019 y 2020

Tabla 18. huella de carbono de la depuradora de Formentera en 2019 y 2020

Tabla 19. Huella de carbono por volumen de agua tratada en 2019 en $\mathrm{kgCO}{ }^{2} \mathrm{eq} / \mathrm{m}_{3}$

Tabla 20. Huella de carbono por volumen de agua tratada en 2020 en $\mathrm{kgCO}{ }^{2} \mathrm{eq} / \mathrm{m}_{3}$

Tabla 21. Huella de carbono de la IDAM Bahía de Palma en el año 2019 y 2020

Tabla 22. Huella de carbono de la IDAM Bahía de Alcudia en el año 2019 y 2020

Tabla 23. Huella de carbono de la IDAM Andratx en el año 2019 y 2020

Tabla 24. Huella de carbono de la IDAM Ciutadella en el año 2019 y 2020

Tabla 25. Huella de carbono de la IDAM Ibiza en el año 2019 y 2020

Tabla 26. Huella de carbono de la IDAM Sant Antoni en el año 2019 y 2020

Tabla 27. Huella de carbono de la IDAM Santa Eulària en el año 2019 y 2020

Tabla 28. Huella de carbono de la IDAM Formentera en el año 2019 y 2020 
Tabla 29. Huella de carbono por volumen de agua captada en el 2019 en $\mathrm{kgCO}{ }^{2} \mathrm{eq} / \mathrm{m}_{3}$

Tabla 30. Huella de carbono por volumen de agua captada en el 2020 en $\mathrm{kgCO}{ }^{2} \mathrm{eq} / \mathrm{m}_{3}$

79

Tabla 31. Huella de carbono del Bombeo sa Costera en el año 2019 y 2020

84

Tabla 32. Huella de carbono del Bombeo sa Marineta en el año 2019 y 2020

Tabla 33. Huella de carbono del Bombeo s'Estremera en el año 2019 y 2020

Tabla 34. Huella de carbono de la red de distribución en alta de la isla de Mallorca en el año 2019 y 2020 


\section{ÍNDICE DE FIGURAS}

Figura 1. Riesgo de las MASbt de no alcanzar el buen estado global

Figura 2. Coeficiente de utilización de las principales desaladoras de las Baleares

Figura 3. Desaladoras, depósitos de agua potable y red de conducciones en alta de la isla de Mallorca

Figura 4. Suministro y consumo de la isla de Mallorca, periodo $2000-2020$

Figura 5. Desaladora de la isla de Menorca

Figura 6. Consumo hídrico de la isla de Menorca, periodo 2000 2020

Figura 7. Desaladoras, depósitos de agua potable y red de conducciones en alta de la isla de Ibiza

Figura 8. Consumo hídrico por fuentes, de la isla de Ibiza para el periodo 2000 - 2020

Figura 9. Desaladora de la isla de Formentera

Figura 10. Consumo hídrico en Formentera para el periodo 2000 - 2020 (íntegramente desalación)

Figura 11. Alcances de la huella de carbono

Figura 12. Acciones que tomar por la compañía una vez calculada la huella de carbono

Figura 13. Árbol de decisiones para determinar qué tipo de Nivel utilizar en la estimación del de las emisiones de metano

Figura 14. Caudales depurados en las depuradoras gestionadas por ABAQUA en la isla de Mallorca para el periodo $2016 / 2019$ 
Figura 15. Producción y captación de agua en la isla de Mallorca para el periodo 2014-2019 (a), durante las temporadas bajas de los años 2015-2019 (b), durante las temporadas altas de los años 2015-2019 (c)

Figura 16. Fachada y vista en planta de la Estación desaladora de la Bahía de Palma (Mallorca, España)

Figura 17. Sala de máquinas de la IDAM Alcudia

66

Figura 18. Vista general de las instalaciones de la desaladora Ciutadella en Menorca

Figura 19. Evolución de la producción de agua desalada en Menorca en el año 2019

Figura 20. Producción de agua desalada en la isla de lbiza para el periodo 2014-2019 (a), durante las temporadas bajas de los años 2015-2019 (b), durante las temporadas altas de los años 2015-2019 (c)

Figura 21. Instalaciones interiores de la IDAM Ibiza .............................. $\quad 72$

Figura 22. Sala de máquinas de la IDAM Sant Antoni en Ibiza ..... 74

Figura 23. Desaladora Santa Eulària en Ibiza, año de creación: 2018

Figura 24. Sala de máquinas de la IDAM Formentera 77

Figura 25. Sala de máquinas del Bombeo sa Costera 83

Figura 26. Localización del Bombeo s'Estremera en Mallorca 86 Figura 27. Esquema del agua distribuida en una red municipal ... 


\section{INTRODUCCIÓN Y OBJETIVO}

Las organizaciones internacionales que lideran la evaluación de los efectos del cambio climático en el planeta, como son el Grupo Intergubernamental de Expertos en Cambio Climático (IPCC), la Organización Meteorológica Mundial (OMM) y la Convención Marco de las Naciones Unidas sobre el Cambio Climático (CMNUCC), coinciden en que los síntomas del calentamiento global son ya palpables en la Tierra.

Estas organizaciones publican periódicamente documentos con datos poco halagüeños para nuestra subsistencia, como son series históricas de precipitaciones, sequías, inundaciones y, en definitiva, fenómenos meteorológicos adversos que son cada vez más frecuentes y dificultan la utilización de los recursos como se ha realizado hasta ahora.

A nivel nacional y regional, cada vez son más las entidades que toman conciencia sobre la delicada situación en la que nos encontramos, y comienzan a implementar medidas para mitigar los efectos del cambio global o adaptarse a él. Una de estas administraciones es el Gobierno Balear, que aprobaba en febrero del año 2019 su Ley del cambio climático y transición energética de les Illes Balears.

Se trata de una Ley pionera en España, cuyo objetivo principal es la transición a un modelo energético sostenible. Los principales objetivos relacionados con la eficiencia energética de la Ley de cambio climático de las Illes Balears son: 
- La implantación progresiva de energías renovables, desplazando el uso de combustibles fósiles con el fin de reducir las emisiones de gases de efecto invernadero

- La estabilización y decrecimiento de la demanda energética a través del ahorro energético y la eficiencia energética

- La reducción de la dependencia energética exterior para alcanzar la autosuficiencia del territorio balear

Con el fin de alcanzar estos objetivos, entre otras medidas, se promoverá la movilidad sostenible. En el archipiélago balear el 35\% de las emisiones de $\mathrm{CO}_{2}$ provienen del sector del transporte, por lo que se desea hacer especial hincapié en la transición energética de este sector debido a su importancia. Otra medida a destacar es la planificación del cese de funcionamiento de las centrales térmicas o la sustitución de fuel por gas natural (menos contaminante) en algunas de estas centrales.

Para poder tomar medidas concretas de mejora, lo ideal es conocer la situación de partida en la que nos encontramos, para comenzar la descarbonización del archipiélago balear en todos sus sectores.

Uno de los sectores importantes en la transición ecológica es el de la producción de agua potable, debido a que es también un consumidor de energía eléctrica para la obtención de agua dulce en las islas (especialmente la desalación).

Este libro tiene como objetivo analizar el estado medioambiental del sector hídrico en les Illes Balears, para lo que se utilizarán dos herramientas: la huella de carbono y la huella hídrica. El cálculo de estos dos indicadores de sostenibilidad ambiental lleva implícito una ordenación de los consumos energéticos. Si se decide actuar sobre los consumos de cualesquiera de los dos recursos es probable obtener no sólo beneficios medioambientales sino también ahorros económicos significativos. 


\subsection{EFECTO INVERNADERO Y CAMBIO CLIMÁTICO Y CAMBIO CLIMÁTICO}

El efecto invernadero es un fenómeno natural mediante el que determinados gases de la atmósfera retienen parte de la energía que el suelo emite, tras haber sido calentado por el sol. Este proceso permite que la temperatura media del planeta se mantenga en $15^{\circ} \mathrm{C}$, haciendo posible la vida en el planeta tal como existe en la actualidad. Sin embargo, se está produciendo un desequilibrio en este fenómeno, producido por el incremento de la concentración de gases de efecto invernadero en la atmósfera debido a las actividades humanas, aumentado así la temperatura media del planeta por encima de niveles que puedan considerarse aceptables. El mantenimiento de esta circunstancia a lo largo del tiempo puede desencadenar eventos en el planeta que conlleven cambios significativos en la vida tal y como la conocemos ahora.

Los gases de efecto invernadero (en adelante, GEI) son aquellos compuestos presentes en la atmósfera (cuya fuente puede ser natural o antropogénica) que absorben y emiten radiación infrarroja. Esta característica de los GEI los hace responsables del efecto invernadero natural, pero también del calentamiento global. Los principales gases que tenemos dentro de esta categoría son los siguientes: Dióxido de carbono $\left(\mathrm{CO}_{2}\right)$, Metano $\left(\mathrm{CH}_{4}\right)$, Óxido nitroso $\left(\mathrm{N}_{2} \mathrm{O}\right)$ y Gases Fluorados.

Las principales fuentes naturales y antropogénicas de estos gases se presentan a continuación:

\section{- Dióxido de carbono}

> Fuentes naturales: descomposición de la materia orgánica del suelo, océanos

$>$ Fuentes antropogénicas: deforestación, quema de combustibles fósiles, reacciones químicas en procesos de manufactura, etc. 
- Metano

$>$ Fuentes naturales: humedales, termitas, etc.

$>$ Fuentes antropogénicas: ganadería de rumiantes, cultivo de arroz, combustión de biomasa, etc.

\section{- Óxido nitroso}

> Fuentes naturales: océanos

$>$ Fuentes antropogénicas: fertilizantes nitrogenados, quema de combustibles fósiles, etc.

En España, las consecuencias del cambio climático comienzan a manifestarse ya mediante los siguientes fenómenos:

- Cambios en la estructura y funcionamiento de los ecosistemas terrestres y marítimos

- Descenso de la biodiversidad

- Disminución de los recursos hídricos

- Desaparición de humedales

- Desaparición de zonas de costa

- Intrusión marina en zonas de la costa mediterránea

- Aumento de los incendios forestales

\subsection{SOSTENIBILIDAD Y CAMBIO CLIMÁTICO}

Los impactos del cambio climático pueden definirse como los efectos en los medios de subsistencia, la salud, los ecosistemas, la economía y la sociedad, fruto de la interacción de las variaciones en el clima y la vulnerabilidad de los sistemas expuestos a ellas (IPCC, 2014), que se detallan a continuación: 
- Impactos en los medios de subsistencia (agricultura y ganadería): la disminución de las precipitaciones y el aumento de la temperatura favorece la aparición de plagas agrícolas, el desplazamiento de zonas de producción de cultivos de unas partes del planeta a otras, disminución de rendimientos debido a las altas temperaturas $\mathrm{y} / \mathrm{o}$ a fenómenos meteorológicos adversos, variabilidad en la disponibilidad de los recursos hídricos con el consecuente riesgo de estrés hídrico para las plantas, etc.

- Impactos en la salud: los efectos en la salud pueden ser de tipo directo, como podría ser un golpe de calor producido por un aumento anormal en las temperaturas; o de tipo indirecto, como las enfermedades respiratorias causadas por la calidad del aire.

- Impactos en los ecosistemas: el cambio del clima genera alteraciones fisiológicas y demográficas que modifican el funcionamiento de los ecosistemas. Dentro de los impactos que se están produciendo en los hábitats podemos encontrar los siguientes: alteración de la migración de las aves, defoliaciones en los árboles, desplazamiento de especies vegetales, aceleración de la duración de las fases larvarias de los insectos y acidificación de los océanos y consecuente destrucción de los corales, entre otros.

- Impactos en la economía: los efectos del cambio climático en los ecosistemas se traducen en pérdidas económicas para el conjunto global. Tanto pérdidas debido a mermas en la agricultura, como pérdidas debido a los destrozos causados por fenómenos meteorológicos adversos (cada vez más frecuentes), alteración en las temporadas turísticas tradicionales, aumento de la frecuencia y duración de los incendios forestales, etc. 


\subsection{ENERGÍAS RENOVABLES}

Las energías renovables son fuentes naturales y prácticamente inagotables de energía, cuyo impacto ambiental en lo referido a emisión de gases de efecto invernadero como el $\mathrm{CO}_{2}$ es nulo $\mathrm{O}$ al menos inferior en comparación con la quema de combustibles fósiles. Las diversas fuentes de energía renovable que están disponibles en el planeta son:

- Solar: la radiación solar puede ser recogida por colectores que atienden a dos tipos de principios diferentes: el efecto fotoeléctrico y el efecto fototérmico. La energía fotovoltaica transforma los rayos del sol en electricidad a través de paneles solares. La energía fototérmica utiliza el calor del sol capturándolo con colectores solares.

- Eólica: es la energía renovable que más eficientemente han logrado explotar los humanos. El principio de la energía eólica es hacer funcionar una turbina de viento que produce energía eléctrica. La turbina eólica se activa por el movimiento de las palas, que a su vez se mueven por la fuerza del viento.

- Hidráulica: las centrales hidroeléctricas se encuentran en los lechos de los ríos para aprovechar la fuerza del agua, que mueve las turbinas de la central, generando electricidad. El porcentaje de energía utilizada en todo el mundo y cubierta por la energía hidroeléctrica es del $16 \%$ (World Bank, 2015).

- Geotérmica: la energía geotérmica está ligada al calor del interior de la superficie terrestre y, si consideramos toda la superficie de la tierra, la energía geotérmica que llega del interior es de 4,2 x 1012J (IDAE, 2008). La energía geotérmica puede ser de alta entalpía, cuando las temperaturas alcanzadas son superiores a $150^{\circ} \mathrm{C}$, o de baja entalpía, cuando las temperaturas están por debajo de esa temperatura. 
- Energía mareomotriz: es una energía azul, ya que aprovecha la energía procedente de las mareas para generar, a través de un sistema de alternadores, energía eléctrica.

\subsection{EL CICLO URBANO DEL AGUA EN LAS ISLAS BALEARES}

El archipiélago de Islas Baleares está formado por las islas de Mallorca, Menorca, Ibiza, Formentera, y una serie de islas menores, prácticamente deshabitadas, y goza de un clima mediterráneo. Las presiones sobre los recursos hídricos que sufre este archipiélago son debidas principalmente a los siguientes aspectos: elevada actividad turística, sobreexplotación de los acuíferos e intrusión marina en estos, contaminación urbana, contaminación difusa proveniente de la actividad agrícola y ganadera, periodos de sequía, etc. (García Servera, 2003). Esta situación puede agravarse, o intensificar las presiones, en un escenario de cambio climático en el que nos encontramos en la actualidad (García \& RodríguezLozano, 2020)

\subsubsection{LAS MASAS DE AGUA SUBTERRÁNEAS}

El aprovechamiento del agua en las 87 masas de agua subterránea (en adelante MASbt) que hay en las Baleares, repartidas en los 4 sistemas de explotación o islas, es el principal recurso para la Demarcación. Y aunque en la revisión anticipada del Plan Hidrológico de las Illes Balears (2 Ciclo 2015-21) se dice que el agua subterránea es un $68 \%$ del recurso hídrico total utilizado en las Baleares, este porcentaje cambia por islas (siendo mucho menor en las Pitiusas) y por años, en función de si fue húmedo o seco. Por ejemplo, si analizamos el consumo de agua urbano en la isla de Mallorca, la extracción de agua subterránea representó más del $85 \%$ del total del recurso para el período 2010-2015, con un máximo del 92,5\% el 
año 2011. Es evidente que, a pesar del aumento del agua procedente de la desalación, especialmente en Mallorca, durante los años húmedos las extracciones de agua subterránea aumentan considerablemente debido a su coste de extracción menor al subir los niveles piezométricos. Este hecho muestra con claridad que las islas de Mallorca y Menorca dependen de las masas de agua subterránea.

La extracción de agua subterránea para uso agrícola también es importante. Aunque la agricultura utiliza unos $15,3 \mathrm{hm}^{3}$ de agua reutilizada, lo que supone el $42 \%$ del total utilizado por todo el sector en la Demarcación (36,4 hm³, valores para el año 2015 en el PHIB 2은 ciclo), la presión que ejerce sobre los acuíferos todavía es muy importante. De hecho, las presiones por extracción de agua para el horizonte 2021 de la agricultura afectan a más del $90 \%$ de las MASbt y las de la ganadería, con un valor muy inferior de extracciones $(0,44$ $\mathrm{hm}^{3}$ repartido por igual entre Mallorca y Menorca), al $93 \%$ de las MASbt (Tabla 1). Es evidente que ha habido un descenso en el consumo de agua por parte de la agricultura, pero su impacto sobre el territorio, en forma de contaminación por nitratos, continúa afectando a una importante cantidad de acuíferos en la Demarcación.

Tabla 1. Presiones agrícolas, ganaderas y de abastecimiento público que afectan las masas de agua subterránea de las Islas Baleares

\begin{tabular}{|l|c|c|c|}
\hline $\begin{array}{c}\text { TIPOS DE } \\
\text { PRESIÓN POR } \\
\text { EXTRACCIÓN DE } \\
\text { AGUA }\end{array}$ & $\begin{array}{c}\text { VOLUMEN } \\
\text { ANUAL } \\
\text { EXTRAÍDO }\left(\mathrm{HM}^{3} /\right.\end{array}$ & $\begin{array}{c}\text { NÚMERO DE } \\
\text { MASAS } \\
\text { AFẼ })\end{array}$ & $\begin{array}{c}\text { PORCENTAJE DE } \\
\text { MASAS } \\
\text { AFECTADAS }\end{array}$ \\
\hline Agricultura & 39,34 & 79 & 90,8 \\
Ganadería & 2,24 & 81 & 93,1 \\
Abastecimiento & 92,89 & 73 & 83,91 \\
público de agua & & 87 & 100 \\
Consumo disperso & 30,72 & & \\
\hline
\end{tabular}

Fuente: GOIB, 2015 
Las presiones por extracción de agua para abastecimiento urbano y el consumo disperso, que afectan a un número elevado de masas (ver Tabla 1), provoca su sobreexplotación. Se extrae más de lo que se recarga y eso genera un impacto sobre la mayoría de las masas de las islas con la consecuente dificultad de recuperación de los niveles piezométricos promedio. Esta afección a los niveles piezométricos es desigual por islas, con sobreexplotaciones cercanas al $150 \%$ en Menorca e Ibiza, y por MASbt. La desigual característica de los acuíferos costeros en cuanto a capacidad y recarga provoca que la posible recuperación de una MASbt frente a la sobreexplotación o a una sequía sea una quimera. El resultado es la creciente salinización de las MASbt costeras (estado químico malo por cloruros) que empeora la calidad del agua y dificulta su recuperación.

Como resultado de todas las presiones, el estado cuantitativo (descenso de los niveles piezométricos y explotación superior al $80 \%$ ) y el estado químico (por nitratos y cloruros) provocan que en 42 MASbt haya un riesgo alto de no alcanzar el buen estado global (Figura 1).

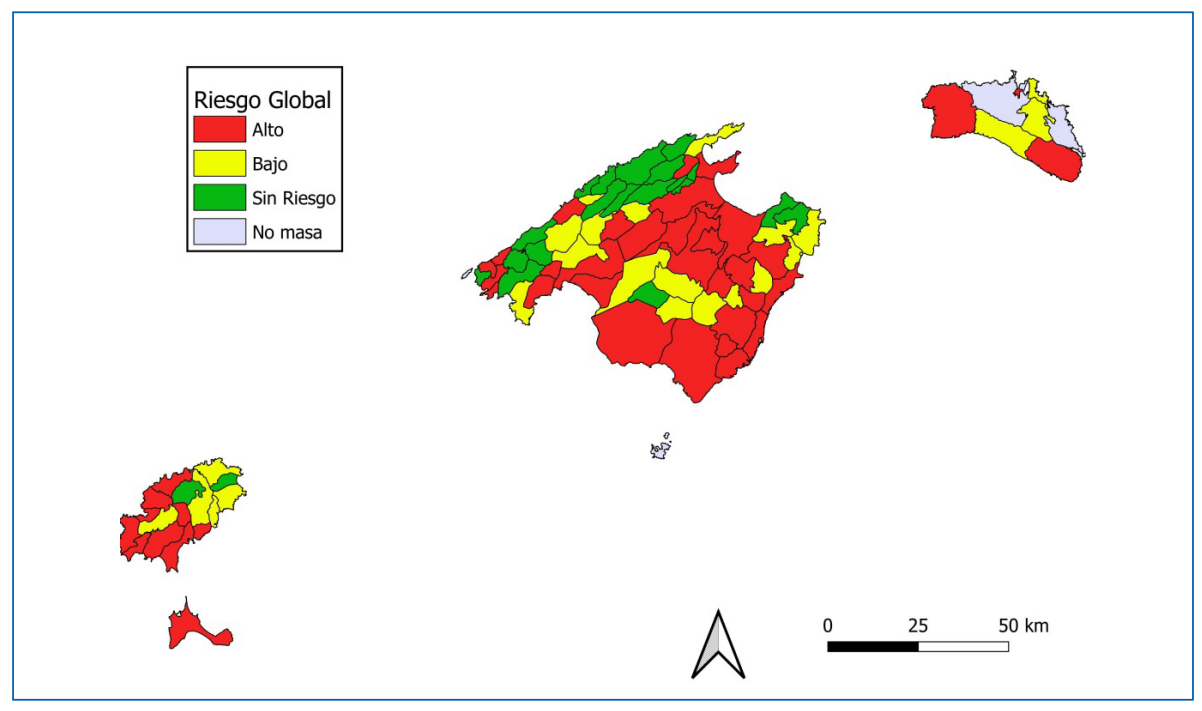

Figura 1. Riesgo de las MASbt de no alcanzar el buen estado global. Fuente: Plan Hidrológico de la Demarcación Hidrográfica de las Illes Balears. Revisión de tercer ciclo (2021-2027) 


\subsubsection{LAS MASAS DE AGUA SUPERFICIALES}

La planificación hidrológica en las Islas Baleares gira en torno a sus aguas subterráneas, lo cual marca una de las grandes diferencias respecto a la gestión del agua en las demarcaciones hidrográficas peninsulares, que se centra en mayor medida en las aguas superficiales. Esta diferencia radica en dos puntos estrechamente relacionados: la ausencia de cursos de agua superficiales con caudal permanente en las Islas Baleares y el hecho de que las aguas subterráneas sean el principal recurso hídrico, como se ha destacado en el apartado anterior. La conectividad vertical entre las aguas subterráneas y superficiales hace que la explotación de los recursos hídricos subterráneos reduzca la disponibilidad de agua superficial en los ecosistemas acuáticos continentales. Ello convierte en un aspecto clave el objetivo de alcanzar un buen estado para las masas de agua superficial. Un claro ejemplo es el río de Santa Eulària (Ibiza), el único curso fluvial que tenía caudal superficial permanente en las Islas Baleares, pero que desde comienzos del siglo $X X$ tiene un régimen hidrológico intermitente debido al descenso del nivel piezométrico por la explotación de las aguas subterráneas. En este sentido, cabe destacar que si bien el resto de los cursos fluviales de las islas, denominados torrentes, tienen un carácter intermitente o efímero natural, también presentan tramos permanentes en sus cabeceras y cerca de sus desembocaduras, los cuales han sufrido, especialmente estos últimos años, un impacto por sobreexplotación de las MASbt que los alimenta a través de surgencias. El régimen hidrológico de los torrentes también ha cambiado durante las últimas décadas. Así, por ejemplo, el número de días al año que los torrentes de la Sierra de Tramuntana tienen caudal superficial ha disminuido durante el periodo 1977-2009 debido a la diminución de las precipitaciones, al incremento de temperatura cobertura forestal (García et al., 2017).

El estado de las masas de agua superficiales (en adelante MASup) debe evaluarse tanto a partir del estado ecológico como del estado 
químico. En la publicación de la revisión de tercer ciclo (2021-2027) del Plan Hidrológico se ha incluido, por primera vez, la evaluación del estado químico del $57 \%$ de las MASup categoría río (torrentes), detectándose un estado químico peor que bueno para tres de las masas evaluadas.

Debemos destacar la existencia de dos embalses en la isla de Mallorca, cuya agua se destina a uso doméstico de la ciudad de Palma: los embalses de Gorg Blau y Cúber. Ambos embalses están situados en la Sierra de la Tramuntanta y conforman un solo sistema, ya que el agua del embalse de Gorg Blau se bombea hasta el embalse de Cúber, del cual parte una tubería hasta la estación potabilizadora de Lloseta. Ambos embalses están gestionados por EMAYA, empresa pública del Ayuntamiento de Palma, por lo que forman parte de la gestión del agua en baja dentro del ciclo integral del agua. La capacidad de los embales es de 11,98 hm³/año (Gorg Blau: 7,34 hm³ y Cúber: 4,64 hm³), si bien el volumen promedio que proporcionan es de $8,06 \mathrm{hm} 3$ al año (Gorg Blau: $4,9 \mathrm{hm}^{3}$ y Cúber: 3,1 hm3; promedio datos 2013-2018). Este volumen supone el $7,7 \%$ del abastecimiento para uso doméstico de la isla de Mallorca y el 5,5\% del total de las Baleares (3er ciclo PHIB 2021-2027).

También existe un tercer embalse, el embalse de Mortitx (realmente se trata de un complejo de dos pequeños embalses), localizado en el torrente de Ses Comes, de concesión privada y destinado al regadío. Los tres embalses (Gorg Blau, Cúber y Mortitx) están clasificados como masas de agua categoría río muy modificadas. Los dos destinados para consumo humano presentan un buen estado ecológico y químico, mientras que el estado del embalse de Mortitx no ha sido evaluado.

\subsubsection{LA DESALACIÓN}

La Demarcación de las Illes Balears tiene una capacidad máxima de producción de agua desalada de más de 55 hm³/año, con ocho 
desaladoras: una en Formentera (1,4 hm³/año), tres en Ibiza (16,6 $\mathrm{hm}^{3} /$ año), tres en Mallorca (31,09 hm³/año) y una en Menorca $\left(3,5 \mathrm{hm}^{3} /\right.$ año).

Las dos últimas desaladoras, que han entrado en pleno funcionamiento el año 2019 (Santa Eulalia y Ciudadela), son herencia del programa AGUA (Actuaciones para la Gestión y la Utilización del Agua, desarrollado por el gobierno de España) y alguna, como la de Ciudadela, ya estaba contemplada en el Plan Hidrológico Nacional (2001). En ambos casos, las plantas, ya construidas, estuvieron sin funcionar seis y nueve años respectivamente por falta de conexión con la red en alta. Y, aunque la capacidad máxima actual ronda esos 55 $\mathrm{hm}^{3} /$ año, el año 2019 en las Islas Baleares se produjeron unos 27 hm³, con las ocho desaladoras en funcionamiento. La máxima producción se alcanza durante los años secos, como durante la sequía de 2016 que alcanzó los 29,7 hm $^{3}$ o los 28 hm $^{3}$ del año 2005 y los 27,9 hm $^{3}$ del año 2001. Por el contrario, los mínimos en la producción $\left(7,4 \mathrm{hm}^{3}\right.$ del 2010 o los $9,5 \mathrm{hm}^{3}$ del 2013) se registran en años húmedos o que culminan con un período de precipitaciones por encima de la media.

En la figura 2 se ha calculado el coeficiente de utilización para las seis desaladoras con un registro de producción activo durante los últimos nueve años. El coeficiente muestra, en porcentaje, cuánta agua desalada produce cada desaladora en función de su capacidad anual. La figura muestra claramente tres aspectos en la demarcación:

- La utilización de las desaladoras en la isla de Mallorca se mueve al ritmo de período seco (aumento de la producción) y período húmedo (descenso de producción). Destaca la desaladora de Palma que alcanzó su máximo en el 2005, situándose en el $90 \%$ de su utilización. Desde entonces, el porcentaje ha estado siempre por debajo del $80 \%$ (o del $60 \%$ desde el 2009).

- En la isla de Ibiza la producción ha ido oscilando, pero siempre con una tendencia al alza, situándose en la actualidad en niveles del 70 y $80 \%$. 
- En la isla de Formentera la producción presenta un aumento paulatino, hasta el $50 \%$ de utilización, con un incremento constante en la demanda, aunque con una marcada estacionalidad que le impedirá subir a niveles mucho más altos en el futuro.

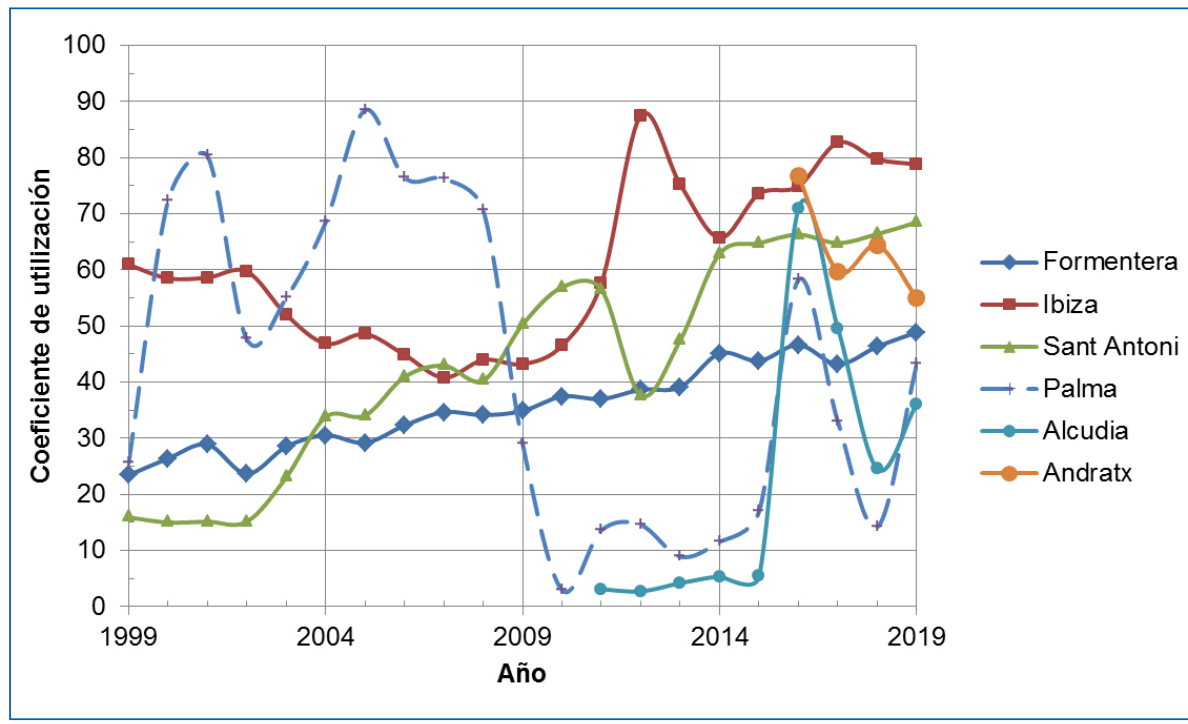

Figura 2. Coeficiente de utilización de las principales desaladoras de las Baleares.

Fuente: García y Rodríguez-Lozano (2020)

Parece muy claro que se ha apostado por la desalación como medida frente a los períodos secos y la falta del recurso subterráneo: casos de las Pitiusas y la isla de Mallorca. Cada período seco representa un aumento en la producción de agua desalada. El problema viene cuando, en períodos húmedos, se sustituye por una fuente tradicional más económica; un hecho que se repite en otras demarcaciones españolas donde la desalación de agua de mar es garantía de suministro y fuente de agua aislada y de emergencia (Cabrera et al., 2019). En el caso de la Demarcación de las Illes Balears, además de garantía de suministro (de algunas zonas), siempre se mostró la desalación como recurso que permitiría recuperar los acuíferos; 
aunque la llegada del período húmedo comportaba la reducción en su producción culpando a los ayuntamientos de no querer comprar agua desalada. El caso es que la desalación en las Islas Baleares debe formar parte de la gestión integrada de los recursos hídricos, para así poder recuperar las MASbt con riesgo alto de no alcanzar el buen estado global, reduciendo su explotación durante períodos húmedos y manteniendo la producción de agua desalada y la utilización de las IDAM a plena capacidad para aprovechar al máximo las economías de escala y evitar el deterioro de las instalaciones. De esta forma, se evitarían situaciones como la acaecida durante la sequía del año 2016, con una elevada sobreexplotación de los acuíferos, mientras que la mayor IDAM de las islas, la de la Bahía de Palma, sólo podía operar al $66 \%$ de su capacidad, al estar averiada por la falta de uso.

\subsection{EL CASO DE MALLORCA}

El suministro en alta que gestiona $A B A Q U A$ en esta isla se alimenta desde las siguientes instalaciones: tres desaladoras (Palma, Alcudia y Andratx); un bombeo en sa Font de Sa Costera (Sóller); seis pozos que explotan el acuífero de s'Estremera; seis bombeos localizados en sa Marineta (Llubí) (Figura 3). Además de contar con infraestructuras de captación de aguas, este sistema incluye también cuatro pozos de infiltración, que permiten desviar agua hacia el acuífero de s'Estremera en los momentos de menor demanda hídrica en la isla, a través del bombeo de sa Font de sa Costera, los pozos de Sa Marineta o, incluso, la desaladora de Alcudia. Abaqua realiza infiltraciones en el acuífero desde el año 2009 aunque sólo han sido superiores a las extracciones realizadas en los años 2009, 2012, 2016, 2017 y 2019. Por ejemplo, este último año, ABAQUA recargó el acuífero con $5,54 \mathrm{hm}^{3}$ y extrajo $4,74 \mathrm{hm}^{3}$. 


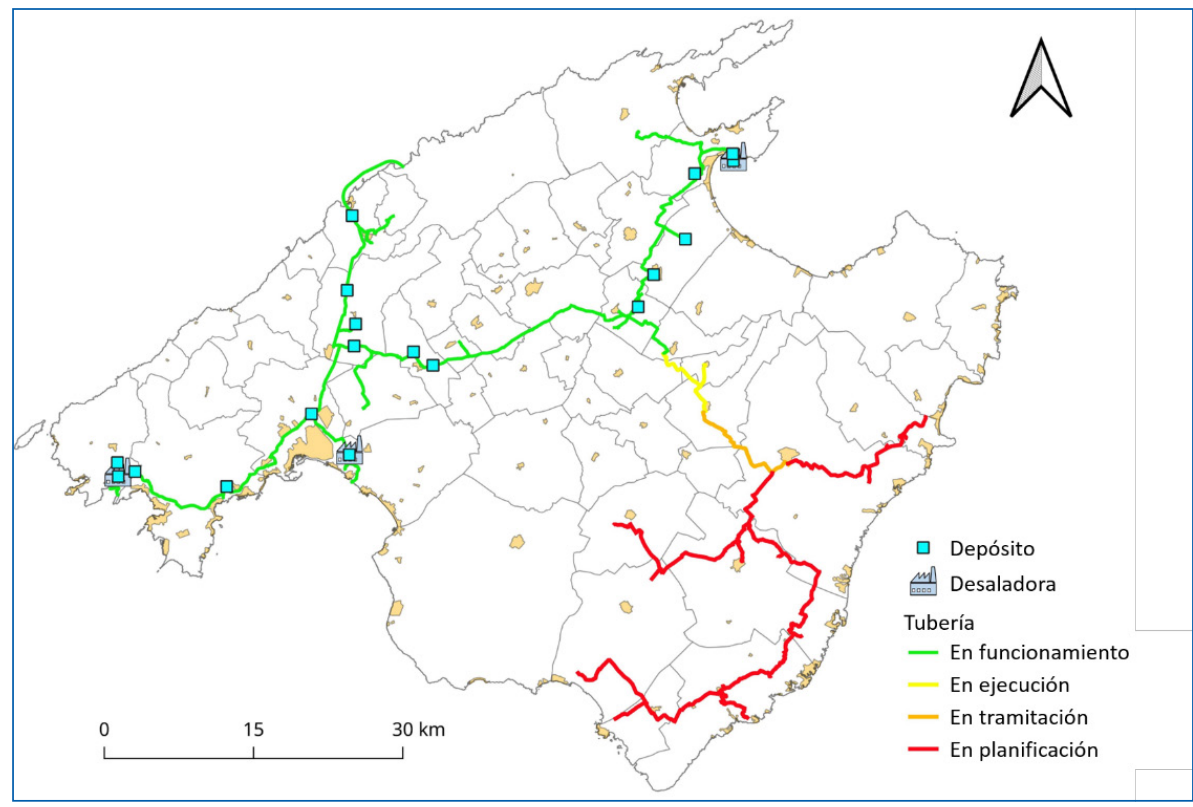

Figura 3. Desaladoras, depósitos de agua potable y red de conducciones en alta de la isla de Mallorca.

Fuente: $A B A Q U A$

Actualmente, la capacidad de producción de las tres desaladoras es de $92.800 \mathrm{~m}^{3} /$ día y anualmente pueden generar $31,09 \mathrm{hm}^{3} /$ año de agua desalada. La desaladora de Palma tiene una capacidad de producción máxima de $64.800 \mathrm{~m}^{3} /$ día, y las desaladoras de Andratx y de Alcudia tienen una capacidad de producción máxima de 14.000 $\mathrm{m}^{3} /$ día cada una.

Para una mayor comprensión de la evolución de la utilización de los diferentes recursos hídricos en la isla de Mallorca, en la Figura 4 se muestran los suministros y consumos anuales de la isla desde el año 2000 hasta el año 2020. 


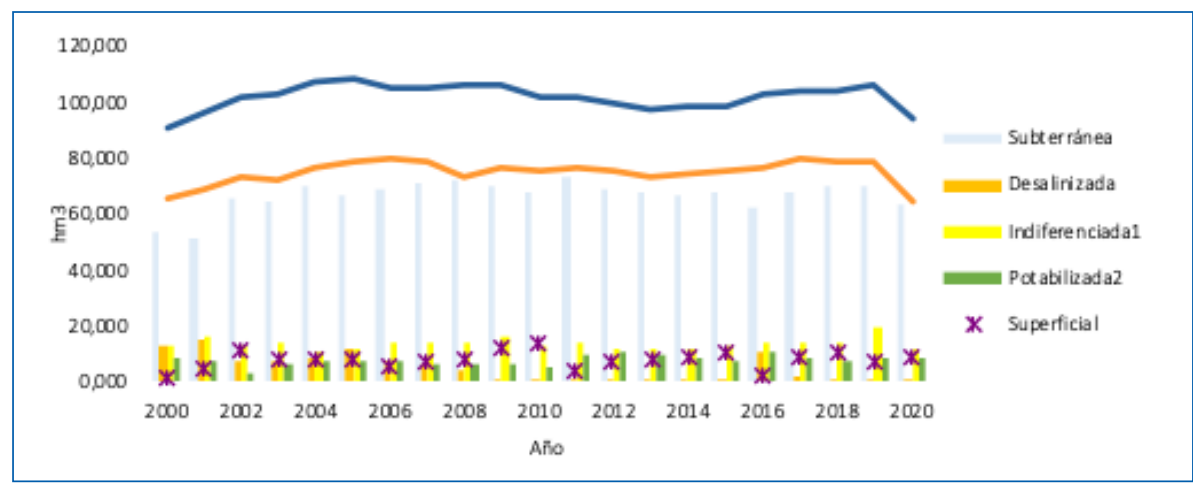

Figura 4. Suministro y consumo de la isla de Mallorca, periodo 2000 - 2020.

Fuente: $A B A Q \cup A$

Una vez captada y/o tratada el agua potable, se debe repartir hacia los consumidores. Para ello, ABAQUA cuenta con $175 \mathrm{~km}$ de recorrido de conducciones en alta (véase la Figura 3), que abastecen a 14 municipios de la isla.

\subsection{EL CASO DE MENORCA}

En Menorca el suministro de agua en alta de ABAQUA se realiza mediante la producción de agua desalada en la IDAM de Ciutadella (Figura 5), que se inauguró en el año 2019 (Figura 6) y tiene una capacidad de producción máxima de $10.000 \mathrm{~m}^{3} /$ día, por lo tanto, al año supone una capacidad de producción de $3,30 \mathrm{hm}^{3}$ de agua desalada. 


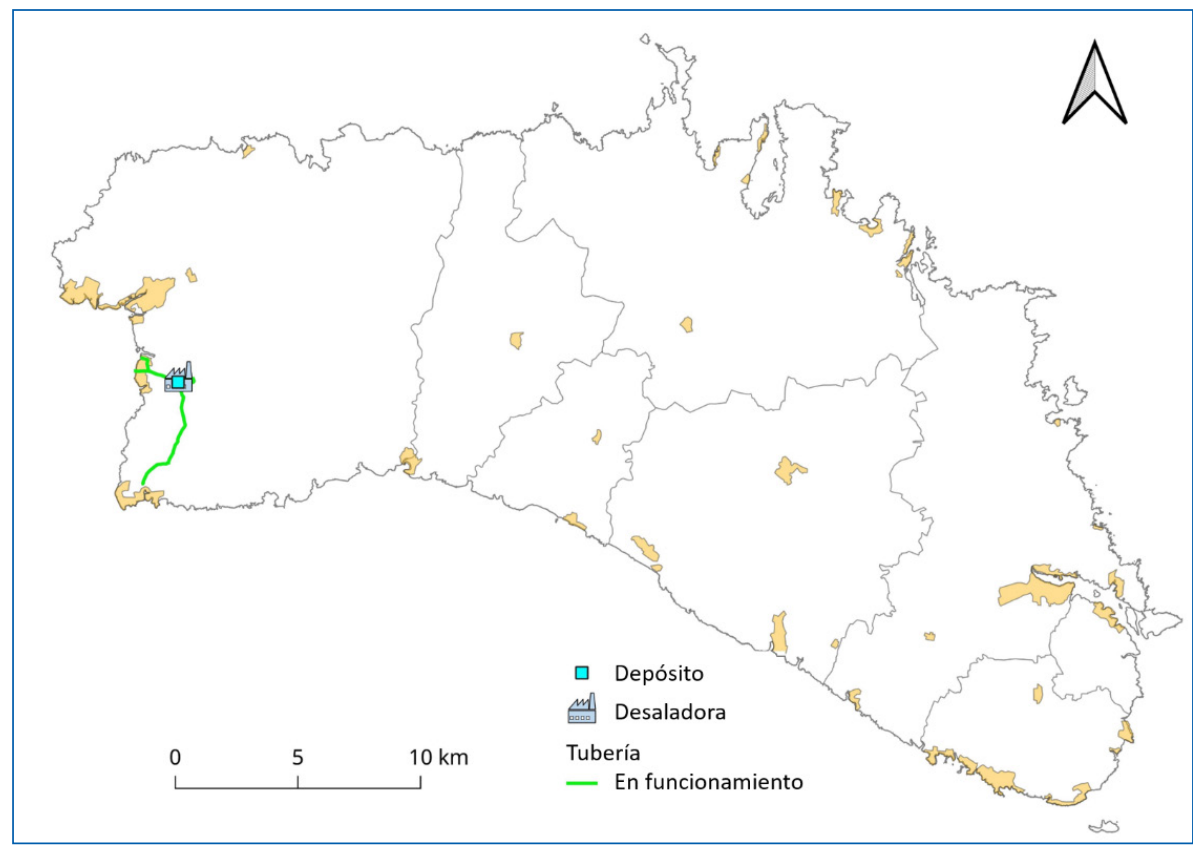

Figura 5. Desaladora de la isla de Menorca.

Fuente: ABAQUA

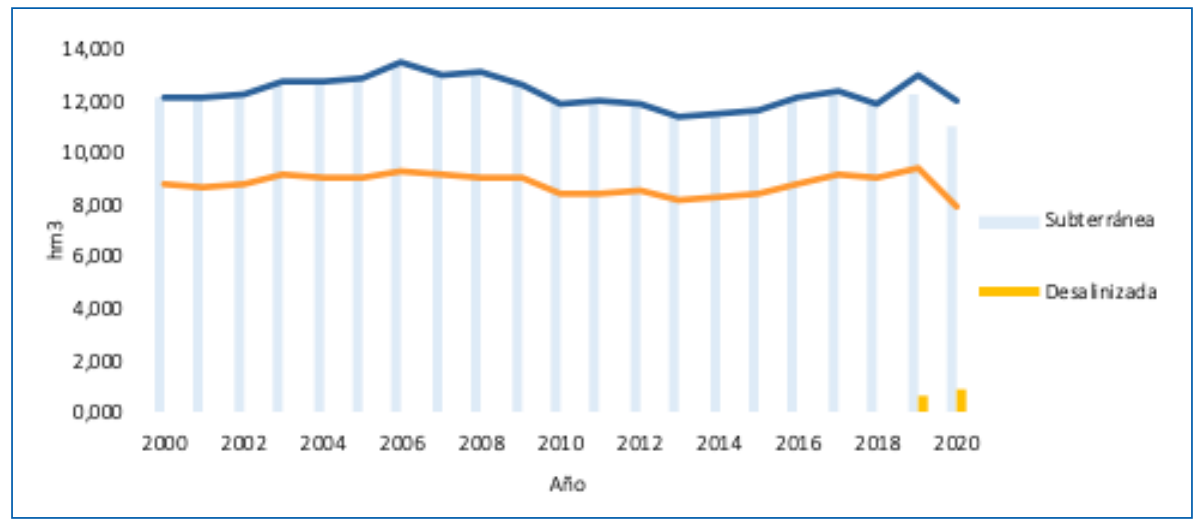

Figura 6. Consumo hídrico de la isla de Menorca, periodo 2000 2020.

Fuente: $A B A Q \cup A$ 


\subsection{EL CASO DE IBIZA}

Ibiza cuenta, al igual que Mallorca, con tres desaladoras para garantizar el suministro en alta. Estas desaladoras son las de Sant Antoni, Ibiza y Santa Eulària (Figura 7), que generan en total $44.500 \mathrm{~m}^{3} /$ día y una producción máxima anual de $14,91 \mathrm{hm}^{3}$ de agua desalada. Además, ABAQUA dispone de una red de conducciones en alta de aproximadamente $80 \mathrm{~km}$, que permiten suministrar agua a los 5 municipios de la isla de Ibiza.

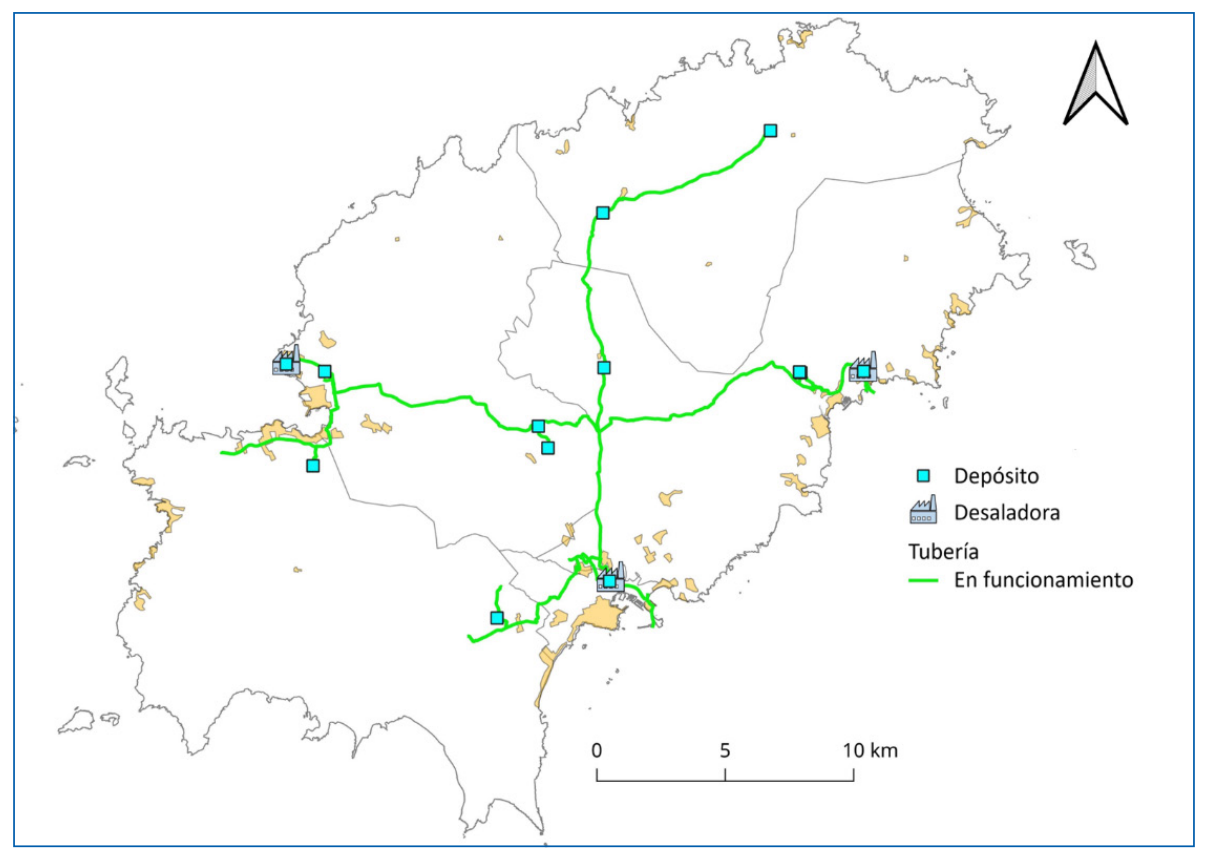

Figura 7. Desaladoras, depósitos de agua potable y red de conducciones en alta de la isla de Ibiza.

Fuente: $A B A Q \cup A$

En el año 2019, por primera vez se superó en Ibiza el consumo de agua desalada respecto al de agua subterránea (Figura 8). Este cambio de tendencia ha sido la respuesta de la política autonómica de fomentar el uso de agua desalada en invierno para reducir la 
presión sobre los acuíferos, así como que en 2019 la red interconexión posibilitó conectar completamente las tres desaladoras con los 5 municipios de la isla.

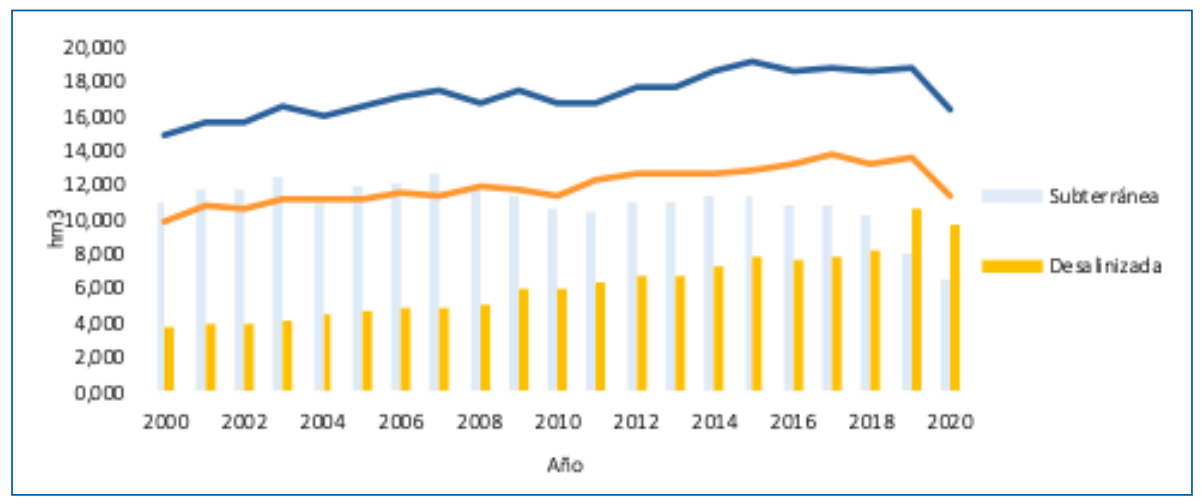

Figura 8. Consumo hídrico por fuentes, de la isla de lbiza para el periodo 2000 - 2020.

Fuente: ABAQUA

\subsection{EL CASO DE FORMENTERA}

En Formentera el suministro de agua en alta se garantiza mediante la producción de agua desalada en la IDAM de Formentera (Figura 9) que tiene una capacidad de producción máxima de $5.000 \mathrm{~m}^{3} /$ día y, por lo tanto, al año supone una producción de 1,68 $\mathrm{hm}^{3}$ de agua desalada. El $100 \%$ del agua suministrada en Formentera es desalada (Figura 10), debido al mal estado cualitativo y cuantitativo en que se encuentra el agua subterránea de su único acuífero. La red de conducciones en alta es de aproximadamente $11 \mathrm{~km}$. 


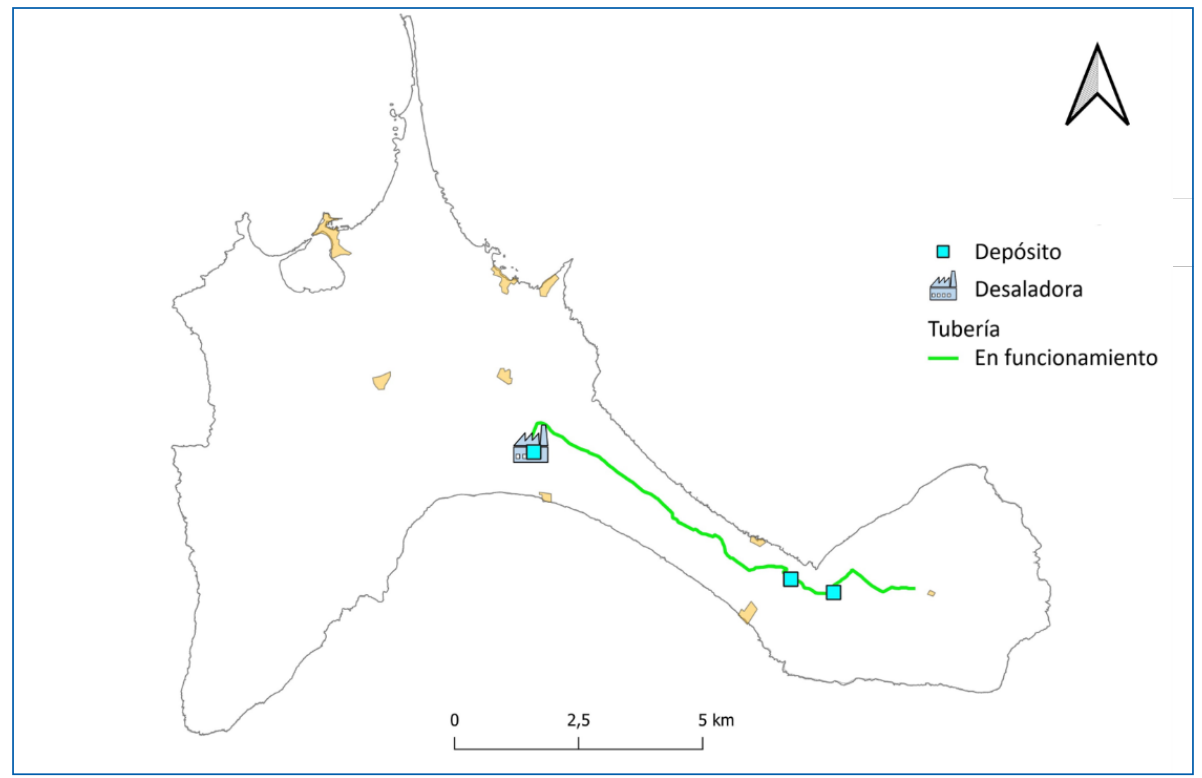

Figura 9. Desaladora de la isla de Formentera.

Fuente: $A B A Q \cup A$

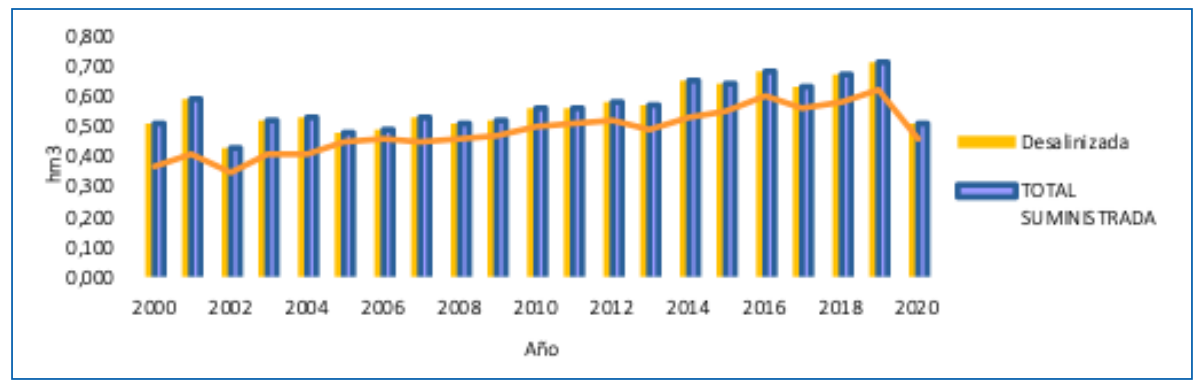

Figura 10. Consumo hídrico en Formentera para el periodo 2000 2020 (integramente desalación).

Fuente: ABAQUA 


\section{2}

\section{METODOLOGÍA}

Para el cálculo de la huella ambiental del sector hidráulico de las Islas Baleares, utilizamos dos indicadores: la huella de carbono y la huella hídrica. A continuación, definimos estos dos indicadores en los siguientes dos apartados para posteriormente definir la metodología concreta aplicada al caso del sector hidráulico del archipiélago balear

\subsection{HUELLA DE CARBONO}

La huella de carbono es un indicador ambiental que contabiliza la totalidad de los gases de efecto invernadero asociados a la producción de un producto, la prestación de un servicio o la realización de una actividad, generados tanto de forma directa como indirecta por la organización (CEPAL, 2008).

Este indicador puede ofrecer ventajas competitivas entre las organizaciones, ya que identifica las fuentes de emisiones de estos gases en la fabricación de un producto o en la prestación de un servicio. Conocer dónde se producen las mayores emisiones, permite a una empresa definir unos objetivos y metas medioambientales, para poder después establecer medidas enfocadas a la reducción de dichas emisiones e, incluso, participar en programas de compensación de huella de carbono. ${ }^{2}$

\footnotetext{
1 Al cálculo de huella de carbono y huella hídrica lo hemos denominado huella ambiental en este libro. Por lo tanto, a partir del apartado 3 se utiliza «huella ambiental» para englobar los resultados obtenidos de la huella de carbono y huella hídrica de las instalaciones estudiadas.

2 https://www.miteco.gob.es/es/cambio-climatico/temas/mitigacion-politicas-ymedidas/registro-huella.aspx
} 
Por lo tanto, calcular la huella de carbono otorga una serie de ventajas, entre las que se encuentran las siguientes:

- Reducir las emisiones de gases de efecto invernadero asociadas a la mejora de la eficiencia energética y en el ahorro económico

- Compensar las emisiones

- Establecer políticas de comunicación en las organizaciones

- Mejorar la imagen y la reputación de la organización y sus productos o servicios, demostrando su compromiso con la sostenibilidad ambiental y la lucha frente al cambio climático

- Dar respuesta a nuevas exigencias de clientes e inversores

- Disminuir los costes asociados a cambios legislativos por conseguir una adaptación temprana a nuevos requisitos

- Identificar potenciales ahorros y oportunidades de acceso a nuevos mercados

- Mejorar la eficiencia energética reduciendo los costes de operación

- Fijar elementos cuantitativos para realizar medidas

- Evaluar alternativas para actuaciones futuras

Para abordar el cálculo de la huella de carbono, se deben contabilizar las diferentes emisiones de la empresa estudiada en cada uno de los tres alcances (Figura 11) que la conforman:

- Alcance 1: emisiones relacionadas con el consumo de combustibles fósiles por parte de la compañía, debido a instalaciones fijas y a vehículos.

- Alcance 2: contabiliza las emisiones relacionadas con el consumo eléctrico de la compañía (se incluyen aquí también los vehículos eléctricos propiedad de la empresa), ya que suponen un aumento de la electricidad consumida en el establecimiento. 
- Alcance 3: emisiones indirectas de la compañía relacionadas con el consumo de combustibles fósiles (se tendrían en cuenta en este apartado los desplazamientos en avión, vehículos de los/as empleados/as, etc.).

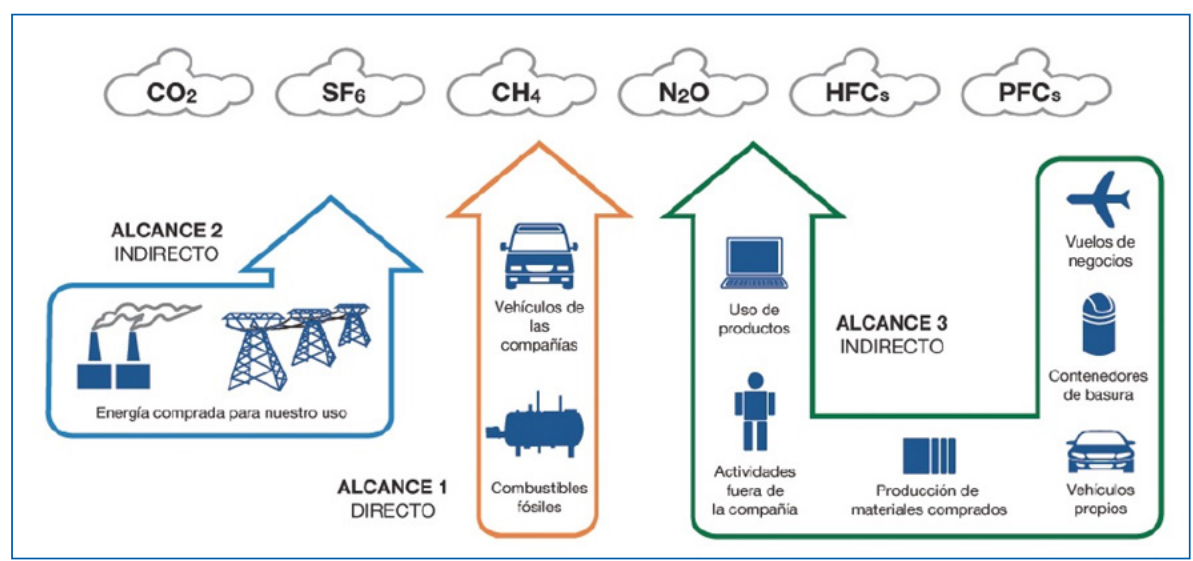

Figura 11. Alcances de la huella de carbono.

Fuente: Escuela de Organización Industrial

Además de definir los alcances, que se denominan el límite operativo de la empresa, debe definirse también los límites de la organización, es decir, el enfoque que se le va a dar al estudio. Este enfoque se refiere a si va a calcularse la huella del $100 \%$ de la compañía, o si se va a realizar por el contrario el cálculo de la huella de una cuota de participación accionaria (esta distinción se realiza principalmente cuando la empresa cuenta con diversas filiales).

Además, se debe distinguir en el tipo de empresa que vamos a estudiar, ya que el cálculo de las emisiones se aborda de manera diferente en función de si estamos analizando un producto, un evento o una organización.

La huella de carbono de una organización se define como el cálculo de los gases de efecto invernadero que produce una organización en su conjunto, para realizar sus productos o desarrollar sus servicios. Incluye todos los sectores o etapas de la organización, desde los 
sectores productivos hasta los comerciales. Esta es la huella de carbono en la que nos vamos a enfocar en este documento.

Una vez la compañía u organización ha determinado la huella de carbono correspondiente al año de cálculo seleccionado, se pueden realizar una serie de acciones, de carácter voluntario, que permiten una gestión más eficaz y completa de las emisiones de gases de efecto invernadero (Figura 12). Estas acciones son las siguientes:

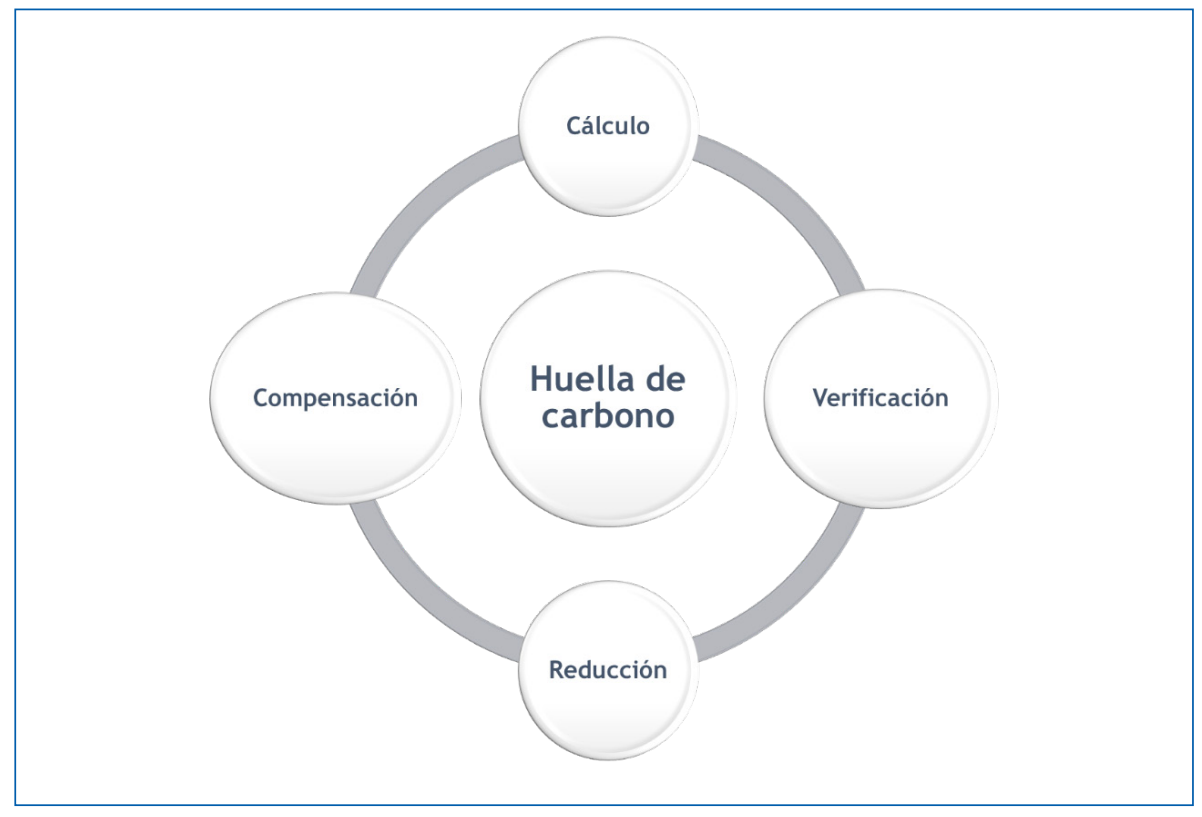

Figura 12. Acciones que tomar por la compañía una vez calculada la huella de carbono

\section{$\checkmark$ Verificación de la huella de carbono}

Este proceso se realiza a través de una Entidad de Verificación (en España, por ejemplo, la ENAC) cuyo objetivo es auditar el proceso de cálculo de huella de carbono y los resultados obtenidos, para garantizar que el cálculo se ha realizado acorde a la metodología 
empleada y que los datos arrojados son correctos. Es decir, de manera más concreta, se contrastará la siguiente información:

- Que los datos presentados no muestran contradicciones

- Que la recogida de datos ha sido rigurosa y se ha realizado conforme a la metodología empleada

- Que la documentación de la instalación estudiada es coherente y completa

- Que los factores de emisión empleados son correctos y se corresponden con el año estudiado (esto es debido a que los factores de emisión varían cada año)

- Se prestará especial atención a las fuentes que puedan presentar un alto riesgo de error

Las ventajas que presenta el proceso de verificación de la huella de carbono son las siguientes:

- Rápida respuesta a exigencias de clientes y/o inversores

- Valor añadido de la compañía

- Permite reducir los costes derivados de cambios legislativos, al anticiparse la empresa posibles exigencias medioambientales

- Permite identificar oportunidades de reducción de GEI

- Mejora la eficiencia energética de la compañía

- Facilita el desarrollo e implantación de estrategias y planes de gestión de GEI (como la participación en mercados ${ }^{3}$ de $\mathrm{CO}_{2}$, por ejemplo)

3 https://www.boe.es/buscar/act.php?id=BOE-A-2005-3941 


\section{$\checkmark$ Registro de la huella de carbono}

El registro de la huella de carbono, creado en España por el Real Decreto $163 / 2014^{4}$, de 14 de marzo, facilita la posibilidad de compensar toda o parte de la huella de carbono de una compañía, mediante una serie de proyectos forestales ubicados en territorio nacional ${ }^{5}$, que además de ventajas sociales y ecosistémicas, permiten también secuestrar carbono.

\section{$\checkmark$ Reducción y compensación}

Una vez calculada la Huella de Carbono (del producto, organización o evento), se deben marcar objetivos de mejora para disminuir el $\mathrm{CO}_{2}$ y la contribución al calentamiento global.

Una vez calculadas las emisiones de GEl e implementadas las medidas de reducción y eficiencia energética, hay ocasiones en las que no se puede evitar la generación de emisiones y no se pueden reducir las mismas. Es ahí donde aparece el concepto de la compensación, que se define como la captación del $\mathrm{CO}_{2}$ por parte de sumideros ${ }^{6}$, cuyo coste se debe asumir desde las fuentes de generación de GEI.

Los sumideros de carbono son aquellas instalaciones o elementos de la naturaleza capaces de absorber gases de efecto invernadero de la atmósfera. A pesar de que existen soluciones variadas para generar sumideros de carbono, solamente contemplaremos aquí aquellas relacionadas de forma directa con el ciclo hídrico, al ser soluciones que se pueden implementar en las instalaciones hídricas o cerca de ellas. Por lo tanto, nos centraremos en dos tipos de infraestructuras

\footnotetext{
4 https://www.boe.es/diario_boe/txt.php?id=BOE-A-2014-3379

5 https://www.miteco.gob.es/es/cambio-climatico/temas/mitigacion-politicas-ymedidas/registrodecompensaciones_tcm30-479333.pdf

6 Las fuentes y los sumideros no tienen por qué encontrarse en el mismo lugar geográfico.
} 
verdes: aquellas relacionadas con lagunajes (lugares de retención de agua de escorrentía superficial donde conviven ecosistemas acuáticos y terrestres, y son la antesala del agua antes de infiltrarse al acuífero) y aquellas relacionadas con filtros verdes para depurar aguas residuales.

\subsubsection{APLICACIÓN DE LA HUELLA DE CARBONO AL CASO DE ESTUDIO}

Para el cálculo de la huella de carbono de las diferentes instalaciones que componen el ciclo integral del agua en el archipiélago balear, se ha empleado la metodología denominada Green House Gas Protoco/7 (en adelante, GHG Protocol).

El GHG Protocol es un estándar internacional muy utilizado para el cálculo y la comunicación del inventario de emisiones de una compañía. La iniciativa del GHG Protocol surge de la unión de diversas empresas, organizaciones no gubernamentales y otros agentes, bajo la coordinación del World Resources Institute (WRI) y el Consejo Económico Mundial para el Desarrollo Sostenible (World Business Council for Sustainable Development, WBCSD). El objetivo de este estándar es evitar heterogeneidades en los métodos y principios empleados para el cálculo de emisiones de gases de efecto invernadero de empresas y organizaciones aceptados de forma internacional. La metodología de este sistema se basa en los siguientes puntos:

- Determinación de los límites de la organización

- Determinación de los límites operacionales

- Seguimiento de las emisiones a través del tiempo y a partir del año base estudiado

7 https://ghgprotocol.org/ 
- Identificación y cálculo de las emisiones

- Gestión de la calidad del inventario

El cálculo de las huellas de carbono de las instalaciones que componen el ciclo integral del agua (para el año de estudio establecido) está basado en la metodología de la organización, el enfoque de control y los alcances 1, 2 y 3 (especificados en el apartado 2.1). El enfoque de control requiere definir el límite organizativo del inventario de operaciones. En este sentido, es necesario tener presente que en una instalación destinada al tratamiento o distribución de agua se distinguen dos tipos de emisiones en función del punto o área de emisión: 1) las emisiones por actividades realizadas en la instalación por empresas concesionarias o autorizadas y 2) las emisiones de la instalación son las realizadas por las actividades desarrolladas por el explotador propiamente. Por lo tanto, el ámbito de estudio de las instalaciones engloba los trabajos de mantenimiento, la estación eléctrica transformadora, estación de carburantes, punto limpio, instalación de suministro de agua potable y red eléctrica.

Por otro lado, el enfoque de control también exige definir el límite operativo o inventario de operaciones sobre las que la instalación ejerce control, distinguiendo en función del alcance y de su naturaleza fija o móvil. Entre las fuentes emisoras asociadas a las operaciones de naturaleza fija cabe incluir las instalaciones destinadas a actividades de administración y de mantenimiento. En relación con las actividades de administración se contabiliza el número de personas que trabajan en cada una de ellas; en las actividades de mantenimiento realizadas se distingue en función de quién las lleve a cabo, bien sea personal propio, personal contratado u otro. Sea cual sea el caso, se cuantifica la frecuencia con la que se realizan dichas actividades por término medio.

La energía procedente de fuentes renovables (eólica, fotovoltaica, hidroeléctrica) presenta una huella de carbono inferior a la energía procedente de fuentes no renovables (Arvizu et al., 2011). En este 
estudio, siguiendo los factores de emisión del Ministerio para la Transición Ecológica y del Reto Democrático, hemos considerado negligible la huella de carbono de las fuentes de energía renovable.

La calidad y exhaustividad de los datos requiere de un procedimiento sistemático de recopilación de información que, además, facilite su tarea en años sucesivos. Siguiendo esta premisa, se ha elaborado un cuestionario, donde la mayor parte de las preguntas son abiertas y se han dividido en función de su implicación en cada uno de los alcances de la huella de carbono. El resto son preguntas orientadas a la formulación de recomendaciones para reducir y/o compensar las huellas. La encuesta va dirigida al gestor/a de la instalación quien, además, deberá respaldar sus respuestas con facturas u otros documentos similares que avalen sus respuestas.

Los datos de actividad recopilados de las diferentes fuentes y expresados en $\mathrm{kWh}$, litros $0 \mathrm{~m}^{3}$ deben ser expresado en términos $\mathrm{tCO}_{2}$ eq. Los factores de emisión permiten el trasvase de una unidad a otra. Los factores de emisión utilizados son los publicados por el Ministerio para la Transición Ecológica y el Reto Demográfico.

Por lo tanto, de forma esquemática, el cálculo de la huella de carbono se puede abordar aplicando el siguiente guion:

a) Se establece el año de cálculo a estudiar

b) Se definen los límites de la organización y los límites operativos (obligatoriamente se debe calcular el alcance 1 y 2 . El alcance 3 se deja de manera opcional a la compañía, aunque se considera recomendable su cálculo debido a la valiosa información complementaria que aporta). Es por ello por lo que, en este estudio, hemos calculado los alcances 1, 2 y 3.

c) Se recopilan los consumos de la compañía (electricidad, combustibles fósiles, etc.) derivados principalmente de las facturas de esta 
d) Estos datos se transforman a toneladas de $\mathrm{CO}_{2}$ equivalente, a través del uso de los factores de emisión ${ }^{8}$

e) Se elabora un informe para poder comunicar los resultados obtenidos

f) Se realiza un plan de reducción de emisiones

g) Se puede ir un paso más allá certificando y/o compensado la huella de la compañía ${ }^{9}$

\subsection{HUELLA HÍDRICA}

La huella hídrica es un indicador ambiental que cuantifica el volumen de agua, tanto directo como indirecto, asociado a un producto o servicio. La huella hídrica puede calcularse desde el punto de vista del consumo o de la producción. La huella hídrica como productor o huella hídrica interna cuantifica el volumen de agua utilizada dentro de los límites del área delimitada en la producción de bienes. La huella hídrica como consumidor o huella hídrica estándar evalúa el agua utilizada en los productos y servicios que son consumidos por los habitantes y que pueden proceder de cualquier parte del planeta (WFN, 2002).

Sea cual sea el caso, se tiene en cuenta tanto el uso directo como indirecto que se hace del agua y los impactos que se deriven de su uso. El agua directa se define como la cantidad de agua requerida únicamente en el proceso productivo o prestación de un servicio. No obstante, la obtención de un producto requiere, por lo general, de la entrada de varias materias primas, productos intermedios y una serie de servicios en las distintas etapas del proceso productivo. Por su

\footnotetext{
8 https://www.miteco.gob.es/es/cambio-climatico/temas/mitigacion-politicas-ymedidas/factores_emision_tcm30-479095.pdf

9 https://www.miteco.gob.es/es/cambio-climatico/temas/mitigacion-politicas-ymedidas/registro-huella.aspx
} 
lado, la prestación de un servicio requiere de herramientas de trabajo. Pues bien, en la producción de estos inputs intermedios o medios de trabajo también se consume agua que no ha sido considerada en el producto final o prestación de servicio. El agua asociada a estas entradas intermedias es el agua indirecta.

Tanto en el uso directo como indirecto se distingue el origen del agua, es decir, se distingue entre los conceptos de agua azul, agua verde y agua gris:

- El agua verde se corresponde con el agua procedente de las precipitaciones que se incorpora al suelo o la vegetación. Se trata de un agua disponible para el libre aprovechamiento de las plantas y constituye el sustento hídrico único de los cultivos de secano, la vegetación espontánea y los bosques, así como parte del sustento de los cultivos de regadío. Este origen del agua es particularmente importante en la producción de cultivos.

- Por su parte, el agua azul se corresponde con la fracción del ciclo hidrológico que se transforma en escorrentía superficial o subterránea y que es consumido por incorporación o evaporación en el proceso evaluado. Alimenta el caudal de los ríos y las reservas de los acuíferos, al tiempo que es susceptible de ser represada naturalmente en forma de lagos o de forma artificial mediante la construcción de embalses. Exceptuando la desalación de aguas marinas y otras fuentes de agua no convencionales, el uso doméstico, industrial y el cultivo de regadío se surten siempre de fuentes de agua azul.

Por último, el agua gris representa el volumen de agua necesario para reducir la carga de contaminantes hasta cumplir con la normativa vigente en materia de calidad del agua. 


\subsection{1.. APLICACIÓN DE LA HUELLA HÍDRICA AL CASO DE ESTUDIO}

Bajo el mismo límite organizativo y desde la perspectiva de la producción de agua potable, el procedimiento seguido en el cálculo de la huella hídrica se inicia con la aproximación de la huella hídrica directa ${ }^{10}$. La huella hídrica directa es el volumen $\left(\mathrm{m}^{3}\right)$ de agua dulce consumida y contaminada en el desarrollo de la actividad de la instalación de estudio.

El valor final de la huella hídrica puede calcularse de diversas maneras en función de la metodología escogida, aunque las opciones más frecuentes son utilizar la suma de los tres tipos de agua (azul, verde y gris), o bien sumar la huella hídrica directa e indirecta. En este estudio no se ha contemplado el cálculo de la huella hídrica indirecta, sino que hemos abordado el cálculo de la huella hídrica directa de las diferentes instalaciones estudiadas a partir de la metodología de la Water Footprint Network (WFN), donde se han empleado los conceptos de agua azul, verde y gris, explicados anteriormente. Si bien, en el caso de las instalaciones hidráulicas la huella hídrica puede calcularse a partir de la huella hídrica azul y gris, siendo la huella hídrica verde despreciable al referirse a la incorporación de agua lluvia en el sector agrícola.

10 En este estudio no se ha contemplado el cálculo de la huella hídrica indirecta, al contabilizar esta el volumen $\left(\mathrm{m}^{3}\right)$ de agua dulce consumida y contaminada asociada a la producción de los bienes que intervienen en la prestación de los servicios. 


\section{3}

\section{CARACTERIZACIÓN DE LA HUELLA AMBIENTAL EN LAS EDAR GESTIONADAS POR ABAQUA}

El objetivo de este apartado es analizar los consumos energéticos e hídricos de las EDAR, estableciendo relaciones entre dichos consumos y las características de las EDAR y detectando aquellas que presenten consumos energéticos superiores al resto para proponer actuaciones encaminadas a la reducción de su huella ambiental.

En el caso de las depuradoras de aguas residuales, además de emisiones de $\mathrm{CO}_{2}$ a la atmósfera, derivadas del consumo de combustibles, electricidad y la actividad de la instalación, también se generan emisiones de metano. El metano es generado debido a la descomposición anaerobia de la materia orgánica que lleva el agua residual en suspensión. Recordemos que el metano es el segundo gas de efecto invernadero en términos cuantitativos, solo por detrás del dióxido de carbono. Es por ello por lo que, además de medirlo, es necesario establecer medidas al respecto que permitan disminuir las emisiones de metano asociadas a la depuración de aguas residuales.

Para el cálculo de las emisiones de metano de una depuradora se sigue la metodología propuesta por el IPCC' (Doorn et al., 2006), donde se necesita conocer la carga orgánica total del agua

1 IPCC: Panel Intergubernamental del Cambio Climático 
(relacionada con la población equivalente a la que da servicio la depuradora), el factor de emisión del metano y las incertidumbres. En este caso, se ha aplicado el Nivel 2 que especifica la norma ${ }^{2}$ (Figura 13).

En la Tabla 2 puede verse la totalidad de EDAR presentes en el archipiélago balear.

Tabla 2. Número de EDAR en el archipiélago balear

\begin{tabular}{|l|c|c|c|}
\hline \multicolumn{1}{|c|}{ ISLA } & $\begin{array}{c}\text { NÚMERO } \\
\text { DE EDARS }\end{array}$ & $\begin{array}{c}\text { POBLACIÓN DE } \\
\text { DISEÑO } \\
\text { (HE) }\end{array}$ & $\begin{array}{c}\text { VOLUMEN } \\
\text { DE DISEÑO } \\
\text { (M³/AÑO) }\end{array}$ \\
\hline Mallorca & 56 & 825.452 & 53.495 .495 \\
Menorca & 12 & 254.502 & 15.882 .975 \\
Ibiza & 10 & 305.530 & 22.293 .105 \\
Formentera & 1 & 30.260 & 1.229 .400 \\
TOTAL (Islas Baleares) & 79 & 1.415 .744 & 92.970 .975 \\
\hline
\end{tabular}

Fuente: $A B A Q \cup A$

2 «El método de Nivel 1 aplica valores por defecto para el factor de emisión y para los parámetros de la actividad. Este método se considera de buena práctica para los países con escasa disponibilidad de datos.

El método de Nivel 2 sigue la misma metodología que el Nivel 1, pero permite la incorporación de un factor de emisión específico del país y de datos de la actividad especificos del país. Por ejemplo, un factor de emisión específico para un importante sistema de tratamiento, basado en mediciones en el terreno se podría incorporar con este método. Hay que tomar en cuenta la cantidad de lodos eliminados por incineración, en vertederos y en suelos agrícolas.

Para un país con buenos datos y metodologías avanzadas, se puede aplicar una metodología específica del país, como un método de Nivel 3. Un método aún más avanzado, específico del país, puede basarse en datos específicos de cada planta en las grandes instalaciones de tratamiento de aguas residuales.» (IPCC, 2006). 


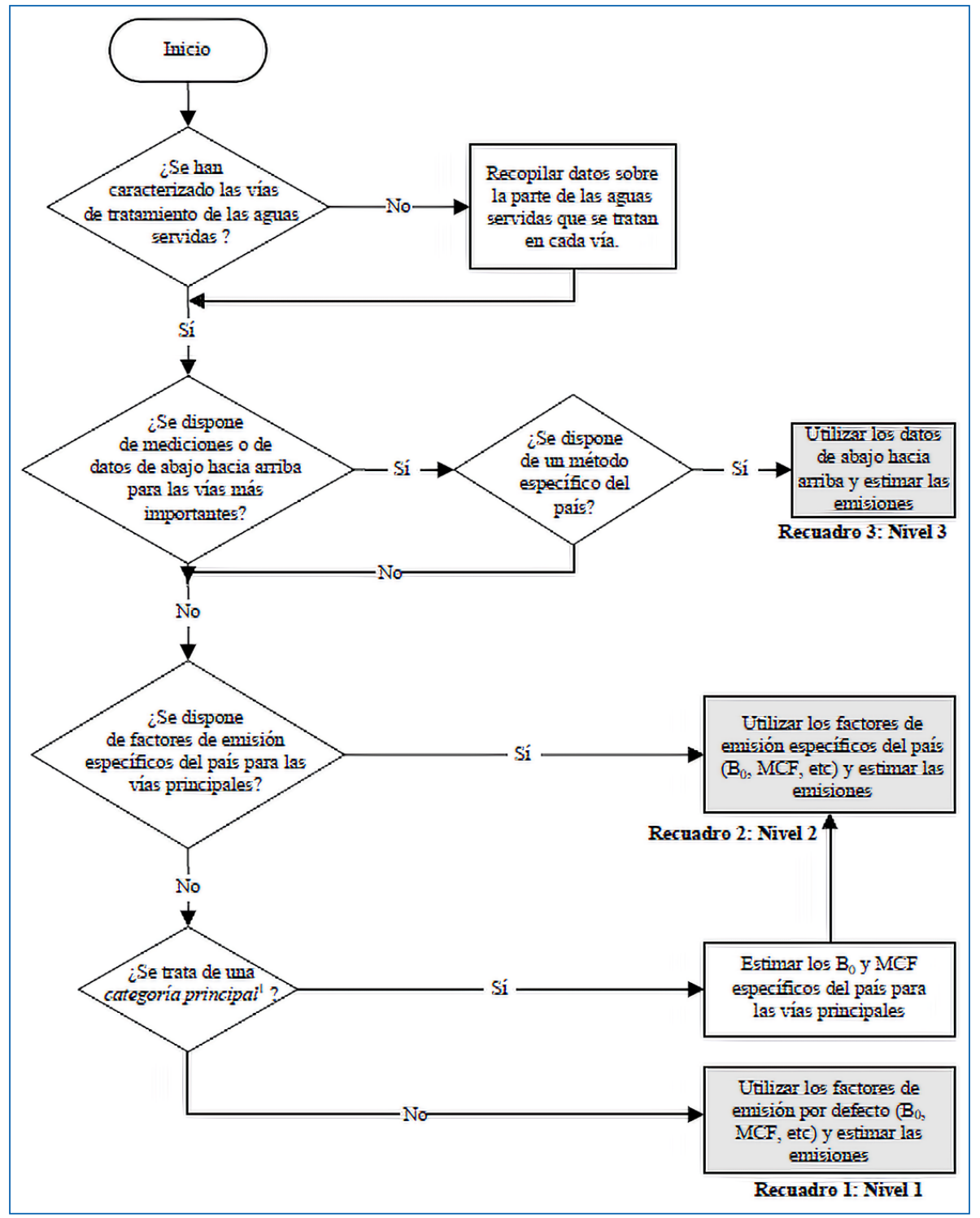

Figura 13. Árbol de decisiones para determinar qué tipo de Nivel utilizar en la estimación del de las emisiones de metano.

Fuente: IPCC, 2006 


\subsection{MALLORCA}

Debido al modelo turístico de las Islas Baleares, las depuradoras de este archipiélago experimentan un aumento de los caudales a depurar durante la época estival. En la Figura 14 puede verse los picos de caudales depurados de la isla de Mallorca en verano.

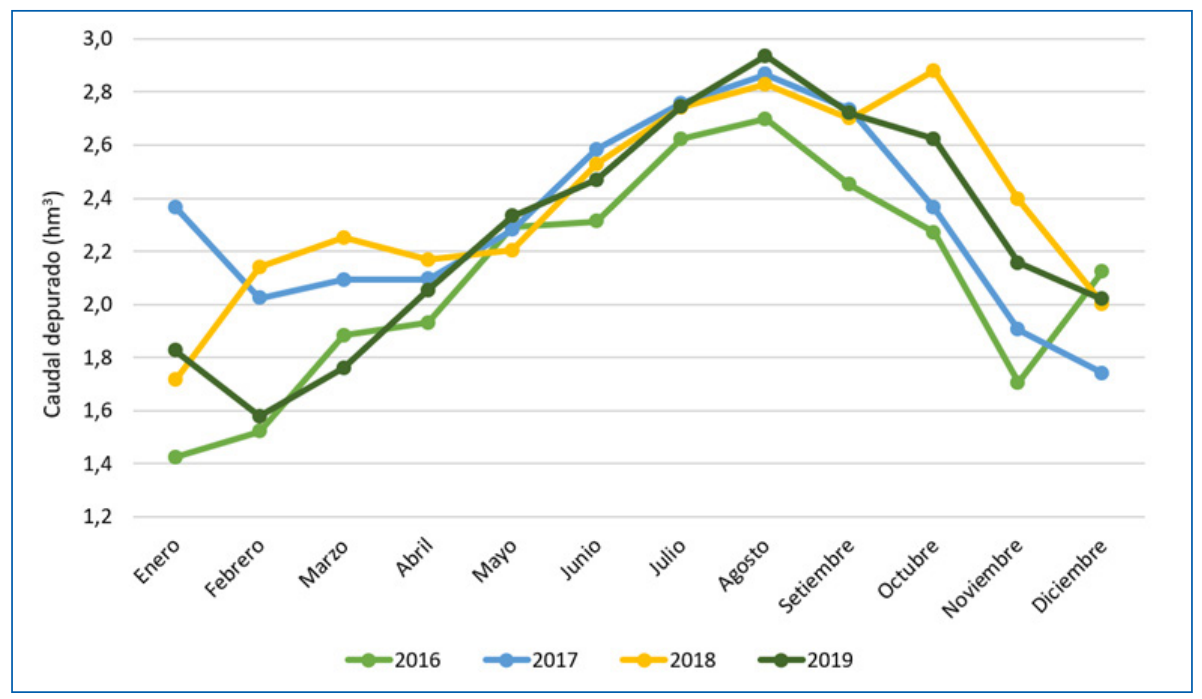

Figura 14. Caudales depurados en las depuradoras gestionadas por ABAQUA en la isla de Mallorca para el periodo 2016/2019.

Fuente: Abaqua

El indicador de caudal de las aguas residuales depuradas compara el caudal de entrada de aguas residuales respecto al caudal de diseño de la depuradora. Este indicador tiene como objetivo identificar aquellas depuradoras que no cumplan los objetivos de calidad de agua residual, debido a presentar un dimensionamiento ineficaz, de tal manera que las actuaciones de ampliación y remodelación sean prioritarias en las instalaciones identificadas.

Durante el año 2019, en Mallorca hubo seis EDAR que presentaron un dimensionado deficiente o muy deficiente, suponiendo un $10,7 \%$ del total de depuradoras de la isla. 
A continuación, se presentan los resultados de la huella de carbono de las depuradoras estudiadas en la isla de Mallorca para los años 2019 y 2020 :

Tabla 3. Huella de carbono de la depuradora de Andratx en 2019 y 2020

\begin{tabular}{|c|c|c|c|c|c|}
\hline \multicolumn{2}{|c|}{ Huella de carbono depuradora Andratx } & \multicolumn{2}{|c|}{2019} & \multicolumn{2}{|c|}{2020} \\
\hline \multicolumn{6}{|c|}{ Alcance 1} \\
\hline & Emisiones Instalaciones fijas & 0,00 & $\mathrm{t} \mathrm{O}_{2} \mathrm{eq}$ & 0,00 & $\mathrm{t} \mathrm{OO}_{2} \mathrm{eq}$ \\
\hline & Vehículos & 2,45 & $\mathrm{t} \mathrm{O}_{2}$ eq & 2,45 & $\mathrm{t} \infty_{2}$ eq \\
\hline \multicolumn{6}{|l|}{ Alcance 2} \\
\hline & Emisiones Instalaciones fijas & 189,31 & $\mathrm{t} \mathrm{O}_{2} \mathrm{eq}$ & 134,73 & $\mathrm{t} \mathrm{O}_{2} \mathrm{eq}$ \\
\hline \multicolumn{6}{|l|}{ Alcance 3} \\
\hline & Vehículos & 6,74 & $\mathrm{t} \mathrm{O}_{2} \mathrm{eq}$ & 6,74 & $\mathrm{t} \infty_{2} \mathrm{eq}$ \\
\hline \multicolumn{6}{|l|}{ Subtotal } \\
\hline & Alcance 1 & 2,45 & $\mathrm{t} \mathrm{CO}_{2} \mathrm{eq}$ & 2,45 & t $\mathrm{CO}_{2}$ eq \\
\hline & Alcance 2 & 189,31 & $\mathrm{t} \mathrm{CO}_{2} \mathrm{eq}$ & 134,73 & $\mathrm{t} \mathrm{CO}_{2} \mathrm{eq}$ \\
\hline & Alcance 3 & 6,74 & $\mathrm{t} \mathrm{CO}_{2} \mathrm{eq}$ & 6,74 & $\mathrm{t} \mathrm{CO}_{2} \mathrm{eq}$ \\
\hline $\begin{array}{c}\text { Huella de } \\
\text { Carbono }\end{array}$ & Total & 198,50 & $\mathrm{t} \mathrm{CO}_{2} \mathrm{eq}$ & 143,92 & $\mathrm{t} \mathrm{CO}_{2}$ eq \\
\hline
\end{tabular}

Tabla 4. Huella de carbono de la depuradora Banyalbufar en 2019 y 2020

\begin{tabular}{|c|c|c|c|c|c|}
\hline \multicolumn{2}{|c|}{ Huella de carbono depuradora Banyalbufar } & \multicolumn{2}{|c|}{2019} & \multicolumn{2}{|c|}{2020} \\
\hline Alcance 1 & & & & & \\
\hline & Emisiones Instalaciones fijas & 0,00 & $\mathrm{t} \infty_{2} \in \mathrm{q}$ & 0,00 & $\mathrm{t} \infty_{2} \mathrm{eq}$ \\
\hline & Vehículos & 3,54 & $\mathrm{t} \infty_{2} \mathrm{eq}$ & 3,54 & $\mathrm{t} \infty_{2}$ eq \\
\hline \multicolumn{6}{|c|}{ Alcance 2} \\
\hline & Emisiones Instalaciones fijas & 8,40 & $\mathrm{t} \infty_{2}$ eq & 6,66 & $\mathrm{t} \infty_{2}$ eq \\
\hline \multicolumn{6}{|l|}{ Alcance 3} \\
\hline & Vehículos & 3,38 & $\mathrm{t} \infty_{2} \in \mathrm{q}$ & 3,38 & $\mathrm{t} \infty_{2}$ eq \\
\hline \multicolumn{6}{|l|}{ Subtotal } \\
\hline & Alcance 1 & 3,54 & $\mathrm{t} \mathrm{CO}_{2}$ eq & 3,54 & $\mathrm{t} \mathrm{CO}_{2}$ eq \\
\hline & Alcance 2 & 8,40 & $\mathrm{t} \mathrm{CO}_{2}$ eq & 6,66 & $\mathrm{t} \mathrm{CO}_{2}$ eq \\
\hline & Alcance 3 & 3,38 & t $\mathrm{CO}_{2}$ eq & 3,38 & $\mathrm{t} \mathrm{CO}_{2} \mathrm{eq}$ \\
\hline $\begin{array}{l}\text { Huella de } \\
\text { Carbono }\end{array}$ & Total & 15,31 & t $\mathrm{CO}_{2}$ eq & 13,58 & $t \mathrm{CO}_{2}$ eq \\
\hline
\end{tabular}


Tabla 5. Huella de carbono de la depuradora Camp de Mar en 2019 y 2020

\begin{tabular}{|c|c|c|c|c|c|}
\hline \multicolumn{2}{|c|}{ Huella de carbono depuradora Camp de Mar } & \multicolumn{2}{|c|}{2019} & \multicolumn{2}{|c|}{2020} \\
\hline \multicolumn{6}{|c|}{ Alcance 1} \\
\hline & Emisiones Instalaciones fijas & 0,00 & $\mathrm{t} \mathrm{O}_{2} \mathrm{eq}$ & 0,00 & $\mathrm{t} \infty_{2} \mathrm{eq}$ \\
\hline & Vehículos & 1,82 & $\mathrm{t} \mathrm{O}_{2}$ eq & 1,82 & $\mathrm{t} \infty_{2}$ eq \\
\hline \multicolumn{6}{|l|}{ Alcance 2} \\
\hline & Emisiones Instalaciones fijas & 49,01 & $\mathrm{t} \mathrm{CO}_{2} \mathrm{eq}$ & 20,63 & $\mathrm{t} \mathrm{OO}_{2} \mathrm{eq}$ \\
\hline \multicolumn{6}{|l|}{ Alcance 3} \\
\hline & Vehículos & 6,74 & $\mathrm{t} \mathrm{O}_{2}$ eq & 6,74 & $\mathrm{t} \mathrm{OO}_{2} \mathrm{eq}$ \\
\hline \multicolumn{6}{|l|}{ Subtotal } \\
\hline & Alcance 1 & 1,82 & $\mathrm{t} \mathrm{CO}_{2}$ eq & 1,82 & $\mathrm{t} \mathrm{CO}_{2}$ eq \\
\hline & Alcance 2 & 49,01 & $\mathrm{t} \mathrm{CO}_{2} \mathrm{eq}$ & 20,63 & $\mathrm{t} \mathrm{CO}_{2}$ eq \\
\hline & Alcance 3 & 6,74 & $\mathrm{t} \mathrm{CO}_{2} \mathrm{eq}$ & 6,74 & t $\mathrm{CO}_{2}$ eq \\
\hline $\begin{array}{l}\text { Huella de } \\
\text { Carbono }\end{array}$ & Total & 57,56 & $\mathrm{t} \mathrm{CO}_{2} \mathrm{eq}$ & 29,18 & $\mathrm{t} \mathrm{CO}_{2} \mathrm{eq}$ \\
\hline
\end{tabular}

Tabla 6. Huella de carbono de la depuradora Deia en 2019 y 2020

\begin{tabular}{|c|c|c|c|c|c|}
\hline \multicolumn{2}{|c|}{ Huella de carbono depuradora Deia } & \multicolumn{2}{|c|}{2019} & \multicolumn{2}{|c|}{2020} \\
\hline \multicolumn{6}{|c|}{ Alcance 1} \\
\hline & Emisiones Instalaciones fijas & 0,00 & $\mathrm{t} \infty_{2}$ eq & 0,00 & $\mathrm{t} \mathrm{O}_{2} \mathrm{eq}$ \\
\hline & Vehículos & 4,20 & $\mathrm{t} \infty_{2}$ eq & 4,20 & $\mathrm{t} \infty_{2}$ eq \\
\hline \multicolumn{6}{|l|}{ Alcance 2} \\
\hline & Emisiones Instalaciones fijas & 8,94 & $\mathrm{t} \mathrm{O}_{2} \mathrm{eq}$ & 4,53 & $\mathrm{t} \mathrm{O}_{2} \mathrm{eq}$ \\
\hline \multicolumn{6}{|l|}{ Alcance 3} \\
\hline & Vehículos & 6,74 & $\mathrm{t} \mathrm{OO}_{2}$ eq & 6,74 & $\mathrm{t} \mathrm{O}_{2}$ eq \\
\hline \multicolumn{6}{|l|}{ Subtotal } \\
\hline & Alcance 1 & 4,20 & $\mathrm{t} \mathrm{CO}_{2} \mathrm{eq}$ & 4,20 & $\mathrm{t} \mathrm{CO}_{2} \mathrm{eq}$ \\
\hline & Alcance 2 & 8,94 & $\mathrm{t} \mathrm{CO}_{2} \mathrm{eq}$ & 4,53 & $\mathrm{t} \mathrm{CO}_{2} \mathrm{eq}$ \\
\hline & Alcance 3 & 6,74 & $\mathrm{t} \mathrm{CO}_{2}$ eq & 6,74 & $\mathrm{t} \mathrm{CO}_{2}$ eq \\
\hline $\begin{array}{l}\text { Huella de } \\
\text { Carbono }\end{array}$ & Total & 19,88 & $\mathrm{t} \mathrm{CO}_{2}$ eq & 15,47 & $\mathrm{t} \mathrm{CO}_{2} \mathrm{eq}$ \\
\hline
\end{tabular}


Tabla 7. Huella de carbono de la depuradora de Estellencs en 2019 y 2020

\begin{tabular}{|c|c|c|c|c|c|}
\hline \multicolumn{2}{|c|}{ Huella de carbono depuradora Estellencs } & \multicolumn{2}{|c|}{2019} & \multicolumn{2}{|c|}{2020} \\
\hline \multicolumn{6}{|c|}{ Alcance 1} \\
\hline & Emisiones Instalaciones fijas & 0,00 & $\mathrm{t} \mathrm{O}_{2} \mathrm{eq}$ & 0,00 & $\mathrm{t} \mathrm{O}_{2} \mathrm{eq}$ \\
\hline & Vehículos & 0,91 & $\mathrm{t} \mathrm{O}_{2}$ eq & 0,91 & $\mathrm{t} \infty_{2} \mathrm{eq}$ \\
\hline \multicolumn{6}{|l|}{ Alcance 2} \\
\hline & Emisiones Instalaciones fijas & 8,33 & $\mathrm{t} \mathrm{O}_{2} \mathrm{eq}$ & 3,72 & $\mathrm{t} \infty_{2} \mathrm{eq}$ \\
\hline \multicolumn{6}{|l|}{ Alcance 3} \\
\hline & Vehículos & 3,38 & $\mathrm{t} \infty_{2}$ eq & 3,38 & $\mathrm{t} \mathrm{OO}_{2} \mathrm{eq}$ \\
\hline \multicolumn{6}{|l|}{ Subtotal } \\
\hline & Alcance 1 & 0,91 & $\mathrm{t} \mathrm{CO}_{2} \mathrm{eq}$ & 0,91 & $\mathrm{t} \mathrm{CO}_{2}$ eq \\
\hline & Alcance 2 & 8,33 & $\mathrm{t} \mathrm{CO}_{2} \mathrm{eq}$ & 3,72 & $\mathrm{t} \mathrm{CO}_{2} \mathrm{eq}$ \\
\hline & Alcance 3 & 3,38 & $\mathrm{t} \mathrm{CO}_{2} \mathrm{eq}$ & 3,38 & $\mathrm{t} \mathrm{CO}_{2} \mathrm{eq}$ \\
\hline $\begin{array}{l}\text { Huella de } \\
\text { Carbono }\end{array}$ & Total & 12,62 & $\mathrm{t} \mathrm{CO}_{2}$ eq & 8,00 & $\mathrm{t} \mathrm{CO} \mathrm{CO}_{2} \mathrm{eq}$ \\
\hline
\end{tabular}

Tabla 8. Huella de carbono de la depuradora de Puigpunyent en 2019 y 2020

\begin{tabular}{|c|c|c|c|c|c|}
\hline \multirow{2}{*}{\multicolumn{2}{|c|}{$\begin{array}{l}\text { Huella de carbono depuradora Puigpunyent } \\
\text { Alcance } 1\end{array}$}} & \multicolumn{2}{|c|}{2019} & \multicolumn{2}{|c|}{2020} \\
\hline & & & & & \\
\hline & Emisiones Instalaciones fijas & 0,00 & $\mathrm{t} \mathrm{O}_{2} \mathrm{eq}$ & 0,00 & $\mathrm{t} \infty_{2}$ eq \\
\hline & Vehículos & 0,91 & $\mathrm{t} \infty_{2}$ eq & 0,91 & $\mathrm{t} \infty_{2}$ eq \\
\hline \multicolumn{6}{|l|}{ Alcance 2} \\
\hline & Emisiones Instalaciones fijas & 35,88 & $\mathrm{t} \infty_{2}$ eq & 22,62 & $\mathrm{t} \infty_{2}$ eq \\
\hline \multicolumn{6}{|l|}{ Alcance 3} \\
\hline & Vehículos & 3,38 & $\mathrm{t} \infty_{2}$ eq & 3,38 & t $\mathrm{CO}_{2}$ eq \\
\hline \multicolumn{6}{|l|}{ Subtotal } \\
\hline & Alcance 1 & 0,91 & $\mathrm{t} \mathrm{CO}_{2} \mathrm{eq}$ & 0,91 & $\mathrm{t} \mathrm{CO}_{2} \mathrm{eq}$ \\
\hline & Alcance 2 & 35,88 & $\mathrm{t} \mathrm{CO}_{2} \mathrm{eq}$ & 22,62 & $\mathrm{t} \mathrm{CO}_{2} \mathrm{eq}$ \\
\hline & Alcance 3 & 3,38 & $\mathrm{t} \mathrm{CO}_{2} \mathrm{eq}$ & 3,38 & $\mathrm{t} \mathrm{CO}_{2} \mathrm{eq}$ \\
\hline $\begin{array}{l}\text { Huella de } \\
\text { Carbono }\end{array}$ & Total & 40,17 & $\mathrm{t} \mathrm{CO}_{2} \mathrm{eq}$ & 26,90 & $\mathrm{t} \mathrm{CO}_{2} \mathrm{eq}$ \\
\hline
\end{tabular}


Tabla 9. Huella de carbono de la depuradora de Soller en 2019 y 2020

\begin{tabular}{|c|c|c|c|c|c|}
\hline Huelle & de carbono depuradora Soller & & 19 & & 20 \\
\hline Alcance 1 & & & & & \\
\hline & Emisiones Instalaciones fijas & 0,00 & $\mathrm{t} \mathrm{CO}_{2} \mathrm{eq}$ & 0,00 & ${\mathrm{t} \mathrm{O}_{2} \mathrm{eq}}$ \\
\hline & Vehículos & 3,63 & $\mathrm{t} \infty_{2}$ eq & 3,63 & $\mathrm{t} \infty_{2}$ eq \\
\hline Alcance 2 & & & & & \\
\hline & Emisiones Instalaciones fijas & 172,80 & $\mathrm{t} \mathrm{CO}_{2} \mathrm{eq}$ & 116,46 & $\mathrm{t} \mathrm{OO}_{2} \mathrm{eq}$ \\
\hline Alcance 3 & & & & & \\
\hline & Vehículos & 6,74 & $\mathrm{t} \mathrm{CO}_{2} \mathrm{eq}$ & 6,74 & $\mathrm{t} \mathrm{O}_{2} \mathrm{eq}$ \\
\hline Subtotal & & & & & \\
\hline & Alcance 1 & 3,63 & $\mathrm{t} \mathrm{CO}_{2} \mathrm{eq}$ & 3,63 & $\mathrm{t} \mathrm{CO}_{2} \mathrm{eq}$ \\
\hline & Alcance 2 & 172,80 & $\mathrm{t} \mathrm{CO}_{2} \mathrm{eq}$ & 116,46 & $\mathrm{t} \mathrm{CO}_{2} \mathrm{eq}$ \\
\hline & Alcance 3 & 6,74 & $\mathrm{t} \mathrm{CO}_{2} \mathrm{eq}$ & 6,74 & $\mathrm{t} \mathrm{CO}_{2} \mathrm{eq}$ \\
\hline $\begin{array}{l}\text { Huella de } \\
\text { Carbono }\end{array}$ & Total & 183,16 & $\mathrm{t} \mathrm{CO}_{2} \mathrm{eq}$ & 126,83 & t $\mathrm{CO}_{2}$ eq \\
\hline
\end{tabular}

En todos los casos, la huella de carbono es inferior en el año 2020 frente a la del 2019. Esto es debido principalmente a una disminución del mix eléctrico de la suministradora de energía, así como una bajada general en el consumo eléctrico de las instalaciones.

Con respecto a la huella hídrica de las depuradoras, la más significativa de todas es, en este caso, la huella hídrica gris (recordemos que la huella hídrica gris hace referencia al volumen teórico de agua necesario para eliminar los contaminantes presentes en el agua. En ningún caso hace referencia al volumen de agua residual en sí mismo). La huella hídrica gris puede calcularse en base al contaminante que predomine en el agua residual tratada. En los caudales de las depuradoras estudiadas, los indicadores de la carga contaminante más destacables son la $\mathrm{DBO}_{5}$, la $\mathrm{DQO}$, los sólidos en suspensión y el nitrógeno ${ }^{3}$. En

\footnotetext{
3 Estos son los contaminantes habituales que se encuentran en las aguas depuradas urbanas, y la carga contaminante permitida la $\mathrm{DBO}_{5}$ y $\mathrm{DQO}$, para el vertido de las
} 
nuestro caso, se ha realizado el cálculo para la $\mathrm{DBO}_{5}$. Por lo tanto, la huella hídrica gris en función de la $\mathrm{DBO}_{5}$ se ha calculado dividiendo la carga de contaminante (V) entre la diferencia de valores que establece la norma de calidad del agua ambiental para ese contaminante y su concentración natural en la masa de agua receptora (Ercin et al., 2011).

$$
\text { HHgris }=(V \times \text { Cagc }) /(C \max -\text { Cnat })
$$

Donde:

$\mathrm{L}=$ Volumen de agua contaminada,

Cagc $=$ Concentración del contaminante en el agua contaminada,

Cmax = Concentración máxima del contaminante,

Cnat $=$ Concentración natural del contaminante,

Los valores de $\mathrm{V}$ y Cagc se han obtenido a partir de la información facilitada por Abaqua, y los valores de Cmax y Cnat se han obtenido a partir de la normativa vigente aplicable en la zona de estudio. Según la normativa española vigente en materia de aguas residuales ${ }^{4}$, el valor máximo de $\mathrm{DBO}_{5}$ en el vertido es de $25 \mathrm{mg} / \mathrm{l}$. El valor de concentración natural de este parámetro es cero, según estudios recientes (Pellicer-Martínez, 2014). Dado que normalmente se pueden encontrar varios contaminantes en el agua, la huella hídrica gris se determina por el contaminante más crítico asociado a la mayor huella hídrica gris de la sustancia crítica, en este caso la sustancia crítica es el indicador $\mathrm{DBO}_{5}$.

aguas residuales tras su depuración, está garantizado en las Islas Baleares y corresponde con lo indicado en el Real Decreto 1620/2007, de 7 de diciembre, por el que se establece el régimen jurídico de la reutilización de las aguas depuradas.

4 BOE. (1996). Real Decreto 509/1996. Normas aplicables al tratamiento de las aguas residuales urbanas. Boletín Oficial Del Estado, p. p.12038. 
Los datos que se han obtenido en relación con la huella hídrica gris ${ }^{5}$ se encuentran en el rango de $60.000 \mathrm{~m}^{3} /$ año hasta $2.300 .000 \mathrm{~m}^{3} /$ año. Esto quiere decir que la depuración de las aguas residuales genera un consumo teórico de agua potable para diluir los contaminantes en ella y que depende, entre otros factores, de los hábitos de la sociedad, de la presencia de industrias, del tipo de tratamiento realizado en la depuradora, etc.

La población y la $\mathrm{DBO}_{5}$ influyen también en la producción de metano de cada instalación, cuyo rango en este caso es de entre 1 y 15 toneladas de metano al año, en función de la tipología de cada depuradora. En la digestión de los fangos, ya se haga en la EDAR o en otro lugar, se emiten grandes cantidades de metano que no se han calculado en este estudio ${ }^{6}$. Por otra parte, como tónica general los fangos producidos son recogidos por empresa especializada y tratados como residuos sólidos en instalación destinada a ese fin. Por su parte, el destino final del efluente depurado varía en cada caso, aunque lo más habitual es que se envíen a emisario submarino y, en algunos casos, se emplea para riego en agricultura, campos de golf y baldeo de calles.

\subsection{MENORCA}

En esta isla encontramos una situación similar en relación con los caudales depurados que aumentan durante los meses de verano.

A continuación, se presentan los resultados de las depuradoras estudiadas en la isla de Menorca para los años 2019 y 2020:

\footnotetext{
5 Nótese aquí que, la carga contaminante que entra en la EDAR, depende de la gestión que hace la ciudadanía y la industria de sus vertidos a la red de saneamiento.

6 Hay que destacar que en algunos casos el biogás se utiliza con el objetivo de que la EDAR tenga su propio suministro eléctrico, siendo este un caso de economía circular.
} 
Tabla 10. Huella de carbono de la depuradora Cala Galdana en 2019 y 2020

\begin{tabular}{|c|c|c|c|c|c|}
\hline \multicolumn{2}{|c|}{ Huella de carbono depuradora Cala Galdana } & \multicolumn{2}{|c|}{2019} & \multicolumn{2}{|c|}{2020} \\
\hline Alcance 1 & & & & & \\
\hline & Emisiones Instalaciones fijas & 0,00 & $\mathrm{t} \infty_{2}$ eq & 0,00 & $\mathrm{t} \mathrm{O}_{2} \mathrm{eq}$ \\
\hline & Vehículos & 1,66 & $\mathrm{t} \infty_{2}$ eq & 1,60 & $\mathrm{t} \infty_{2}$ eq \\
\hline \multicolumn{6}{|l|}{ Alcance 2} \\
\hline & Emisiones Instalaciones fijas & 34,78 & $\mathrm{t} \mathrm{O}_{2}$ eq & 18,13 & $\mathrm{t} \infty_{2}$ eq \\
\hline \multicolumn{6}{|l|}{ Alcance 3} \\
\hline & Vehículos & 4,50 & $\mathrm{t} \infty_{2}$ eq & 4,50 & $\mathrm{t} \infty_{2}$ eq \\
\hline \multicolumn{6}{|l|}{ Subtotal } \\
\hline & Alcance 1 & 1,66 & $\mathrm{t} \mathrm{CO}_{2} \mathrm{eq}$ & 1,60 & $\mathrm{t} \mathrm{CO}_{2} \mathrm{eq}$ \\
\hline & Alcance 2 & 34,78 & t $\mathrm{CO}_{2}$ eq & 18,13 & $\mathrm{t} \mathrm{CO}_{2}$ eq \\
\hline & Alcance 3 & 4,50 & $\mathrm{t} \mathrm{CO}_{2} \mathrm{eq}$ & 4,50 & $\mathrm{t} \mathrm{CO}_{2}$ eq \\
\hline $\begin{array}{l}\text { Huella de } \\
\text { Carbono }\end{array}$ & Total & 40,94 & $\mathrm{t} \mathrm{CO}_{2} \mathrm{eq}$ & 24,23 & $\mathrm{t} \mathrm{CO}_{2} \mathrm{eq}$ \\
\hline
\end{tabular}

Tabla 11. Huella de carbono de la depuradora Es Migjorn en 2019 y 2020

\begin{tabular}{|c|c|c|c|c|c|}
\hline \multicolumn{2}{|c|}{ Huella de carbono depuradora Es Migjorn } & \multicolumn{2}{|c|}{2019} & \multicolumn{2}{|c|}{2020} \\
\hline \multicolumn{6}{|c|}{ Alcance 1} \\
\hline & Emisiones Instalaciones fijas & 0,00 & $\mathrm{t} \infty_{2}$ eq & 0,00 & $\mathrm{t} \infty_{2}$ eq \\
\hline & Vehículos & 1,66 & $\mathrm{t} \infty_{2}$ eq & 1,60 & $\mathrm{t} \infty_{2}$ eq \\
\hline \multicolumn{6}{|c|}{ Alcance 2} \\
\hline & Emisiones Instalaciones fijas & 40,14 & $\mathrm{t} \infty_{2}$ eq & 21,90 & $\mathrm{t} \infty_{2}$ eq \\
\hline \multicolumn{6}{|l|}{ Alcance 3} \\
\hline & Vehículos & 3,75 & $\mathrm{t} \infty_{2}$ eq & 3,75 & $\mathrm{t} \infty_{2}$ eq \\
\hline \multicolumn{6}{|l|}{ Subtotal } \\
\hline & Alcance 1 & 1,66 & $\mathrm{t} \mathrm{CO}_{2} \mathrm{eq}$ & 1,60 & $\mathrm{t} \mathrm{CO}_{2} \mathrm{eq}$ \\
\hline & Alcance 2 & 40,14 & $\mathrm{t} \mathrm{CO}_{2} \mathrm{eq}$ & 21,90 & $\mathrm{t} \mathrm{CO}_{2} \mathrm{eq}$ \\
\hline & Alcance 3 & 3,75 & $\mathrm{t} \mathrm{CO}_{2} \mathrm{eq}$ & 3,75 & $\mathrm{t} \mathrm{CO}_{2} \mathrm{eq}$ \\
\hline $\begin{array}{l}\text { Huella de } \\
\text { Carbono }\end{array}$ & Total & 45,55 & $\mathrm{t} \mathrm{CO}_{2} \mathrm{eq}$ & 27,25 & $\mathrm{t} \mathrm{CO}_{2} \mathrm{eq}$ \\
\hline
\end{tabular}


Tabla 12. Huella de carbono de la depuradora Ferreries en 2019 y 2020

\begin{tabular}{|c|c|c|c|c|c|}
\hline \multicolumn{2}{|c|}{ Huella de carbono depuradora Ferreries } & \multicolumn{2}{|c|}{2019} & \multicolumn{2}{|c|}{2020} \\
\hline \multicolumn{6}{|c|}{ Alcance 1} \\
\hline & Emisiones Instalaciones fijas & 0,00 & $\mathrm{t} \infty_{2}$ eq & 0,00 & $\mathrm{t} \infty_{2}$ eq \\
\hline & Vehículos & 2,57 & $\mathrm{t} \infty_{2}$ eq & 2,51 & $\mathrm{t} \mathrm{O}_{2} \mathrm{eq}$ \\
\hline \multicolumn{6}{|l|}{ Alcance 2} \\
\hline & Emisiones Instalaciones fijas & 47,75 & $\mathrm{t} \mathrm{O}_{2} \mathrm{eq}$ & 34,15 & $\mathrm{t} \infty_{2} \mathrm{eq}$ \\
\hline \multicolumn{6}{|l|}{ Alcance 3} \\
\hline & Vehículos & 7,23 & $\mathrm{t} \infty_{2}$ eq & 7,23 & $\mathrm{t} \infty_{2}$ eq \\
\hline \multicolumn{6}{|l|}{ Subtotal } \\
\hline & Alcance 1 & 2,57 & $\mathrm{t} \mathrm{CO}_{2} \mathrm{eq}$ & 2,51 & $\mathrm{t} \mathrm{CO}_{2} \mathrm{eq}$ \\
\hline & Alcance 2 & 47,75 & $\mathrm{t} \mathrm{CO}_{2} \mathrm{eq}$ & 34,15 & $\mathrm{t} \mathrm{CO}_{2} \mathrm{eq}$ \\
\hline & Alcance 3 & 7,23 & $\mathrm{t} \mathrm{CO}_{2} \mathrm{eq}$ & 7,23 & $\mathrm{t} \mathrm{CO}_{2} \mathrm{eq}$ \\
\hline $\begin{array}{l}\text { Huella de } \\
\text { Carbono }\end{array}$ & Total & 57,55 & $\mathrm{t} \mathrm{CO}_{2} \mathrm{eq}$ & 43,89 & $\mathrm{t} \mathrm{CO} \mathrm{CO}_{2} \mathrm{eq}$ \\
\hline
\end{tabular}

Tabla 13. Huella de carbono de la depuradora Ciutadella Nord en 2019 y 2020

\begin{tabular}{|c|c|c|c|c|c|}
\hline Huella d & e carbono depuradora Ciut. Nord & & 19 & & 20 \\
\hline Alcance 1 & & & & & \\
\hline & Emisiones Instalaciones fijas & 0,00 & $\mathrm{t} \mathrm{O}_{2} \mathrm{eq}$ & 0,00 & $\mathrm{t} \mathrm{O}_{2} \mathrm{eq}$ \\
\hline & Vehículos & 3,03 & $\mathrm{t} \mathrm{CO}_{2}$ eq & 3,03 & $\mathrm{t} \infty_{2}$ eq \\
\hline Alcance 2 & & & & & \\
\hline & Emisiones Instalaciones fijas & 49,77 & $\mathrm{t} \mathrm{OO}_{2} \mathrm{eq}$ & 20,73 & $\mathrm{t} \mathrm{OO}_{2} \mathrm{eq}$ \\
\hline Alcance 3 & & & & & \\
\hline & Vehículos & 7,12 & $\mathrm{t} \infty_{2}$ eq & 7,12 & $\mathrm{t} \mathrm{O}_{2}$ eq \\
\hline Subtotal & & & & & \\
\hline & Alcance 1 & 3,03 & $\mathrm{t} \mathrm{CO}_{2} \mathrm{eq}$ & 3,03 & $\mathrm{t} \mathrm{CO}_{2} \mathrm{eq}$ \\
\hline & Alcance 2 & 49,77 & $\mathrm{t} \mathrm{CO}_{2} \mathrm{eq}$ & 20,73 & $\mathrm{t} \mathrm{CO}_{2} \mathrm{eq}$ \\
\hline & Alcance 3 & 7,12 & $\mathrm{t} \mathrm{CO}_{2} \mathrm{eq}$ & 7,12 & $\mathrm{t} \mathrm{CO}_{2}$ eq \\
\hline $\begin{array}{c}\text { Huella de } \\
\text { Carbono }\end{array}$ & Total & 59,91 & t $\mathrm{CO}_{2} \mathrm{eq}$ & 30,87 & $\mathrm{t} \mathrm{CO}_{2} \mathrm{eq}$ \\
\hline
\end{tabular}


Tabla 14. Huella de carbono de la depuradora Ciutadella Sud en 2019 y 2020

\begin{tabular}{|c|c|c|c|c|c|}
\hline \multicolumn{2}{|c|}{ Huella de carbono depuradora Ciutadella Sud } & \multicolumn{2}{|c|}{2019} & \multicolumn{2}{|c|}{2020} \\
\hline \multicolumn{6}{|c|}{ Alcance 1} \\
\hline & Emisiones Instalaciones fijas & 0,00 & $\mathrm{t} \mathrm{O}_{2} \mathrm{eq}$ & 0,00 & $\mathrm{t} \mathrm{OO}_{2} \mathrm{eq}$ \\
\hline & Vehículos & 10,35 & $\mathrm{t} \infty_{2}$ eq & 10,35 & $\mathrm{t} \infty_{2}$ eq \\
\hline \multicolumn{6}{|l|}{ Alcance 2} \\
\hline & Emisiones Instalaciones fijas & 306,53 & $\mathrm{t} \infty_{2}$ eq & 176,29 & $\mathrm{t} \infty_{2} \mathrm{eq}$ \\
\hline \multicolumn{6}{|l|}{ Alcance 3} \\
\hline & Vehículos & 37,79 & $\mathrm{t} \infty_{2}$ eq & 37,79 & $\mathrm{t} \infty_{2}$ eq \\
\hline \multicolumn{6}{|l|}{ Subtotal } \\
\hline & Alcance 1 & 10,35 & $\mathrm{t} \mathrm{CO}_{2} \mathrm{eq}$ & 10,35 & $\mathrm{t} \mathrm{CO}_{2}$ eq \\
\hline & Alcance 2 & 306,53 & $\mathrm{t} \mathrm{CO}_{2} \mathrm{eq}$ & 176,29 & $\mathrm{t} \mathrm{CO}_{2} \mathrm{eq}$ \\
\hline & Alcance 3 & 37,79 & $\mathrm{t} \mathrm{CO}_{2} \mathrm{eq}$ & 37,79 & t $\mathrm{CO}_{2} \mathrm{eq}$ \\
\hline $\begin{array}{l}\text { Huella de } \\
\text { Carbono }\end{array}$ & Total & 354,67 & $\mathrm{t} \mathrm{CO}_{2} \mathrm{eq}$ & 224,43 & $\mathrm{t} \mathrm{CO}_{2} \mathrm{eq}$ \\
\hline
\end{tabular}

Las depuradoras de Cala Galdana, Ferreries y Es Migjorn comparten el vehículo de empresa, por lo tanto, como no tienen consumo de gasóleo para instalaciones fijas, estas tres depuradoras son las que presentan un menor alcance 1. Con respecto al alcance 2 de estas tres depuradoras, hay que destacar que a partir de septiembre de 2020 se sustituyó el vehículo de empresa de Diesel por uno eléctrico, por lo tanto, la huella de carbono a partir del año 2021 no tendrá valores asociados al alcance 1 en estas depuradoras, sino del alcance 2 , al ser el nuevo vehículo dependiente de la energía eléctrica y no de los combustibles fósiles. El punto de carga de dicho vehículo se encuentra en la depuradora de Ferreries, que es donde permanece en descanso este.

En la EDAR Ferreries hay una instalación de placas fotovoltaicas en la planta, con una modalidad de autoconsumo con excedentes, siendo la producción de las placas del orden de $60.000 \mathrm{kWh}$ al año aproximadamente. En la EDAR Ciutadella Nord también se ha 
sustituido el vehículo de empresa por uno eléctrico en septiembre de 2020.

Por su parte, la EDAR Ciutadella Sud es la que da respuesta a una mayor población, por lo tanto, presenta la mayor huella de carbono al tener el mayor consumo eléctrico de todas. También es la que tiene un mayor número de vehículos asociados y un mayor número de trabajadores. Esta depuradora, al ser la más grande, es donde se encuentran los almacenes, siendo el punto central de abastecimiento y donde los proveedores suelen suministrar todo lo necesario. Es por ello por lo que, desde aquí se envía aprovisionamiento de forma periódica a las demás depuradoras según necesidad.

Con respecto al alcance 3, todas las depuradoras presentan proveedores y gestión de residuos autorizada, principalmente relacionada con el tratamiento de los fangos generados en la instalación. Los fangos purgados pasan por un tratamiento de digestión, una vez digeridos pasan a espesamiento y se deshidratan mediante decantadores centrífugos (uso de polielectrolito para el espesamiento). El efluente depurado va, en todos los casos, a emisario submarino.

En el caso de la huella hídrica, la que presenta el valor más elevado es la de Ciutadella Sud, debido a que es la de mayor entidad y la que trata un mayor caudal de aguas residuales urbanas. Las otras 4 depuradoras estudiadas presentan todas valores inferiores de $\mathrm{HH}_{\text {gris }}$ a 1 millón de $\mathrm{m}^{3}$ /año.

\subsection{IBIZA}

La mayoría de las EDAR de Ibiza presentan un dimensionamiento adecuado, solo la depuradora de Sant Joan de Labritja supera el caudal de diseño durante cinco meses y, por lo tanto, un dimensionado deficiente. 
A continuación, se presentan los resultados de las depuradoras estudiadas en la isla de Ibiza para los años 2019 y 2020:

Tabla 15. Huella de carbono de la depuradora Ibiza en 2019 y 2020

\begin{tabular}{|c|c|c|c|c|c|}
\hline \multicolumn{2}{|c|}{ Huella de carbono depuradora Ibiza } & \multicolumn{2}{|c|}{2019} & \multicolumn{2}{|c|}{2020} \\
\hline \multicolumn{6}{|c|}{ Alcance 1} \\
\hline & Emisiones Instalaciones fijas & 0,00 & $\mathrm{t} \mathrm{O}_{2} \mathrm{eq}$ & 0,00 & $\mathrm{t} \mathrm{OO}_{2}$ eq \\
\hline & Vehículos & 10,30 & $\mathrm{t} \infty_{2}$ eq & 10,30 & $\mathrm{t} \infty_{2}$ eq \\
\hline \multicolumn{6}{|l|}{ Alcance 2} \\
\hline & Emisiones Instalaciones fijas & 257,51 & $\mathrm{t} \mathrm{O}_{2} \mathrm{eq}$ & 178,85 & $\mathrm{t} \mathrm{OO}_{2} \mathrm{eq}$ \\
\hline \multicolumn{6}{|l|}{ Alcance 3} \\
\hline & Vehículos & 6,74 & $\mathrm{t} \infty_{2}$ eq & 6,74 & $\mathrm{t} \infty_{2}$ eq \\
\hline \multicolumn{6}{|l|}{ Subtotal } \\
\hline & Alcance 1 & 10,30 & $\mathrm{t} \mathrm{CO}_{2} \mathrm{eq}$ & 10,30 & t $\mathrm{CO}_{2}$ eq \\
\hline & Alcance 2 & 257,51 & $\mathrm{t} \mathrm{CO}_{2}$ eq & 178,85 & $\mathrm{t} \mathrm{CO}_{2}$ eq \\
\hline & Alcance 3 & 6,74 & $\mathrm{t} \mathrm{CO}_{2} \mathrm{eq}$ & 6,74 & $\mathrm{t} \mathrm{CO}_{2}$ eq \\
\hline $\begin{array}{l}\text { Huella de } \\
\text { Carbono }\end{array}$ & Total & 274,55 & t $\mathrm{CO}_{2} \mathrm{eq}$ & 195,89 & $\mathrm{t} \mathrm{CO}_{2} \mathrm{eq}$ \\
\hline
\end{tabular}

Tabla 16. Huella de carbono de la depuradora de San Antonio en 2019 y 2020

\begin{tabular}{|c|c|c|c|c|c|}
\hline \multicolumn{2}{|c|}{ Huella de carbono depuradora San Antonio } & \multicolumn{2}{|c|}{2019} & \multicolumn{2}{|c|}{2020} \\
\hline \multicolumn{6}{|c|}{ Alcance 1} \\
\hline & Emisiones Instalaciones fijas & 0,00 & $\mathrm{t} \mathrm{O}_{2} \mathrm{eq}$ & 0,00 & $\mathrm{t} \mathrm{O}_{2} \mathrm{eq}$ \\
\hline & Vehículos & 12,83 & $\mathrm{t} \mathrm{O}_{2}$ eq & 12,83 & $\mathrm{t} \infty_{2}$ eq \\
\hline \multicolumn{6}{|l|}{ Alcance 2} \\
\hline & Emisiones Instalaciones fijas & 636,74 & $\mathrm{t} \infty_{2}$ eq & 415,90 & $\mathrm{t} \infty_{2}$ eq \\
\hline \multicolumn{6}{|l|}{ Alcance 3} \\
\hline & Vehículos & 10,10 & $\mathrm{t} \mathrm{O}_{2}$ eq & 10,10 & $\mathrm{t} \mathrm{O}_{2}$ eq \\
\hline \multicolumn{6}{|l|}{ Subtotal } \\
\hline & Alcance 1 & 12,83 & $\mathrm{t} \mathrm{CO}_{2} \mathrm{eq}$ & 12,83 & $\mathrm{t} \mathrm{CO}_{2} \mathrm{eq}$ \\
\hline & Alcance 2 & 636,74 & $\mathrm{t} \mathrm{CO}_{2} \mathrm{eq}$ & 415,90 & t $\mathrm{CO}_{2}$ eq \\
\hline & Alcance 3 & 10,10 & $\mathrm{t} \mathrm{CO}_{2}$ eq & 10,10 & $\mathrm{t} \mathrm{CO}_{2} \mathrm{eq}$ \\
\hline $\begin{array}{l}\text { Huella de } \\
\text { Carbono }\end{array}$ & Total & 659,67 & $\mathrm{t} \mathrm{CO} \mathrm{CO}_{2} \mathrm{eq}$ & 438,83 & $\mathrm{t} \mathrm{CO} \mathrm{CO}_{2} \mathrm{eq}$ \\
\hline
\end{tabular}


Tabla 17. Huella de carbono de la depuradora de Cala Tarida en 2019 y 2020

\begin{tabular}{|c|c|c|c|c|c|}
\hline \multicolumn{2}{|c|}{ Huella de carbono depuradora Cala Tarida } & \multicolumn{2}{|c|}{2019} & \multicolumn{2}{|c|}{2020} \\
\hline \multicolumn{6}{|c|}{ Alcance 1} \\
\hline & Emisiones Instalaciones fijas & 0,00 & $\mathrm{t} \infty_{2}$ eq & 0,00 & $\mathrm{t} \infty_{2}$ eq \\
\hline & Vehículos & 0,45 & $\mathrm{t} \infty_{2}$ eq & 0,45 & $\mathrm{t} \infty_{2}$ eq \\
\hline \multicolumn{6}{|l|}{ Alcance 2} \\
\hline & Emisiones Instalaciones fijas & 74,40 & $\mathrm{t} \infty_{2}$ eq & 33,86 & $\mathrm{t} \infty_{2}$ eq \\
\hline \multicolumn{6}{|l|}{ Alcance 3} \\
\hline & Vehículos & 0,02 & $\mathrm{t} \infty_{2}$ eq & 0,02 & $\mathrm{t} \infty_{2}$ eq \\
\hline \multicolumn{6}{|l|}{ Subtotal } \\
\hline & Alcance 1 & 0,45 & $\mathrm{t} \mathrm{CO}_{2} \mathrm{eq}$ & 0,45 & $\mathrm{t} \mathrm{CO}_{2}$ eq \\
\hline & Alcance 2 & 74,40 & $\mathrm{t} \mathrm{CO}_{2}$ eq & 33,86 & $\mathrm{t} \mathrm{CO}_{2}$ eq \\
\hline & Alcance 3 & 0,02 & $\mathrm{t} \mathrm{CO}_{2} \mathrm{eq}$ & 0,02 & $\mathrm{t} \mathrm{CO}_{2}$ eq \\
\hline $\begin{array}{l}\text { Huella de } \\
\text { Carbono }\end{array}$ & Total & 74,87 & t $\mathrm{CO}_{2} \mathrm{eq}$ & 34,33 & $\mathrm{t} \mathrm{CO}_{2}$ eq \\
\hline
\end{tabular}

También en Ibiza se mantiene el patrón de la disminución de la huella de carbono en el año 2020, con respecto a la del 2019. Hay que destacar que el alcance 3 en las depuradoras de Ibiza no ha sido especialmente elevado, dado que no cuentan con un gran número de proveedores ni trabajadores en las instalaciones (si se compara con las desaladoras, por ejemplo).

Con respecto a la huella hídrica, compuesta por la huella hídrica gris en este caso, al ser la huella hídrica azul y verde no significativas en nuestro caso, en las desaladoras de Ibiza y San Antonio alcanza valores especialmente elevados, del orden de 12 y 6 millones de metros cúbicos al año respectivamente. La de Cala Tarida tiene un valor bastante inferior, del orden del 350.000 m³/año, al tratar un volumen de caudal depurado notablemente inferior a las otras. 


\subsection{FORMENTERA}

El caudal tratado por la EDAR de Formentera aumenta aproximadamente cuatro veces más en temporada alta que en temporada baja. Sin embargo, se trata de una instalación que cumple el indicador de caudal y está correctamente dimensionada para todas las épocas del año.

A continuación, se presentan los resultados de la depuradora estudiada en la isla de Formentera para los años 2019 y 2020:

Tabla 18. huella de carbono de la depuradora de Formentera en 2019 y 2020

\begin{tabular}{|c|c|c|c|c|c|}
\hline \multicolumn{2}{|c|}{ Huella de carbono depuradora Formentera } & \multicolumn{2}{|c|}{2019} & \multicolumn{2}{|c|}{2020} \\
\hline \multicolumn{6}{|c|}{ Alcance 1} \\
\hline & Emisiones Instalaciones fijas & 0,00 & $\mathrm{t} \mathrm{O}_{2} \mathrm{eq}$ & 0,00 & $\mathrm{t} \mathrm{O}_{2} \mathrm{eq}$ \\
\hline & Vehículos & 3,03 & $\mathrm{t} \mathrm{O}_{2}$ eq & 3,03 & $\mathrm{t} \infty_{2}$ eq \\
\hline \multicolumn{6}{|l|}{ Alcance 2} \\
\hline & Emisiones Instalaciones fijas & 138,33 & $\mathrm{t} \infty_{2}$ eq & 106,38 & $\mathrm{t} \mathrm{O}_{2} \mathrm{eq}$ \\
\hline \multicolumn{6}{|l|}{ Alcance 3} \\
\hline & Vehículos & 8,37 & $\mathrm{t} \infty_{2}$ eq & 8,37 & $\mathrm{t} \mathrm{O}_{2} \mathrm{eq}$ \\
\hline \multicolumn{6}{|l|}{ Subtotal } \\
\hline & Alcance 1 & 3,03 & t $\mathrm{CO}_{2}$ eq & 3,03 & t $\mathrm{CO}_{2}$ eq \\
\hline & Alcance 2 & 138,33 & $\mathrm{t} \mathrm{CO}_{2} \mathrm{eq}$ & 106,38 & t $\mathrm{CO}_{2}$ eq \\
\hline & Alcance 3 & 8,37 & t $\mathrm{CO}_{2}$ eq & 8,37 & $\mathrm{t} \mathrm{CO}_{2}$ eq \\
\hline $\begin{array}{l}\text { Huella de } \\
\text { Carbono }\end{array}$ & Total & 149,73 & $\mathrm{t} \mathrm{CO}_{2} \mathrm{eq}$ & 117,78 & $\mathrm{t} \mathrm{CO}_{2} \mathrm{eq}$ \\
\hline
\end{tabular}

En la depuradora de Formentera es notable el alcance 3, ya que a esta depuradora acuden diariamente para la retirada de fangos deshidratados, de tal manera que el recorrido diario del camión destinado a ese fin eleva las emisiones de este alcance.

Como cierre de este apartado, se plantean dos tablas donde se puede observar la huella de carbono de las depuradoras del archipiélago balear, en función de la cantidad de agua residual tratada: 
Tabla 19. Huella de carbono por volumen de agua tratada en 2019 en $\mathrm{kgCO}{ }^{2} \mathrm{eq} / \mathrm{m}_{3}$

\begin{tabular}{|c|c|c|c|c|}
\hline EAR & $\begin{array}{l}\text { Volumen } \\
\text { tratado en } \\
2019\left(\mathrm{Hm}^{3}\right)\end{array}$ & $\begin{array}{l}\text { Huella de carbono } \\
\text { en } 2019\left(\mathrm{tCO}_{2} \mathrm{eq}\right)\end{array}$ & $\begin{array}{c}\text { Huella de carbono por } \\
\text { volumen de agua tratada } \\
\text { para el } 2019\left(\mathrm{tCO}_{2} \mathrm{eq} / \mathrm{Hm}^{3}\right)\end{array}$ & $\begin{array}{c}\text { Huella de carbono por } \\
\text { volumen de agua tratada } \\
\text { para el } 2019\left(\mathrm{kgCO}_{2} \mathrm{eq} / \mathrm{m}^{3}\right)\end{array}$ \\
\hline Andratx & 0,95 & 198,50 & 208,95 & 0,21 \\
\hline Banyalbufar & 0,02 & 15,31 & 765,50 & 0,77 \\
\hline Camp de Mar & 0,14 & 57,56 & 411,14 & 0,41 \\
\hline Deia & 0,11 & 19,88 & 180,73 & 0,18 \\
\hline Estellencs & 0,016 & 12,62 & 788,75 & 0,79 \\
\hline Puigpunyent & 0,08 & 40,17 & 502,13 & 0,50 \\
\hline Soller & 1,07 & 183,16 & 171,18 & 0,17 \\
\hline Cala Galdana & 0,3 & 40,94 & 136,47 & 0,14 \\
\hline Es Migjorn & 0,19 & 45,55 & 239,74 & 0,24 \\
\hline Ferreries & 0,39 & 57,55 & 147,56 & 0,15 \\
\hline Qutadella Nord & 0,3 & 59,91 & 199,70 & 0,20 \\
\hline Gutadella Sud & 4,3 & 354,67 & 82,48 & 0,08 \\
\hline Evissa & 5,6 & 274,55 & 49,03 & 0,05 \\
\hline Sant Antoni & 3,08 & 659,67 & 214,18 & 0,21 \\
\hline Cala Tarida & 0,144 & 74,87 & 519,93 & 0,52 \\
\hline Formentera & 0,48 & 149,73 & 311,94 & 0,31 \\
\hline
\end{tabular}

Tabla 20. Huella de carbono por volumen de agua tratada en 2020 en $\mathrm{kgCO} e \mathrm{eq} / \mathrm{m}_{3}$

\begin{tabular}{|c|c|c|c|c|}
\hline DAR & $\begin{array}{c}\text { Volumen } \\
\text { tratado en } \\
2020\left(\mathrm{Hm}^{3}\right)\end{array}$ & $\begin{array}{l}\text { Huella de carbono } \\
\text { en } 2020\left(\mathrm{tCO}_{2} \text { eq) }\right.\end{array}$ & $\begin{array}{l}\text { Huella de carbono por } \\
\text { volumen de agua tratada } \\
\text { para el } 2020\left(\mathrm{tCO}_{2} \mathrm{eq} / \mathrm{Hm}^{3}\right)\end{array}$ & $\begin{array}{c}\text { Huella de carbono por } \\
\text { volumen de agua tratada } \\
\text { para el } 2020\left(\mathrm{kgCO}_{2} \mathrm{eq} / \mathrm{m}^{3}\right)\end{array}$ \\
\hline Andratx & 0,88 & 143,92 & 163,55 & 0,16 \\
\hline Banyalbufar & 0,019 & 13,58 & 714,74 & 0,71 \\
\hline Camp de Mar & 0,05 & 29,18 & 583,60 & 0,58 \\
\hline Deia & 0,079 & 15,74 & 199,24 & 0,20 \\
\hline Estellencs & 0,011 & 8,00 & 727,27 & 0,73 \\
\hline Puigpunyent & 0,077 & 26,90 & 349,35 & 0,35 \\
\hline Soller & 0,99 & 126,83 & 128,11 & 0,13 \\
\hline Cala Galdana & 0,24 & 24,23 & 100,96 & 0,10 \\
\hline Es Migjorn & 0,086 & 27,25 & 316,86 & 0,32 \\
\hline Ferreries & 0,356 & 43,89 & 123,29 & 0,12 \\
\hline Gutadella Nord & 0,15 & 30,87 & 205,80 & 0,21 \\
\hline Gutadella Sud & 3,4 & 224,43 & 66,01 & 0,07 \\
\hline Evissa & 6,08 & 195,89 & 32,22 & 0,03 \\
\hline Sant Antoni & 2,17 & 438,83 & 202,23 & 0,20 \\
\hline Cala Tarida & 0,073 & 34,33 & 470,27 & 0,47 \\
\hline Formentera & 0,49 & 117,78 & 240,37 & 0,24 \\
\hline
\end{tabular}

Puede observarse como, las instalaciones que tratan un caudal más elevado resultan más eficientes desde el punto de vista energético, al presentar las depuradoras de agua residual una huella de carbono 
función del volumen tratado por la instalación. Sin embargo, hay que tener en cuenta que el valor que marcará la idoneidad de la planta depuradora es la eficiencia de esta para eliminar los contaminantes del agua, y esto solo se consigue cuando se trabaja por debajo del caudal de diseño. 


\section{CARACTERIZACIÓN DE LA HUELLA AMBIENTAL EN LAS IDAM GESTIONADAS POR ABAQUA}

El objetivo de este apartado es analizar los consumos energéticos e hídricos de las IDAM, estableciendo relaciones entre dichos consumos y las características de las IDAM y detectando aquellas que presenten consumos energéticos superiores al resto para proponer actuaciones encaminadas a la reducción de su huella ambiental.

\section{La huella hídrica en las IDAM}

La huella hídrica no contempla el agua de mar dentro de sus cálculos, al considerarla una fuente inagotable de recurso. Es por ello por lo que, a pesar de considerar el agua de mar tratada en desaladora como una fuente de agua potable, esta no computa ni como agua azul, verde o gris. Del mismo modo, al enviarse la salmuera de nuevo al mar (realizándose esta operación con las garantías medioambientales requeridas), no contamos tampoco con agua gris al no tener que contar con agua dulce para la dilución de los contaminantes generados. Por otra parte, el agua verde queda desestimada al ser la desaladora una instalación cerrada y estanca.

Finalmente, podría tenerse en cuenta la huella hídrica indirecta de la desaladora calculando la huella hídrica del uniforme de los/as 
trabajadores/as, o el agua consumida para la producción de energía eléctrica por parte de la suministradora, etc. Sin embargo, no se ha abordado el cálculo hasta ese alcance en este documento.

Por lo tanto, los siguientes apartados se centrarán en la huella de carbono de las IDAM, dividiendo la información por islas.

\subsection{MALLORCA}

La producción de agua desalada durante el periodo 2014-2019 en la isla de Mallorca se ha quintuplicado (Figura 15), y el aumento más importante se produjo del 2015 al 2016 y se corresponde con la puesta en marcha de las desaladoras de Andratx y Alcudia. La puesta en marcha de las desaladoras dio la posibilidad de cubrir las demandas hídricas urbanas durante el periodo de sequía.

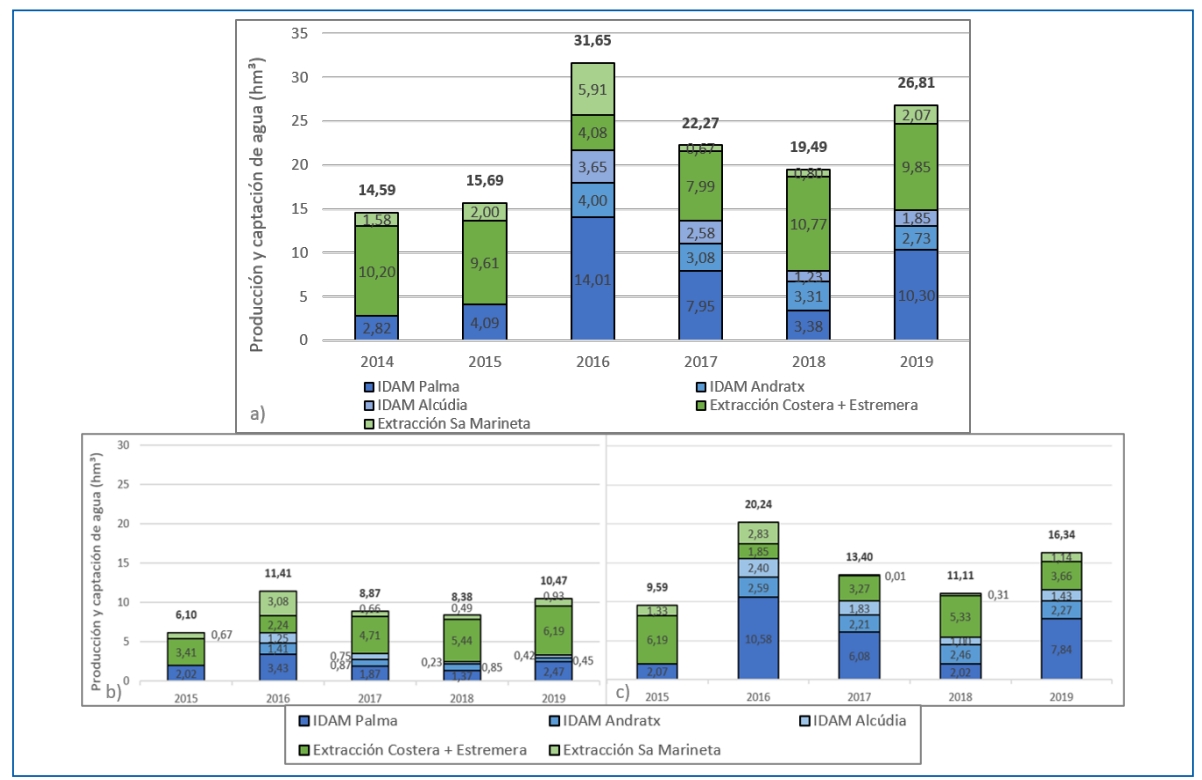

Figura 15. Producción y captación de agua en la isla de Mallorca para el periodo 2014-2019 (a), durante las temporadas bajas de los años 2015-2019 (b), durante las temporadas altas de los años 2015-2019 (c). Fuente: $A B A Q \cup A$ 


\section{a) IDAM Bahía de Palma}

Se trata de una desaladora, explotada en la actualidad por la empresa Suez Treatment Solutions, que en el año 2019 generó un caudal de agua potable de $4.588 .230 \mathrm{~m}^{3}$ (Figura 16). Su producción de agua desalada sufre un incremento en la época estival y, a su vez, las temporadas estivales son irregulares entre sí, debido principalmente a si se trata de años secos o lluviosos.

En la Tabla 21 pueden verse los resultados de la huella de carbono divididos por alcances. Como cabía esperar, el alcance 2 de las desaladoras es bastante elevado comparado con el resto de las instalaciones estudiadas en este informe. Esto es debido a que las desaladoras son grandes consumidoras de energía eléctrica para su funcionamiento, y dado que el alcance 2 es el que tiene en cuenta las emisiones relacionadas con el consumo de electricidad por parte de la compañía, ha arrojado resultados elevados en todas las desaladoras estudiadas.
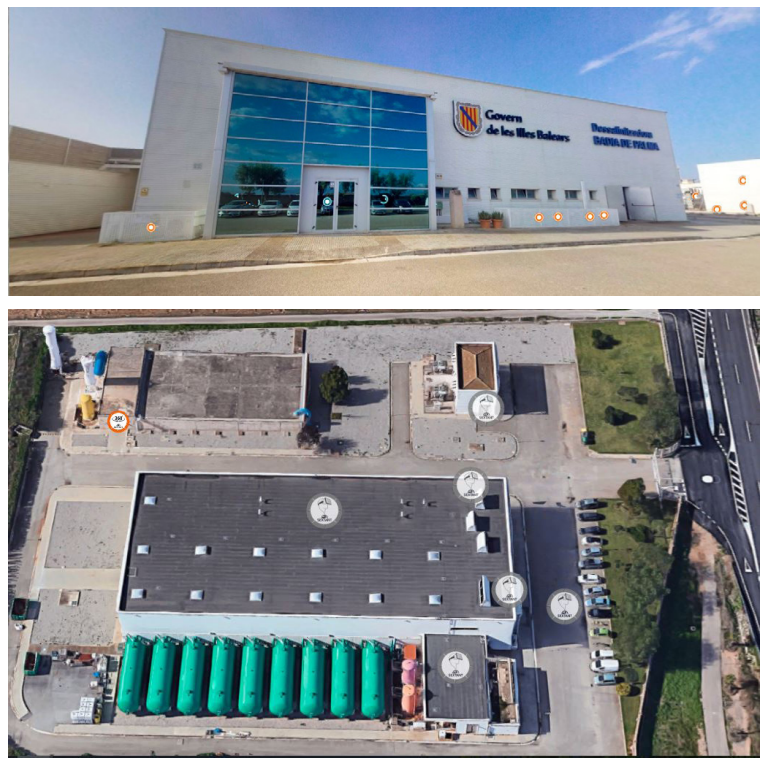

Figura 16. Fachada y vista en planta de la Estación desaladora de la Bahía de Palma (Mallorca, España) 
Tabla 21. Huella de carbono de la IDAM Bahía de Palma en el año 2019 y 2020

\begin{tabular}{|c|c|c|c|c|c|}
\hline \multicolumn{2}{|c|}{ Huella de carbono desaladora Bahía de Palma } & \multicolumn{2}{|c|}{2019} & \multicolumn{2}{|c|}{2020} \\
\hline \multicolumn{6}{|c|}{ Alcance 1} \\
\hline & Emisiones Instalaciones fijas & 8,11 & $\mathrm{t} \infty_{2} \in \mathrm{q}$ & 8,80 & $\mathrm{t} \infty_{2}$ eq \\
\hline & Vehículos & 1,77 & $\mathrm{t} \infty_{2} \in \mathrm{q}$ & 1,77 & $\mathrm{t} \infty_{2}$ eq \\
\hline \multicolumn{6}{|l|}{ Alcance 2} \\
\hline & Emisiones Instalaciones fijas & $10.665,31$ & $\mathrm{t} \infty_{2}$ eq & $3.140,56$ & $\mathrm{t} \infty_{2}$ eq \\
\hline \multicolumn{6}{|l|}{ Alcance 3} \\
\hline & Vehículos & $18.501,05$ & t $\infty_{2}$ eq & $18.494,43$ & $\mathrm{t} \infty_{2}$ eq \\
\hline \multicolumn{6}{|l|}{ Subtotal } \\
\hline & Alcance 1 & 9,88 & $\mathrm{t} \mathrm{CO}_{2} \mathrm{eq}$ & 10,57 & $\mathrm{t} \mathrm{CO}_{2} \mathrm{eq}$ \\
\hline & Alcance 2 & $10.665,31$ & $\mathrm{t} \mathrm{CO}_{2}$ eq & $3.140,56$ & $\mathrm{t} \mathrm{CO}_{2}$ eq \\
\hline & Alcance 3 & $18.501,05$ & $\mathrm{t} \mathrm{CO}_{2} \mathrm{eq}$ & $18.494,43$ & $\mathrm{t} \mathrm{CO}_{2} \mathrm{eq}$ \\
\hline $\begin{array}{l}\text { Huella de } \\
\text { Carbono }\end{array}$ & Total & $29.176,25$ & $\mathrm{t} \mathrm{CO}_{2}$ eq & $21.645,56$ & $\mathrm{t} \mathrm{CO}_{2} \mathrm{eq}$ \\
\hline
\end{tabular}

Una de las alternativas que existen para poder compensar el alcance 2 de la huella de carbono, es seleccionar empresas suministradoras con un mix eléctrico igual a cero. El mix eléctrico se calcula para cada empresa eléctrica, teniendo en cuenta las fuentes de generación de energía. Si la empresa utiliza íntegramente fuentes de energía renovable para la producción de electricidad, el mix eléctrico es cero. A medida que incorpora fuentes no renovables, aumenta el mix eléctrico ' debido a las emisiones asociadas a la quema de combustibles fósiles de esas fuentes.

Por otra parte, el alcance 1 está conformado por el consumo de gasoil de la instalación, así como por el combustible consumido por los tres vehículos que hay asociados a esta instalación (desplazamiento del personal y actividades relacionadas con la desaladora).

\footnotetext{
1 El valor del mix eléctrico de las diferentes suministradoras existentes en nuestro país, puede consultarse en la página web del Ministerio para la Transición Ecológica y le Reto Demográfico.
} 
Finalmente, en el alcance 3 tenemos unas emisiones elevadas debido principalmente al gran número de trabajadores/as de la desaladora (22 en total), la cantidad de proveedores (6, que acuden con diferente frecuencia a la desaladora) y la gestión de residuos que se realiza trimestralmente. Los recorridos realizados por los vehículos de proveedores, trabajadores/as y gestión de residuos, disparan notablemente la huella de carbono de la instalación. Esto es algo habitual en todas aquellas empresas que dan un servicio, ya que generalmente cuentan con un gran número de trabajadores/as y requieren de numerosos proveedores que les asistan para garantizar el servicio (repuestos, material de oficina, mantenimiento puntual realizado por empresas externas, revisiones, averías, etc.).

Por otra parte, observamos que la huella de carbono del año 2020 es inferior a la del 2019, esto es una tendencia que se repite en todas las desaladoras estudiadas en el ciclo del agua de las Islas Baleares y es debido principalmente a las siguientes razones:

- En el año 2020 los factores de emisión de las suministradoras eléctricas disminuyeron en los dos casos (Endesa e Iberdrola). Esto es producido por la inclusión de energías renovables en su mix eléctrico, que reducen la quema de combustibles fósiles $\mathrm{y}$, por ende, sus emisiones a la atmósfera

- El año 2020 se vio afectado por la pandemia mundial Covid-19. Teniendo en cuenta que las desaladoras adaptan su producción a los picos de demanda, y sabiendo que en el año 2020 se produjo un parón en todas las actividades, donde el turismo se vio completamente bloqueado, es natural que los caudales captados y desalados por las IDAM disminuyesen. Al disminuir la producción, disminuye también el consumo eléctrico de la instalación, lo que, favorece la disminución de la huella de carbono de la instalación también

En cualquier caso, esta tendencia de disminución de huella de carbono es la deseable y, de seguir el estudio en los años posteriores, lo ideal 
sería que cada año fuese dando una huella de carbono inferior a la anterior.

\section{b) IDAM Bahía de Alcudia}

La IDAM Alcudia (Figura 17) se pone en marcha, junto con la de Andratx, entre los años 2015 y 2016, para cubrir las demandas hídricas de la isla de Mallorca durante los periodos de sequía. Especialmente se deseaba aliviar la presión existente sobre el acuífero de s'Estremera, que llegó a su nivel mínimo en 2016.

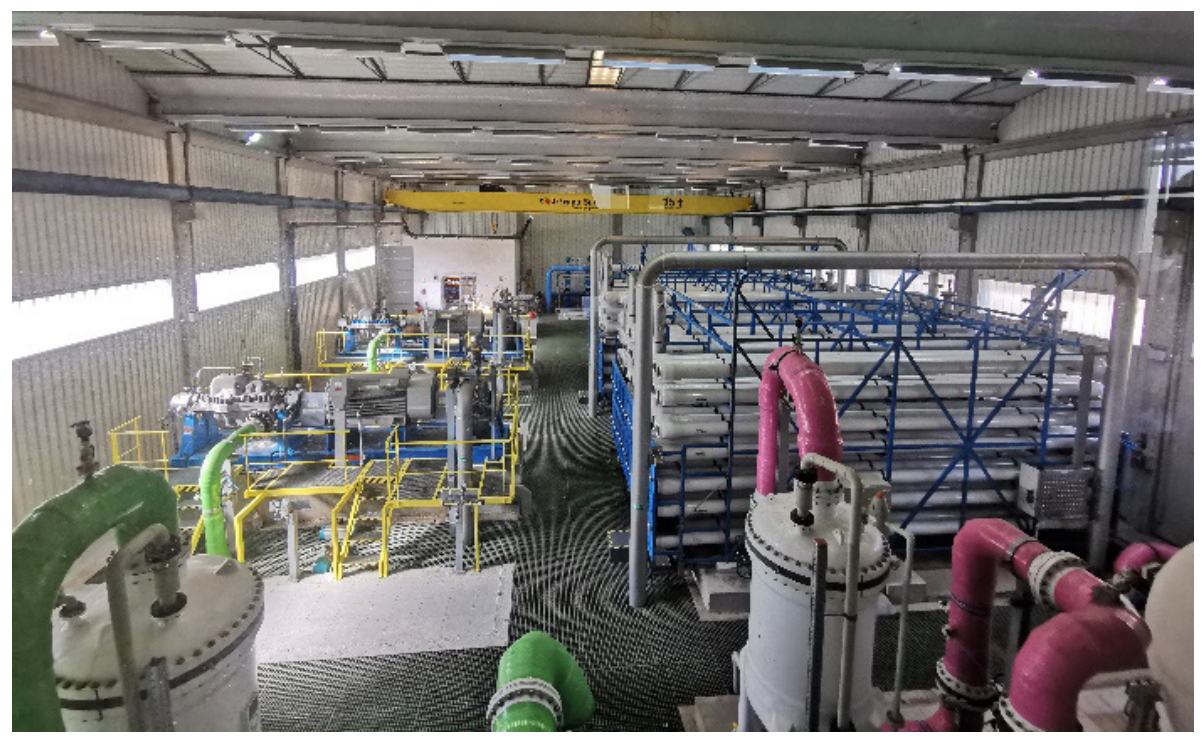

Figura 17. Sala de máquinas de la IDAM Alcudia

Se observa aquí el mismo patrón de la Bahía de Palma, un elevado alcance 2 debido al consumo eléctrico y un alcance 3 también notable, por los mismos motivos explicados anteriormente en la Bahía de Palma. Sin embargo, esta es la desaladora con la huella de carbono más baja de las tres, ya que es la que trata los caudales más bajos y, por lo tanto, tiene un menor consumo eléctrico, menos trabajadores/ as y menos proveedores. 
Tabla 22. Huella de carbono de la IDAM Bahía de Alcudia en el año 2019 y 2020

\begin{tabular}{|c|c|c|c|c|c|}
\hline \multicolumn{2}{|c|}{ Huella de carbono desaladora de Alcudia } & \multicolumn{2}{|c|}{2019} & \multicolumn{2}{|c|}{2020} \\
\hline \multicolumn{6}{|c|}{ Alcance 1} \\
\hline & Emisiones Instalaciones fijas & 15,40 & $\mathrm{t} \infty_{2}$ eq & 12,02 & $\mathrm{t} \infty_{2}$ eq \\
\hline & Vehículos & 16,37 & $\mathrm{t} \infty_{2}$ eq & 13,45 & $\mathrm{t} \infty_{2}$ eq \\
\hline \multicolumn{6}{|l|}{ Alcance 2} \\
\hline & Emisiones Instalaciones fijas & $1.311,58$ & $\mathrm{t} \infty_{2}$ eq & 391,63 & $\mathrm{t} \mathrm{OO}_{2}$ eq \\
\hline \multicolumn{6}{|l|}{ Alcance 3} \\
\hline & Vehículos & $7.009,10$ & $\mathrm{t} \infty_{2}$ eq & $7.009,10$ & $\mathrm{t} \mathrm{OO}_{2}$ eq \\
\hline \multicolumn{6}{|l|}{ Subtotal } \\
\hline & Alcance 1 & 31,78 & $\mathrm{t} \mathrm{CO}_{2} \mathrm{eq}$ & 25,47 & $\mathrm{t} \mathrm{CO}_{2}$ eq \\
\hline & Alcance 2 & $1.311,58$ & $\mathrm{t} \mathrm{CO}_{2}$ eq & 391,63 & $\mathrm{t} \mathrm{CO}_{2}$ eq \\
\hline & Alcance 3 & $7.009,10$ & $\mathrm{t} \mathrm{CO}_{2}$ eq & $7.009,10$ & $\mathrm{t} \mathrm{CO}_{2}$ eq \\
\hline $\begin{array}{l}\text { Huella de } \\
\text { Carbono }\end{array}$ & Total & $8.352,46$ & $\mathrm{t} \mathrm{CO} \mathrm{CO}_{2} \mathrm{eq}$ & $7.426,21$ & t $\mathrm{CO}_{2}$ eq \\
\hline
\end{tabular}

\section{c) IDAM Andratx}

Se creó paralelamente a la de Alcudia para dar respuesta a la demanda hídrica de la isla de Mallorca en la época estival, y para aliviar las presiones ejercidas por el consumo urbano y turístico en los acuíferos de la isla.

Es la que tiene una huella de carbono con un valor intermedio entre la de Palma y la de Alcudia. Esta desaladora cuenta con 11 operarios/ as y 20 proveedores, así como dos vehículos asociados a la operativa diaria. 
Tabla 23. Huella de carbono de la IDAM Andratx en el año 2019 y 2020

\begin{tabular}{|c|c|c|c|c|c|}
\hline \multicolumn{2}{|c|}{ Huella de carbono desaladora de Andratx } & \multicolumn{2}{|c|}{2019} & \multicolumn{2}{|c|}{2020} \\
\hline \multicolumn{6}{|l|}{ Alcance 1} \\
\hline & Emisiones Instalaciones fijas & 4,00 & $\mathrm{t} \mathrm{O}_{2} \mathrm{eq}$ & 2,09 & $\mathrm{t} \infty_{2}$ eq \\
\hline & Vehículos & 6,20 & $\mathrm{t} \infty_{2}$ eq & 6,20 & $\mathrm{t} \infty_{2}$ eq \\
\hline \multicolumn{6}{|l|}{ Alcance 2} \\
\hline & Emisiones Instalaciones fijas & $2.109,12$ & $\mathrm{t} \mathrm{CO}_{2}$ eq & 579,46 & $\mathrm{t} \infty_{2}$ eq \\
\hline \multicolumn{6}{|l|}{ Alcance 3} \\
\hline & Vehículos & $8.446,56$ & $\mathrm{t} \infty_{2}$ eq & $8.414,97$ & $\mathrm{t} \infty_{2}$ eq \\
\hline \multicolumn{6}{|l|}{ Subtotal } \\
\hline & Alcance 1 & 10,20 & $\mathrm{t} \mathrm{CO}_{2} \mathrm{eq}$ & 8,28 & $\mathrm{t} \mathrm{CO}_{2} \mathrm{eq}$ \\
\hline & Alcance 2 & $2.109,12$ & $\mathrm{t} \mathrm{CO}_{2} \mathrm{eq}$ & 579,46 & $\mathrm{t} \mathrm{CO}_{2} \mathrm{eq}$ \\
\hline & Alcance 3 & $8.446,56$ & $\mathrm{t} \mathrm{CO}_{2} \mathrm{eq}$ & $8.414,97$ & $\mathrm{t} \mathrm{CO}_{2} \mathrm{eq}$ \\
\hline $\begin{array}{l}\text { Huella de } \\
\text { Carbono }\end{array}$ & Total & $10.565,88$ & $\mathrm{t} \mathrm{CO}_{2} \mathrm{eq}$ & $9.002,72$ & $\mathrm{t} \mathrm{CO}_{2}$ eq \\
\hline
\end{tabular}

En la actualidad, las tres desaladoras de la isla de Mallorca producen $92.800 \mathrm{~m}^{3}$ /día cubriendo, en las temporadas altas de las islas (meses de verano), aproximadamente el $69 \%$ de la demanda hídrica urbana y turística.

\subsection{MENORCA}

\section{a) IDAM Ciutadella}

La desaladora de Ciutadella tiene dos líneas de producción de 5.000 $\mathrm{m}^{3} /$ día con la posibilidad de ampliar a una línea más. Por tanto, actualmente tiene una capacidad de producción anual de $3,30 \mathrm{hm}^{3}$ (Figura 18). Esta IDAM suministra agua al depósito de Artrutx y Son Blanc. 


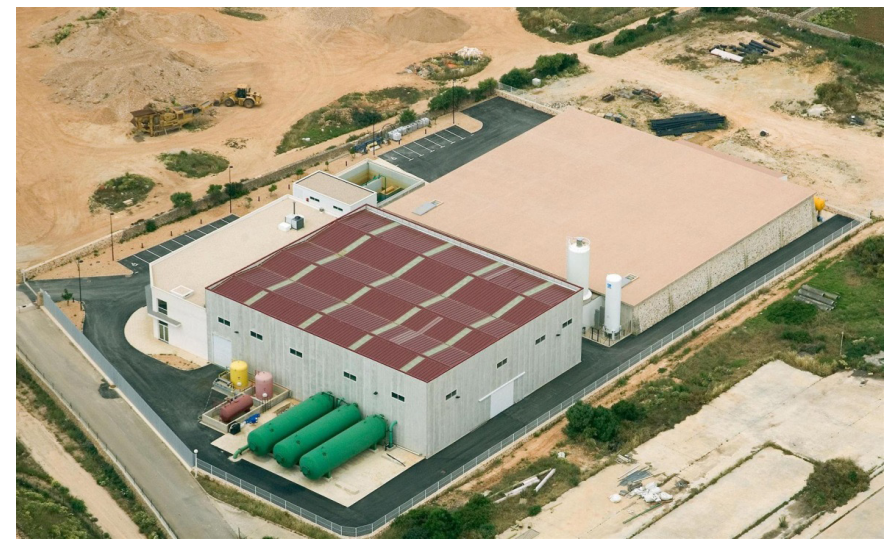

Figura 18. Vista general de las instalaciones de la desaladora Ciutadella en Menorca

Debido a que entró en funcionamiento recientemente, año 2019, no se pueden establecer tendencias de volúmenes desalados. Lo que sí es claro es que se produce un pico de producción en la época estival (Figura 19), debido a la llegada de turistas a la isla.

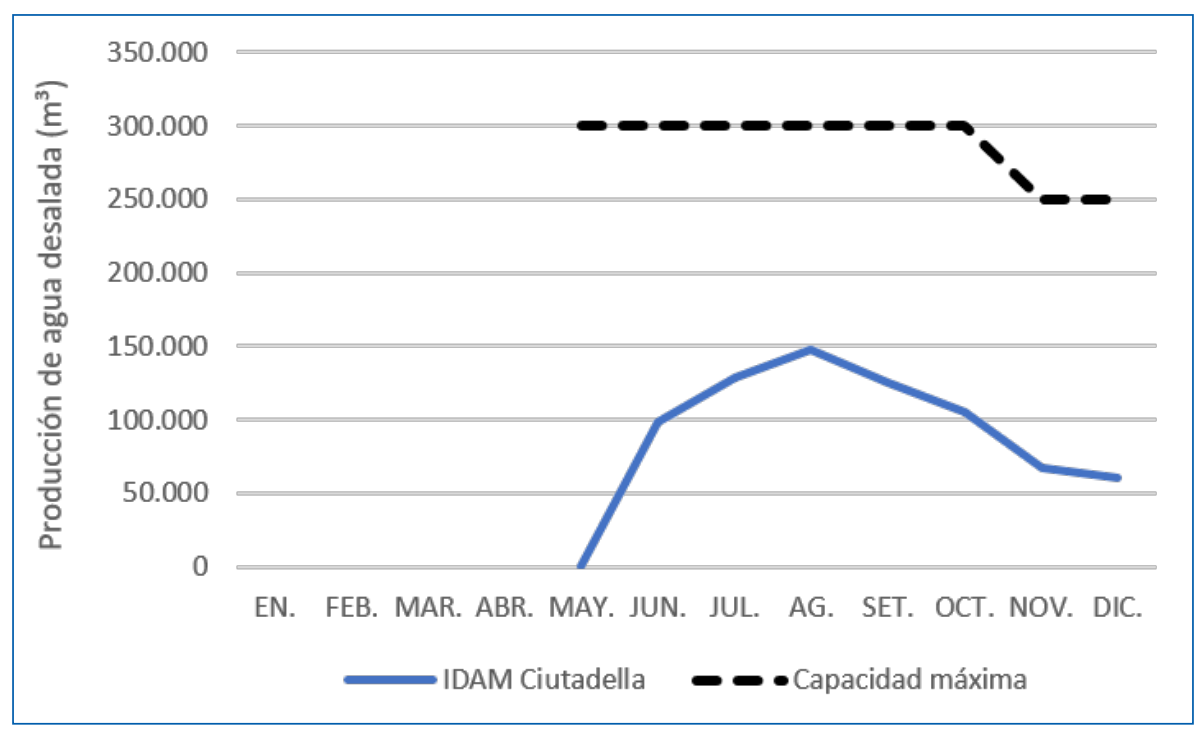

Figura 19. Evolución de la producción de agua desalada en Menorca en el año 2019.

Fuente: $A B A Q \cup A$ 
En la Tabla 24 aparecen los resultados de la huella de la desaladora de Menorca para los años 2019 y 2020. A pesar de que se mantiene la tónica general de una huella de carbono inferior en el año 2020, vemos un incremento en el alcance 1 en el año 2020, debido a la incorporación de un vehículo más a la flota destinada a la desaladora.

Tabla 24. Huella de carbono de la IDAM Ciutadella en el año 2019 y 2020

\begin{tabular}{|c|c|c|c|c|c|}
\hline \multicolumn{2}{|c|}{ Huella de carbono desaladora Ciutadella } & \multicolumn{2}{|c|}{2019} & \multicolumn{2}{|c|}{2020} \\
\hline \multicolumn{6}{|c|}{ Alcance 1} \\
\hline & Emisiones Instalaciones fijas & 0,00 & $\mathrm{t} \infty_{2}$ eq & 0,67 & $\mathrm{t} \infty_{2}$ eq \\
\hline & Vehículos & 1,04 & $\mathrm{t} \infty_{2}$ eq & 4,18 & $\mathrm{t} \infty_{2}$ eq \\
\hline \multicolumn{6}{|l|}{ Alcance 2} \\
\hline & Emisiones Instalaciones fijas & 810,00 & $\mathrm{t} \infty_{2}$ eq & 756,00 & $\mathrm{t} \infty_{2}$ eq \\
\hline \multicolumn{6}{|l|}{ Alcance 3} \\
\hline & Vehículos & $5.601,46$ & $\mathrm{t} \infty_{2}$ eq & $5.601,46$ & $\mathrm{t} \infty_{2}$ eq \\
\hline \multicolumn{6}{|l|}{ Subtotal } \\
\hline & Alcance 1 & 1,04 & $\mathrm{t} \mathrm{CO}_{2} \mathrm{eq}$ & 4,85 & $\mathrm{t} \mathrm{CO}_{2} \mathrm{eq}$ \\
\hline & Alcance 2 & 810,00 & $\mathrm{t} \mathrm{CO}_{2}$ eq & 756,00 & $\mathrm{t} \mathrm{CO}_{2} \mathrm{eq}$ \\
\hline & Alcance 3 & $5.601,46$ & $\mathrm{t} \mathrm{CO}_{2} \mathrm{eq}$ & $5.601,46$ & $\mathrm{t} \mathrm{CO}_{2} \mathrm{eq}$ \\
\hline $\begin{array}{l}\text { Huella de } \\
\text { Carbono }\end{array}$ & Total & $6.412,51$ & $\mathrm{t} \mathrm{CO}_{2} \mathrm{eq}$ & $6.362,31$ & $\mathrm{t} \mathrm{CO}_{2} \mathrm{eq}$ \\
\hline
\end{tabular}

\subsection{IBIZA}

La producción de agua desalada durante el periodo 2014-2019 en la isla de Ibiza ha aumentado un 54,40\%, destacando el incremento del $29,63 \%$ entre los años 2018 y 2019. periodo 2018-2019 con un incremento del Este incremento se corresponde con la puesta en marcha de la desaladora de Santa Eulària (Figura 20). 

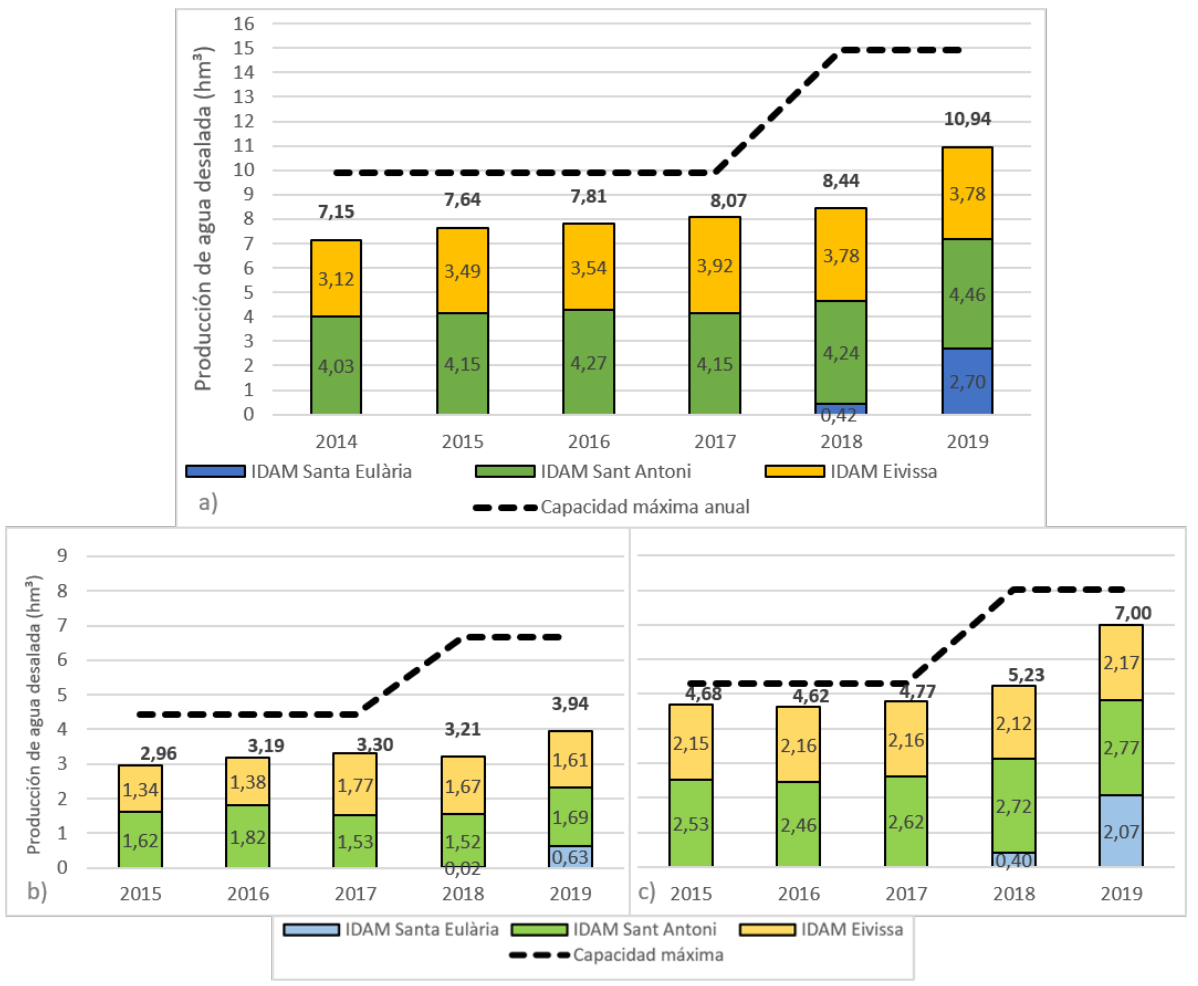

Figura 20. Producción de agua desalada en la isla de Ibiza para el periodo 2014-2019 (a), durante las temporadas bajas de los años 2015-2019 (b), durante las temporadas altas de los años 2015-2019 (c). Fuente: $A B A Q U A$

En total, en Ibiza hay tres desaladoras que están interconectadas en el centro de la isla, facilitando la gestión en la producción y ofreciendo garantías de no interrupción en el suministro de agua. La producción de agua desalada representa casi el $50 \%$ del suministro total de agua en la isla.

\section{a) IDAM Ibiza}

Esta desaladora tuvo su producción máxima en el año 2017, incluso en los meses que tradicionalmente tienen un consumo hídrico bajo, 
como febrero o noviembre. Esto provocó la necesidad de construir una nueva desaladora, que se introdujo en el ciclo del agua de Ibiza en el año 2018, con la incorporación al sistema de la desaladora de Santa Eulària.

La IDAM de Ibiza (Figura 21) cuenta con una producción de agua bastante estable a lo largo del año, ya que no sufre tantas fluctuaciones entre el verano e invierno como las otras dos desaladoras presentes en la isla.
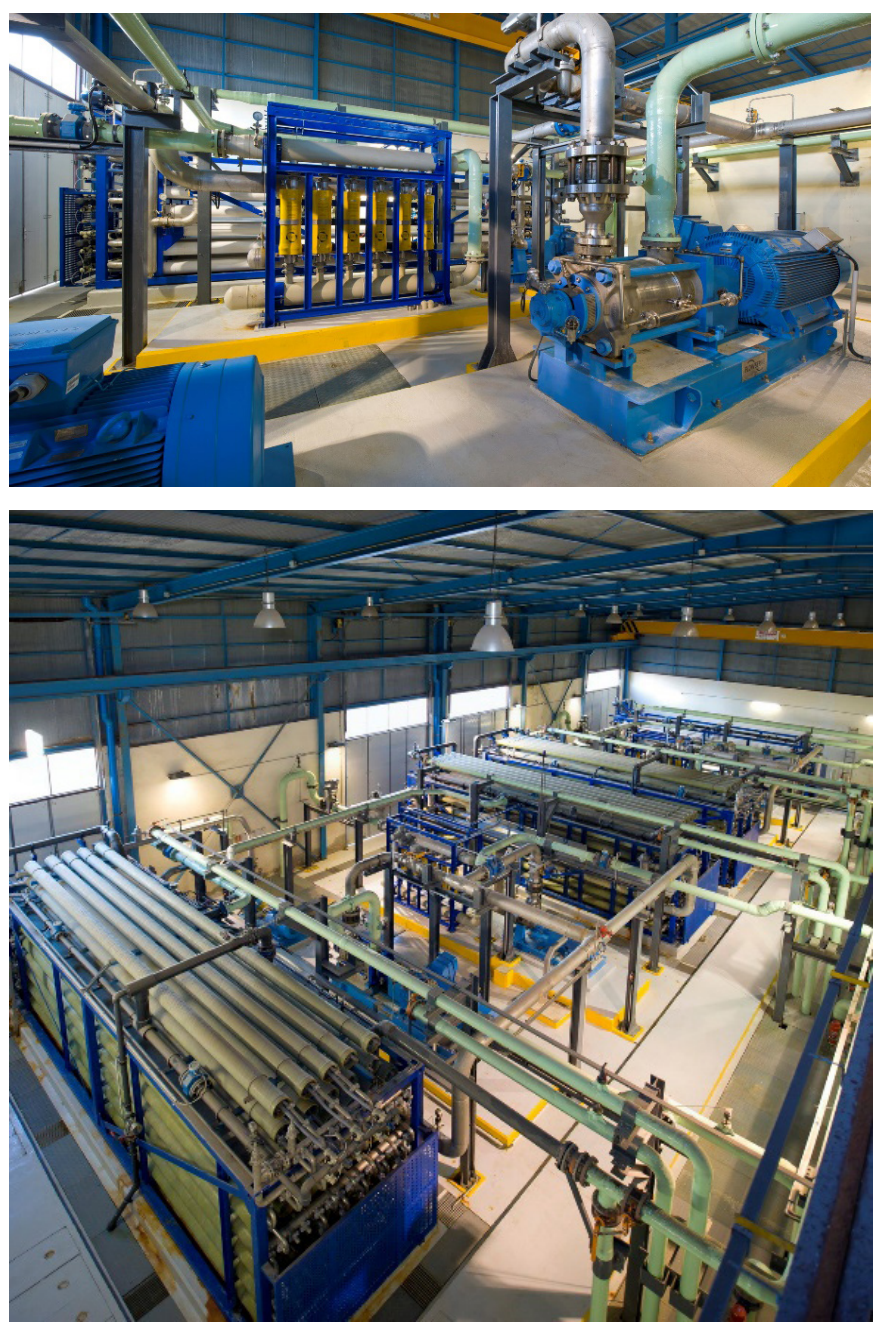

Figura 21. Instalaciones interiores de la IDAM Ibiza 
La IDAM Ibiza es la que presenta una mayor huella de carbono de las tres instaladas en la isla. Se trata de la desaladora que mayor producción anual presenta, por lo tanto, se elevan el alcance 2 y 3 como hemos visto anteriormente.

Tabla 25. Huella de carbono de la IDAM Ibiza en el año 2019 y 2020

\begin{tabular}{|c|c|c|c|c|c|}
\hline \multicolumn{2}{|c|}{ Huella de carbono desaladora Ibiza } & \multicolumn{2}{|c|}{2019} & \multicolumn{2}{|c|}{2020} \\
\hline \multicolumn{6}{|c|}{ Alcance 1} \\
\hline & Emisiones Instalaciones fijas & 995,95 & $\mathrm{t} \infty_{2}$ eq & 710,82 & $\mathrm{t} \infty_{2}$ eq \\
\hline & Vehículos & 1,21 & $\mathrm{t} \infty_{2}$ eq & 1,21 & $\mathrm{t} \infty_{2}$ eq \\
\hline \multicolumn{6}{|l|}{ Alcance 2} \\
\hline & Emisiones Instalaciones fijas & $2.683,62$ & $\mathrm{t} \infty_{2}$ eq & $1.727,44$ & $\mathrm{t} \infty_{2}$ eq \\
\hline \multicolumn{6}{|l|}{ Alcance 3} \\
\hline & Vehículos & $11.853,43$ & $\mathrm{t} \infty_{2}$ eq & $11.853,43$ & $\mathrm{t} \mathrm{O}_{2}$ eq \\
\hline \multicolumn{6}{|l|}{ Subtotal } \\
\hline & Alcance 1 & 997,16 & $\mathrm{t} \mathrm{CO}_{2}$ eq & 712,03 & $\mathrm{t} \mathrm{CO}_{2}$ eq \\
\hline & Alcance 2 & $2.683,62$ & $\mathrm{t} \mathrm{CO}_{2} \mathrm{eq}$ & $1.727,44$ & t $\mathrm{CO}_{2}$ eq \\
\hline & Alcance 3 & $11.853,43$ & $\mathrm{t} \mathrm{CO}_{2} \mathrm{eq}$ & $11.853,43$ & $\mathrm{t} \mathrm{CO}_{2}$ eq \\
\hline $\begin{array}{l}\text { Huella de } \\
\text { Carbono }\end{array}$ & Total & $15.534,21$ & $\mathrm{t} \mathrm{CO}_{2} \mathrm{eq}$ & $14.292,90$ & $\mathrm{t} \mathrm{CO}_{2}$ eq \\
\hline
\end{tabular}

\section{b) IDAM Sant Antoni}

Esta desaladora tuvo un pico de producción en el mes de abril del 2019, debido a una avería en la IDAM Ibiza. Como se ha comentado anteriormente, estas tres desaladoras están interconectadas entre sí y compensan la producción de la isla entre ellas.

Tradicionalmente, la IDAM Sant Antoni (Figura 22) tiene un mayor volumen de producción en los meses de verano, que se alargan hasta octubre. 


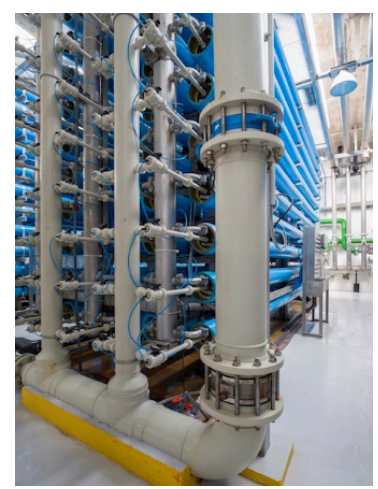

Figura 22. Sala de máquinas de la IDAM Sant Antoni en Ibiza

La IDAM Sant Antoni presenta la menor huella de carbono de las desaladoras de la isla de lbiza, cabe aquí destacar que, si la instalación no tuviese vehículos asociados, o si los vehículos fuesen eléctricos, quedaría compensado el alcance 1 al no tener emisiones relacionadas con las instalaciones fijas (grupos electrógenos o similares que consuman gasoil para su funcionamiento).

Tabla 26. Huella de carbono de la IDAM Sant Antoni en el año 2019 y 2020

\begin{tabular}{|c|c|c|c|c|c|}
\hline \multicolumn{2}{|c|}{ Huella de carbono desaladora Sant Antoni } & \multicolumn{2}{|c|}{2019} & \multicolumn{2}{|c|}{2020} \\
\hline \multicolumn{6}{|c|}{ Alcance 1} \\
\hline & Emisiones Instalaciones fijas & 0,00 & $\mathrm{t} \infty_{2}$ eq & 0,00 & $\mathrm{t} \mathrm{O}_{2}$ eq \\
\hline & Vehículos & 1,82 & $\mathrm{t} \infty_{2}$ eq & 1,82 & $\mathrm{t} \mathrm{O}_{2}$ eq \\
\hline \multicolumn{6}{|l|}{ Alcance 2} \\
\hline & Emisiones Instalaciones fijas & $3.526,56$ & $\mathrm{t} \mathrm{O}_{2} \mathrm{eq}$ & $2.217,83$ & $\mathrm{t} \mathrm{O}_{2}$ eq \\
\hline \multicolumn{6}{|l|}{ Alcance 3} \\
\hline & Vehículos & $7.373,43$ & $\mathrm{t} \infty_{2}$ eq & $7.373,43$ & $\mathrm{t} \infty_{2}$ eq \\
\hline \multicolumn{6}{|l|}{ Subtotal } \\
\hline & Alcance 1 & 1,82 & $\mathrm{t} \mathrm{CO}_{2}$ eq & 1,82 & $\mathrm{t} \mathrm{CO} \mathrm{Cq}_{2}$ \\
\hline & Alcance 2 & $3.526,56$ & $\mathrm{t} \mathrm{CO}_{2} \mathrm{eq}$ & $2.217,83$ & $\mathrm{t} \mathrm{CO}_{2} \mathrm{eq}$ \\
\hline & Alcance 3 & $7.373,43$ & $\mathrm{t} \mathrm{CO}_{2}$ eq & $7.373,43$ & $\mathrm{t} \mathrm{CO}_{2} \mathrm{eq}$ \\
\hline $\begin{array}{l}\text { Huella de } \\
\text { Carbono }\end{array}$ & Total & $10.901,80$ & t $\mathrm{CO}_{2} \mathrm{eq}$ & $9.593,08$ & $\mathrm{t} \mathrm{CO} \mathrm{Cq}_{2}$ \\
\hline
\end{tabular}




\section{c) IDAM Santa Eulària}

Se trata de una desaladora que se puso en marcha en el año 2018 (Figura 23), después de la que la producción de agua desalada en la isla pasó de $29.500 \mathrm{~m}^{3} / \mathrm{d}$ a $44.500 \mathrm{~m}^{3} / \mathrm{d}$.

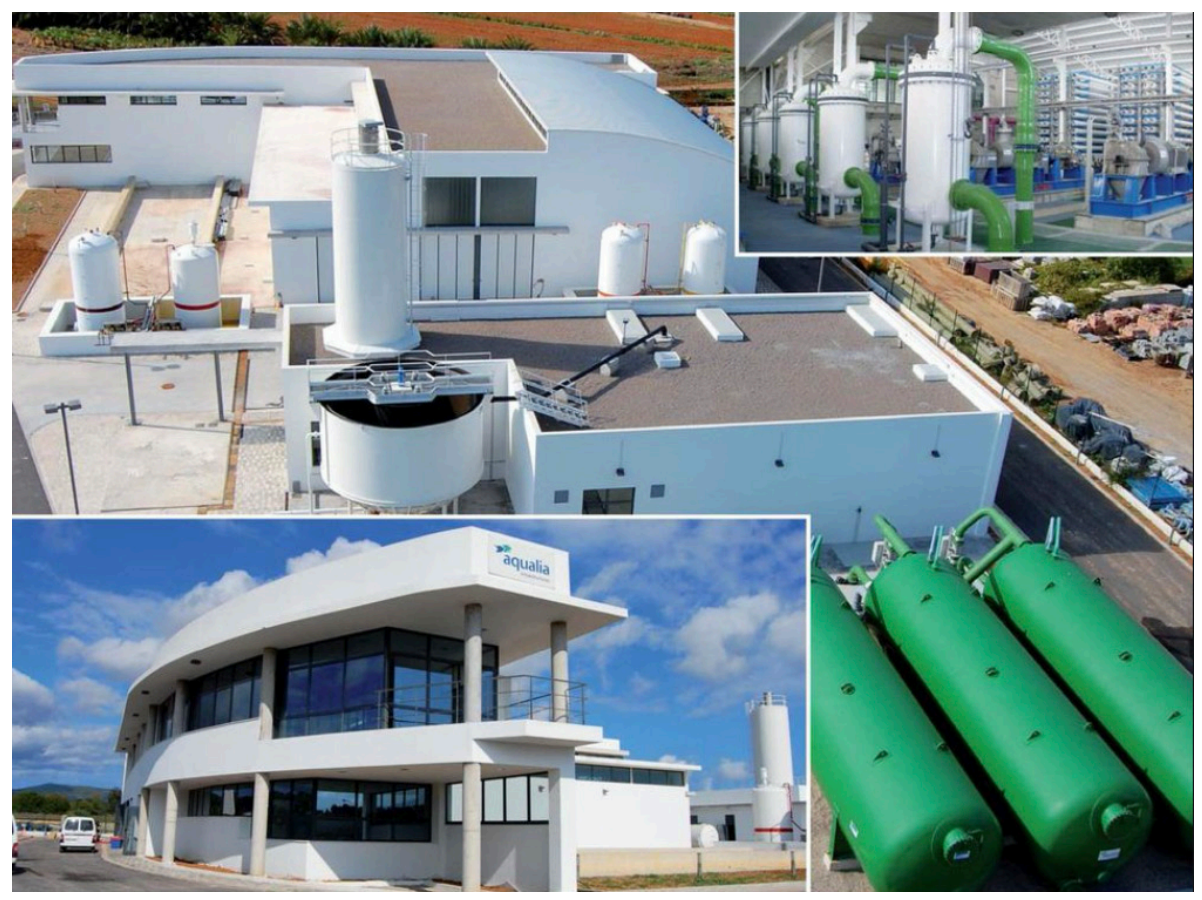

Figura 23. Desaladora Santa Eulària en Ibiza, año de creación: 2018

A pesar de presentar un consumo eléctrico similar a la desaladora Sant Antoni, la IDAM Santa Eulària sí tiene emisiones fijas asociadas a las instalaciones fijas dentro del alcance 1, así como emisiones derivadas de los vehículos móviles con los que cuenta la instalación para sus trabajadores/as. 
Tabla 27. Huella de carbono de la IDAM Santa Eulària en el año 2019 y 2020

\begin{tabular}{|c|c|c|c|c|c|}
\hline \multirow{2}{*}{\multicolumn{2}{|c|}{$\begin{array}{l}\text { Huella de carbono desaladora Santa Eularia } \\
\text { Alcance } 1\end{array}$}} & \multicolumn{2}{|c|}{2019} & \multicolumn{2}{|c|}{2020} \\
\hline & & & & & \\
\hline & Emisiones Instalaciones fijas & 2,99 & $\mathrm{t} \infty_{2}$ eq & 2,99 & $\mathrm{t} \infty_{2}$ eq \\
\hline & Vehículos & 3,43 & $\mathrm{t} \infty_{2}$ eq & 3,92 & $\mathrm{t} \infty_{2}$ eq \\
\hline \multicolumn{6}{|l|}{ Alcance 2} \\
\hline & Emisiones Instalaciones fijas & $2.911,15$ & $\mathrm{t} \mathrm{O}_{2}$ eq & $2.276,31$ & $\mathrm{t} \infty_{2}$ eq \\
\hline \multicolumn{6}{|l|}{ Alcance 3} \\
\hline & Vehículos & $8.080,49$ & $\mathrm{t} \infty_{2}$ eq & $8.080,49$ & $\mathrm{t} \infty_{2}$ eq \\
\hline \multicolumn{6}{|l|}{ Subtotal } \\
\hline & Alcance 1 & 6,42 & $\mathrm{t} \mathrm{CO}_{2} \mathrm{eq}$ & 6,91 & $\mathrm{t} \mathrm{CO}_{2} \mathrm{eq}$ \\
\hline & Alcance 2 & $2.911,15$ & $\mathrm{t} \mathrm{CO}_{2} \mathrm{eq}$ & $2.276,31$ & $\mathrm{t} \mathrm{CO}_{2} \mathrm{eq}$ \\
\hline & Alcance 3 & $8.080,49$ & $\mathrm{t} \mathrm{CO}_{2} \mathrm{eq}$ & $8.080,49$ & $\mathrm{t} \mathrm{CO}_{2} \mathrm{eq}$ \\
\hline $\begin{array}{l}\text { Huella de } \\
\text { Carbono }\end{array}$ & Total & $10.998,06$ & $\mathrm{t} \mathrm{CO}_{2} \mathrm{eq}$ & $10.363,71$ & $\mathrm{t} \mathrm{CO}_{2}$ eq \\
\hline
\end{tabular}

\subsection{FORMENTERA}

La producción de agua desalada durante el periodo 2014-2019 en la isla de Formentera ha aumentado en un 8,72\% en 2019. En general, la producción de agua desalada en Formentera a lo largo de los años es estable, con pequeñas fluctuaciones debidas principalmente a la afluencia turística.

En Formentera el $100 \%$ del agua suministrada es desalada. Su único acuífero no puede ser explotado por el mal estado tanto cuantitativo como cualitativo que presenta. De este modo, la IDAM Formentera suministra agua a los núcleos urbanos mediante la red de suministro municipal. Además, el suministro de agua a las viviendas aisladas se garantiza mediante surtidores municipales por camiones cisterna que representan el $30 \%$ del suministro total en la isla. 


\section{a) IDAM Formentera}

En el 2015 se realizó una ampliación para aumentar la capacidad máxima productiva de la IDAM Formentera (Figura 24) de 4.000 a $5.000 \mathrm{~m}^{3} /$ día para hacer frente a la demanda de los meses de julio y agosto. Además, una tercera línea de $2.000 \mathrm{~m}^{3} /$ día ya construida, se dejó en reserva y actualmente las obras de remodelación de esta línea están en proceso de contratación.

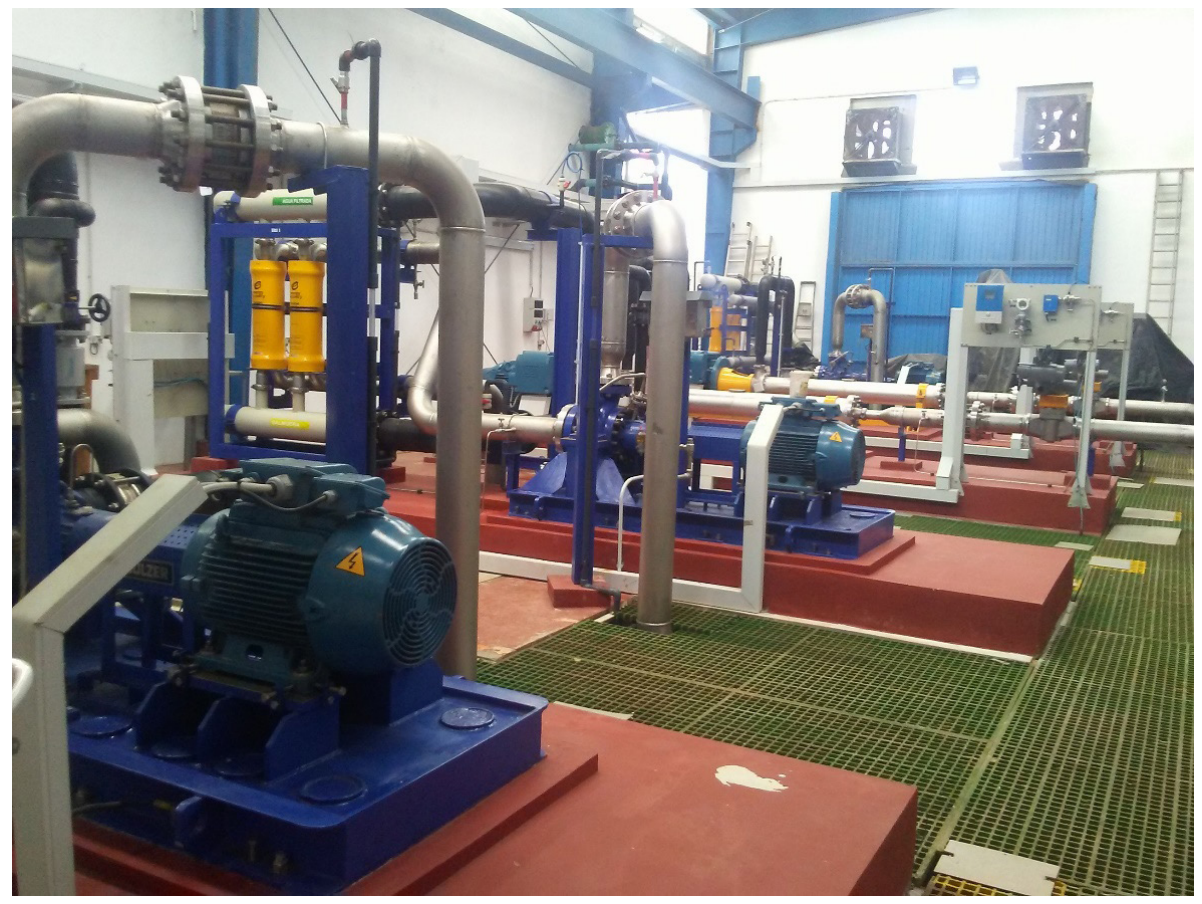

Figura 24. Sala de máquinas de la IDAM Formentera

Esta desaladora presenta la huella de carbono más baja de todo el archipiélago balear, debido principalmente a que es la que menor volúmenes de producción de agua potable maneja (708.812 $\mathrm{m}^{3}$ desalinizados en 2019 y $514.125 \mathrm{~m}^{3}$ en 2020). 
Tabla 28. Huella de carbono de la IDAM Formentera en el año 2019 y 2020

\begin{tabular}{|c|c|c|c|c|c|}
\hline \multicolumn{2}{|c|}{ Huella de carbono desaladora Formentera } & \multicolumn{2}{|c|}{2019} & \multicolumn{2}{|c|}{2020} \\
\hline \multicolumn{6}{|c|}{ Alcance 1} \\
\hline & Emisiones Instalaciones fijas & 0,00 & $\mathrm{t} \infty_{2}$ eq & 0,00 & $\mathrm{t} \mathrm{O}_{2}$ eq \\
\hline & Vehículos & 1,82 & $\mathrm{t} \infty_{2}$ eq & 1,82 & $\mathrm{t} \infty_{2}$ eq \\
\hline \multicolumn{6}{|l|}{ Alcance 2} \\
\hline & Emisiones Instalaciones fijas & 391,79 & $\mathrm{t} \infty_{2}$ eq & 249,22 & $\mathrm{t} \infty_{2}$ eq \\
\hline \multicolumn{6}{|l|}{ Alcance 3} \\
\hline & Vehículos & $3.362,90$ & $\mathrm{t} \infty_{2}$ eq & $3.362,90$ & $\mathrm{t} \infty_{2}$ eq \\
\hline \multicolumn{6}{|l|}{ Subtotal } \\
\hline & Alcance 1 & 1,82 & $\mathrm{t} \mathrm{CO}_{2}$ eq & 1,82 & $\mathrm{t} \mathrm{CO}_{2} \mathrm{eq}$ \\
\hline & Alcance 2 & 391,79 & $\mathrm{t} \mathrm{CO}_{2} \mathrm{eq}$ & 249,22 & $\mathrm{t} \mathrm{CO}_{2} \mathrm{eq}$ \\
\hline & Alcance 3 & $3.362,90$ & $\mathrm{t} \mathrm{CO}_{2} \mathrm{eq}$ & $3.362,90$ & $\mathrm{t} \mathrm{CO}_{2} \mathrm{eq}$ \\
\hline $\begin{array}{l}\text { Huella de } \\
\text { Carbono }\end{array}$ & Total & $3.756,50$ & $\mathrm{t} \mathrm{CO}_{2} \mathrm{eq}$ & $3.613,93$ & $\mathrm{t} \mathrm{CO}_{2}$ eq \\
\hline
\end{tabular}

A modo de resumen, debido a que se tienen los valores de los caudales captados por las desaladoras estudiadas, así como la huella de carbono para ambos años, se proponen las siguientes tablas donde se relaciona la huella de carbono por volumen de agua producida en el archipiélago balear:

Tabla 29. Huella de carbono por volumen de agua captada en el 2019 en $\mathrm{kgCO} e \mathrm{eq} / \mathrm{m}_{3}$

\begin{tabular}{|c|c|c|c|c|}
\hline IDAM & $\begin{array}{c}\text { Volumen } \\
\text { captado en } \\
2019\left(\mathrm{Hm}^{3}\right)\end{array}$ & $\begin{array}{l}\text { Huella de carbono } \\
\text { en } 2019\left(\mathrm{tCO}_{2} \mathrm{eq}\right)\end{array}$ & $\begin{array}{c}\text { Huella de carbono por } \\
\text { volumen de agua captada } \\
\text { para el } 2019\left(\mathrm{tCO}_{2} \mathrm{eq} / \mathrm{Hm}^{3}\right)\end{array}$ & $\begin{array}{c}\text { Huella de carbono por } \\
\text { volumen de agua captada } \\
\text { para el } 2019\left(\mathrm{kgCO}_{2} \mathrm{eq} / \mathrm{m}^{3}\right)\end{array}$ \\
\hline Bahía de Palma & 10,3 & $29.176,25$ & $2.832,65$ & 2,83 \\
\hline Aládia & 1,85 & $8.811,51$ & $4.762,98$ & 4,76 \\
\hline Andratx & 2,73 & $11.304,07$ & $4.140,68$ & 4,14 \\
\hline Gutadella & 1,95 & $6.412,51$ & $3.288,47$ & 3,29 \\
\hline Evissa & 8,28 & $15.534,21$ & $1.876,11$ & 1,88 \\
\hline Sant Antoni & 9,83 & $10.901,80$ & $1.109,03$ & 1,11 \\
\hline SantaEulària & 6,25 & $10.998,06$ & $1.759,69$ & 1,76 \\
\hline Formentera & 0,9 & $3.756,50$ & $4.173,89$ & 4,17 \\
\hline
\end{tabular}


Tabla 30. Huella de carbono por volumen de agua captada en el 2020 en $\mathrm{kgCO}{ }^{2} \mathrm{eq} / \mathrm{m}_{3}$

\begin{tabular}{|c|c|c|c|c|}
\hline IDAM & $\begin{array}{c}\text { Volumen } \\
\text { captado en } \\
\mathbf{2 0 2 0}\left(\mathbf{H m}^{3}\right)\end{array}$ & $\begin{array}{c}\text { Huella de carbono } \\
\text { en } \mathbf{2 0 2 0}\left(\mathbf{t C O}_{\mathbf{2}} \mathbf{e q}\right)\end{array}$ & $\begin{array}{c}\text { Huella de carbono por } \\
\text { volumen de agua captada } \\
\text { para el } \mathbf{2 0 2 0}\left(\mathbf{t C O}_{\mathbf{2}} \mathbf{e q} / \mathbf{H m}^{\mathbf{3}}\right)\end{array}$ & $\begin{array}{c}\text { Huella de carbono por } \\
\text { volumen de agua captada } \\
\left.\text { para el } \mathbf{2 0 2 0} \mathbf{( \mathbf { k g C O }} \mathbf{\mathbf { e q }} / \mathbf{~ m}^{\mathbf{3}}\right)\end{array}$ \\
\hline BahíadePalma & 10 & $21.645,56$ & $2.164,56$ & 2,16 \\
Acúdia & 1,2 & $7.426,21$ & $6.188,51$ & 6,19 \\
Andratx & 1,24 & $9.002,72$ & $7.260,26$ & 7,26 \\
Gutadella & 2,38 & $6.362,31$ & $2.673,24$ & 2,67 \\
Evissa & 8,34 & $14.292,90$ & $1.713,78$ & 1,71 \\
Sant Antoni & 8,86 & $10.901,80$ & $1.230,45$ & 1,23 \\
SantaEulària & 6,55 & $10.363,71$ & $1.582,25$ & 1,58 \\
Formentera & 1,15 & $3.613,93$ & $3.142,55$ & 3,14 \\
\hline
\end{tabular}

Puede observarse como la huella de carbono por volumen de agua captada es generalmente inferior en el año 2020 frente al 2019 para la mayoría de las IDAM. Esto se debe principalmente a que en la mayoría de los casos el caudal captado por la desaladora es inferior en el año 2020 (posiblemente debido a la disminución de la actividad turística en la isla), así como en la disminución del factor de emisión en las dos compañías que suministran la energía eléctrica (Iberdrola y Endesa, en las instalaciones estudiadas).

Se observa que no necesariamente un menor volumen de agua captado en la desaladora implica una menor huella de carbono. Esto es debido a que influye lo siguiente en los diferentes alcances:

- Alcance 1: aquellas instalaciones que hacen uso de combustibles fósiles en instalaciones fijas y vehículos incrementan el alcance 1, que tiene un impacto notable en la huella de carbono global debido a los valores de los factores de emisión para el gasoil y gasolina

- Alcance 2: el consumo eléctrico sí está directamente relacionado con la capacidad de trabajo de la planta

- Alcance 3: la gestión de la desaladora (proveedores y gestión de residuos), así como el número de trabajadores de esta, dispara o disminuye la huella de carbono en cada caso. Encontramos 
que aquellas desaladoras con mayor número de trabajadores y empresas externas contratadas aumentan la huella de carbono en el alcance 3

Por ejemplo, en el caso de la IDAM de Alcudia y Andratx, una disminución en el volumen de agua captado en 2020 respecto a 2019, se traduce en un aumento de su huella de carbono por volumen de agua captado. Esto se debe a que, si bien la huella de carbono asociada al alcance 1 y 2 de estas IDAM disminuye en 2020 con respecto a 2019, la huella de carbono del alcance 3 , que es la que presenta una mayor huella de carbono, se mantiene prácticamente constante. 


\section{CARACTERIZACIÓN DE LA HUELLA AMBIENTAL EN EL RESTO DE LAS INSTALACIONES DEL CICLO DEL AGUA GESTIONADAS POR ABAQUA}

El objetivo de este apartado es analizar los consumos energéticos de las instalaciones de captación y distribución del agua en alta, detectando aquellas que presenten consumos energéticos superiores a la media de instalaciones y en la medida de lo posible proponer actuaciones encaminadas a la reducción de su huella ambiental.

\subsection{CAPTACIONES DE AGUA POTABLE MEDIANTE BOMBEO}

Los bombeos de agua potable obtenidos mediante pozos de captación requieren de energía consumida habitualmente mediante el uso de combustibles fósiles y electricidad. Por lo tanto, en estas instalaciones encontraremos emisiones asociadas a los tres alcances de la huella de carbono. 


\section{La huella hídrica directa en las instalaciones de captación de agua por bombeo}

La huella hídrica azul contabiliza la cantidad de agua potable que se extrae de una fuente subterránea o superficial y de la que se hace un uso consuntivo. El uso consuntivo del agua comprende principalmente cuatro actividades (Hoekstra et al., 2021) que se detallan a continuación:

1. Evaporación del agua

2. Volumen de agua que se incorpora a un producto

3. Volumen de agua que no regresa al mismo lugar de captación

4. Volumen de agua que no regresa en el mismo periodo (extracción en periodos secos y devolución en periodos húmedos)

Por lo tanto, el agua captada del acuífero por la instalación de bombeo puede considerarse huella hídrica azul, al ser un agua que no regresa al mismo lugar de captación. Sin embargo, para evitar caer en las dobles contabilizaciones, no sería justo incurrir toda la huella hídrica azul a la empresa explotadora, ya que esta debería ser correctamente atribuida al uso por parte de los/as usuarios/as finales de esa agua. Es por ello por lo que solamente se contemplará aquí las pérdidas de agua potable atribuibles a la instalación debido a fugas o algún tipo de deficiencia existente en el bombeo.

Con respecto a la huella hídrica verde, queda desestimada al no incorporarse el agua de lluvia en la instalación. Tampoco se contabilizará la huella hídrica gris al no ser una instalación que trate con agua contaminada.

\subsubsection{MALLORCA}

La Agencia Balear del Agua ha establecido unos límites para la extracción del agua potable para evitar el deterioro de los acuíferos. Estos límites se recogen a continuación: 
- La extracción máxima para cada uno de los pozos se establece entre 659 y $824 \mathrm{~m}^{3} / \mathrm{h}$ y la profundidad máxima que puede lograr el nivel piezométrico respecto de los pozos es de 72 metros de profundidad.

- Si se sobrepasa este límite las extracciones tienen que ser igual a las infiltraciones llegando como máximo al segundo límite de 52 metros de profundidad.

\section{a) Bombeo sa Costera}

La regulación de extracciones en Sa Font de Sa Costera (Figura 25) únicamente establece que es necesario mantener un caudal ecológico de la fuente al mar para evitar perjudicar el entorno natural vinculado a esta surgencia de agua dulce.

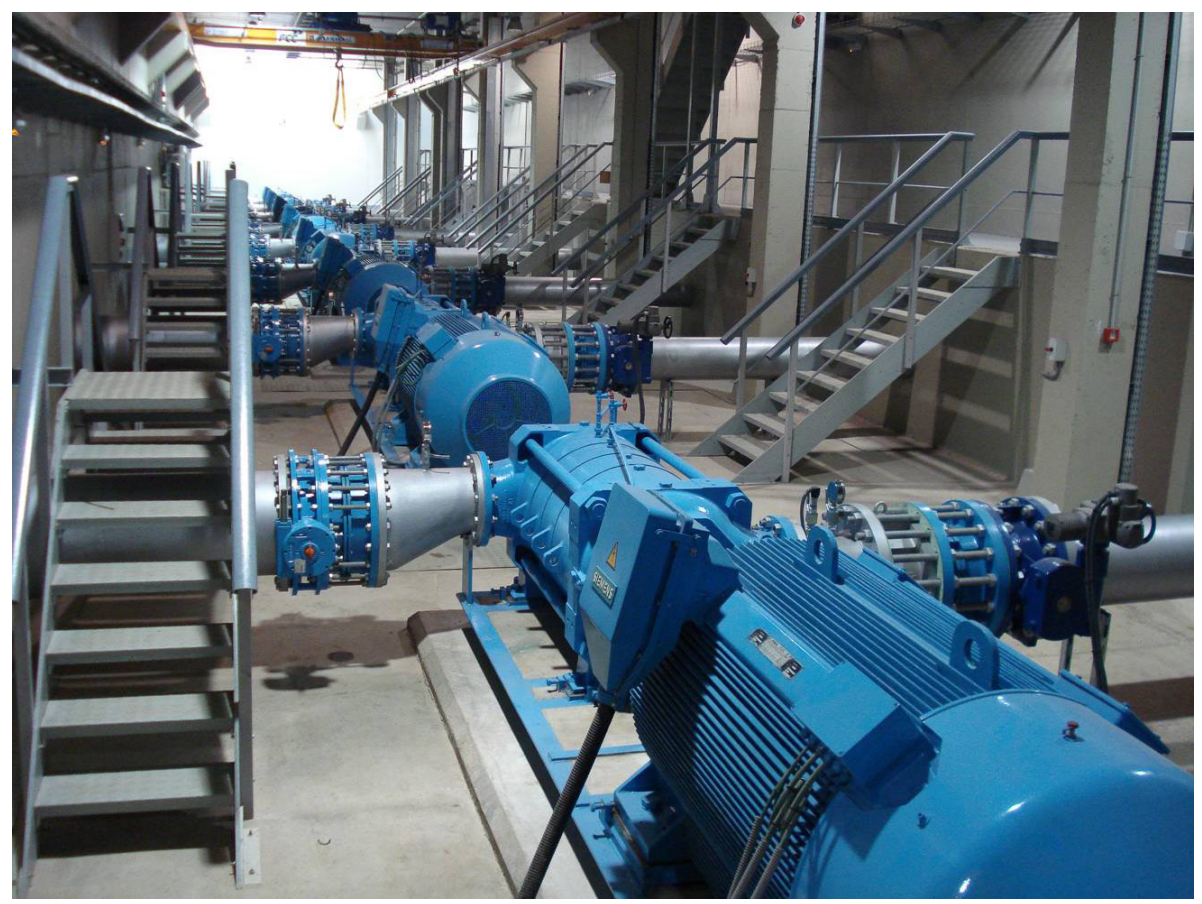

Figura 25. Sala de máquinas del Bombeo sa Costera 
Resultados huella de carbono

Este bombeo es el que presenta una mayor huella de carbono de los tres estudiados, debido principalmente a que es el que tiene un consumo eléctrico más elevado de los tres (Tabla 31).

Tabla 31. Huella de carbono del Bombeo sa Costera en el año 2019 y 2020

\begin{tabular}{|c|c|c|c|c|c|}
\hline Huella d & e carbono del Bombeo sa Costera & 201 & & 202 & \\
\hline Alcance 1 & & & & & \\
\hline & Emisiones Instalaciones fijas & 4,78 & $\mathrm{t} \infty_{2}$ eq & 3,20 & $\mathrm{t} \infty_{2}$ eq \\
\hline & Vehículos & 0,022 & $\mathrm{t} \infty_{2}$ eq & 0,022 & $\mathrm{t} \infty_{2}$ eq \\
\hline Alcance 2 & & & & & \\
\hline & Emisiones Instalaciones fijas & $1.332,70$ & $\mathrm{t} \infty_{2}$ eq & 816,81 & $\mathrm{t} \infty_{2}$ eq \\
\hline Alcance 3 & & & & & \\
\hline & Vehículos & $1.687,28$ & $\mathrm{t} \infty_{2}$ eq & $1.687,28$ & $\mathrm{t} \infty_{2}$ eq \\
\hline Subtotal & & & & & \\
\hline & Alcance 1 & 4,803 & $\mathrm{t} \mathrm{CO}_{2} \mathrm{eq}$ & 3,219 & $\mathrm{t} \mathrm{CO}_{2} \mathrm{eq}$ \\
\hline & Alcance 2 & $1.332,70$ & $\mathrm{t} \mathrm{CO}_{2} \mathrm{eq}$ & 816,81 & $\mathrm{t} \mathrm{CO}_{2} \mathrm{eq}$ \\
\hline & Alcance 3 & $1.687,28$ & t $\mathrm{CO}_{2} \mathrm{eq}$ & $1.687,28$ & t $\mathrm{CO}_{2} \mathrm{eq}$ \\
\hline $\begin{array}{l}\text { Huella de } \\
\text { Carbono }\end{array}$ & Total & $3.024,78$ & $\mathrm{t} \mathrm{CO}_{2}$ eq & $2.507,30$ & t $\mathrm{CO}_{2} \mathrm{eq}$ \\
\hline
\end{tabular}

\section{Resultados huella hídrica}

La huella hídrica asociada al Bombeo sa Costera es de 51.142.382,00 m³/año en el 2019 y de 39.618,60 m³/año en el 2020, al suponer el agua no registrada de la instalación un $1 \%$ del total del volumen bombeado. La diferencia entre ambos valores es debido a que el caudal captado en 2020 fue inferior al captado en 2019.

\section{b) Bombeo sa Marineta}

La actividad extractiva por parte de la Agencia Balear del agua del acuífero de Sa Marineta se inició a principios de los 2000. Actualmente 
hay 5 pozos distribuidos en los municipios de Llubí, Son Mulet, Binifalet, Son Sitges y Ses Lletreres. Estos pozos se utilizan para suministrar agua a los municipios de Palma y Calvià con un máximo de $1,5 \mathrm{hm}^{3}$ anuales por municipio.

\section{Resultados huella de carbono}

Tabla 32. Huella de carbono del Bombeo sa Marineta en el año 2019 y 2020

\begin{tabular}{|c|c|c|c|c|c|}
\hline \multicolumn{2}{|c|}{ Huella de carbono del bombeo sa Marineta } & \multicolumn{2}{|c|}{2019} & \multicolumn{2}{|c|}{2020} \\
\hline \multicolumn{6}{|l|}{ Alcance 1} \\
\hline & Emisiones Instalaciones fijas & 7,01 & $\mathrm{t} \infty_{2}$ eq & 3,44 & $\mathrm{t} \infty_{2}$ eq \\
\hline & Vehículos & 0,022 & $\mathrm{t} \infty_{2}$ eq & 0,022 & $\mathrm{t} \infty_{2}$ eq \\
\hline \multicolumn{6}{|l|}{ Alcance 2} \\
\hline & Emisiones Instalaciones fijas & 539,51 & $\mathrm{t} \mathrm{CO}_{2}$ eq & 285,45 & $\mathrm{t} \infty_{2}$ eq \\
\hline \multicolumn{6}{|l|}{ Alcance 3} \\
\hline & Vehículos & 847,28 & $\mathrm{t} \mathrm{O}_{2}$ eq & 847,28 & $\mathrm{t} \infty_{2}$ eq \\
\hline \multicolumn{6}{|l|}{ Subtotal } \\
\hline & Alcance 1 & 7,035 & $\mathrm{t} \mathrm{CO}_{2} \mathrm{eq}$ & 3,460 & t $\mathrm{CO}_{2}$ eq \\
\hline & Alcance 2 & 539,51 & $\mathrm{t} \mathrm{CO}_{2}$ eq & 285,45 & t $\mathrm{CO}_{2}$ eq \\
\hline & Alcance 3 & 847,28 & t $\mathrm{CO}_{2}$ eq & 847,28 & t $\mathrm{CO}_{2}$ eq \\
\hline \multicolumn{6}{|l|}{ Huella de } \\
\hline Carbono & Total & $1.393,83$ & t $\mathrm{CO}_{2} \mathrm{eq}$ & $1.136,18$ & t $\mathrm{CO}_{2}$ eq \\
\hline
\end{tabular}

\section{Resultados huella hídrica}

La huella hídrica asociada al Bombeo sa Marineta es de 242.103,05 m³ año en el 2019 y de 184.141,05 m³/año en el 2020, al suponer el agua no registrada de la instalación un $5 \%$ del total del volumen bombeado.

\section{c) Bombeo s'Estremera}

La evolución mensual de las extracciones en s'Estremera (Figura 26) fluctúan en función de las infiltraciones, marcadas a su vez por la climatología de cada año: 
- Desde noviembre del 2014 a marzo del 2015, las infiltraciones no superan las extracciones.

- En el año 2016 las extracciones estivales decayeron. El episodio de sequía impidió continuar con la actividad extractiva puesto que la infiltración natural del acuífero fue muy baja durante ese año.

- El verano del 2017 se priorizó la desalación ante la captación de agua para recuperar el estado óptimo del acuífero. Durante este verano, además, se promueve la infiltración de agua en s'Estremera.

- Durante la temporada alta del 2019 se decidió potenciar el uso de las desaladoras frente la extracción de agua de los acuíferos para garantizar el buen estado de estos. De este modo la curva de extracciones se allana durante el verano evitando así las bajadas repentinas del nivel piezométrico del acuífero. Esta nueva gestión de las extracciones fomenta la estabilidad estructural del acuífero confinado.

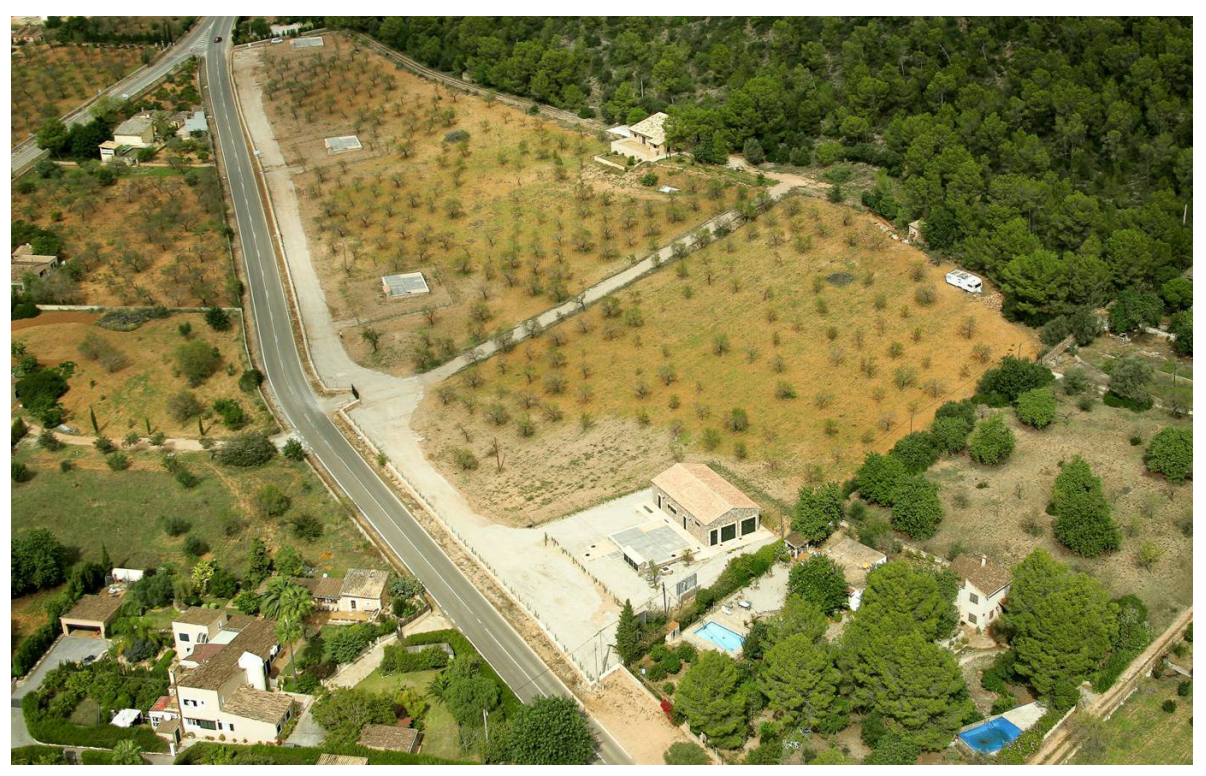

Figura 26. Localización del Bombeo s’Estremera en Mallorca 
Resultados huella de carbono

Tabla 33. Huella de carbono del Bombeo s'Estremera en el año 2019 y 2020

\begin{tabular}{|c|c|c|c|c|c|}
\hline \multirow{2}{*}{\multicolumn{2}{|c|}{$\begin{array}{l}\text { Huella de carbono del bombeo s'Estremera } \\
\text { Alcance } 1\end{array}$}} & \multicolumn{2}{|c|}{2019} & \multicolumn{2}{|c|}{2020} \\
\hline & & & & & \\
\hline & Emisiones Instalaciones fijas & 5,26 & $\mathrm{t} \mathrm{CO}_{2}$ eq & 2,36 & $\mathrm{t} \infty_{2}$ eq \\
\hline & Vehículos & 0,022 & $\mathrm{t} \infty_{2}$ eq & 0,022 & $\mathrm{t} \infty_{2}$ eq \\
\hline \multicolumn{6}{|l|}{ Alcance 2} \\
\hline & Emisiones Instalaciones fijas & 631,19 & t $\infty_{2}$ eq & 273,71 & $\mathrm{t} \infty_{2}$ eq \\
\hline \multicolumn{6}{|l|}{ Alcance 3} \\
\hline & Vehículos & 847,28 & $\mathrm{t} \mathrm{CO}_{2}$ eq & 847,28 & $\mathrm{t} \infty_{2}$ eq \\
\hline \multicolumn{6}{|l|}{ Subtotal } \\
\hline & Alcance 1 & 5,282 & $\mathrm{t} \mathrm{CO}_{2}$ eq & 2,386 & $\mathrm{t} \mathrm{CO}_{2}$ eq \\
\hline & Alcance 2 & 631,19 & t $\mathrm{CO}_{2}$ eq & 273,71 & $\mathrm{t} \mathrm{CO}_{2}$ eq \\
\hline & Alcance 3 & 847,28 & $\mathrm{t} \mathrm{CO}_{2} \mathrm{eq}$ & 847,28 & $\mathrm{t} \mathrm{CO}_{2} \mathrm{eq}$ \\
\hline $\begin{array}{l}\text { Huella de } \\
\text { Carbono }\end{array}$ & Total & $1.483,74$ & $\mathrm{t} \mathrm{CO}_{2}$ eq & $1.123,37$ & $\mathrm{t} \mathrm{CO}_{2}$ eq \\
\hline
\end{tabular}

\section{Resultados huella hídrica}

La huella hídrica asociada al Bombeo s'Estremera es de 198.082,75 $\mathrm{m}^{3} /$ año en el 2019 y de $118.956,15 \mathrm{~m}^{3} / a n ̃ o$, al suponer el agua no registrada de la instalación un $4,19 \%$ del total del volumen bombeado.

\subsection{RED DE DISTRIBUCIÓN EN ALTA}

La Agencia Balear del agua suministra agua a 21 de los 67 municipios de las Islas Baleares que representa el $30 \%$ de los municipios de las Baleares: 14 municipios de la isla de Mallorca, 5 municipios de la isla de Ibiza, 1 municipio de Menorca y 1 municipio de Formentera. Para ello, dispone de una red de tuberías de, aproximadamente, $271 \mathrm{~km}$ en las Islas Baleares: $175 \mathrm{~km}$ en la isla de Mallorca, $80 \mathrm{~km}$ en la isla de Ibiza, $11 \mathrm{~km}$ en la isla de Formentera y $5 \mathrm{~km}$ en la isla de Menorca. 
Dentro de las redes de distribución, uno de los parámetros más significativos de la eficiencia en la distribución del agua, son las pérdidas de agua no registrada en la red

Las pérdidas de agua no registrada hacen referencia al volumen de agua distribuida, pero que no llega al usuario final. El agua que se pierde en una red puede ser debido a pérdidas reales 0 aparentes (Figura 27). Las pérdidas reales se deben principalmente a los siguientes aspectos: materiales defectuosos o inadecuados, roturas de tubos por mala ejecución de puesta en obra, errores de explotación, corrosión, fisuras, fallos en accesorios de la red, etc. Sin embargo, las pérdidas aparentes se deben principalmente a una instalación incorrecta de medidores, fugas en la instalación interior, acometidas clandestinas, antigüedad del parque de contadores, contadores manipulados, etc.

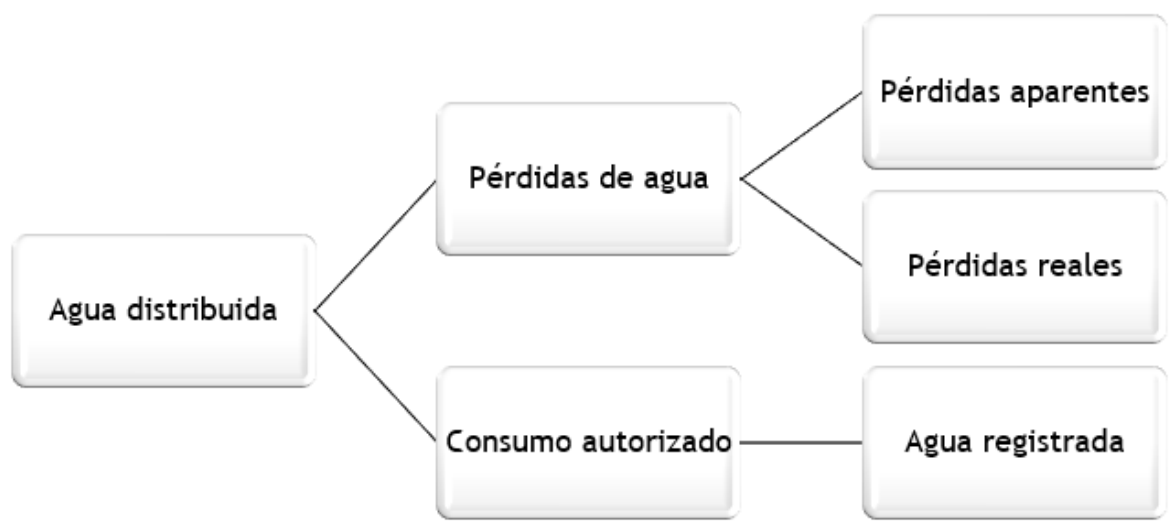

Figura 27. Esquema del agua distribuida en una red municipal

Una buena gestión del agua no registrada puede conllevar los siguientes beneficios para el explotador de la instalación:

- Se cubre la demanda con menos recursos

- Preservación de los recursos hídricos 
- Menor riesgo de contaminación

- Mejora la calidad del servicio

- Se tiene un mayor y mejor conocimiento del sistema

Dentro de la huella hídrica, las pérdidas de agua no registrada se contabilizan como huella hídrica azul.

\subsection{1.. MALLORCA}

\section{Resultados huella de carbono}

Nos encontramos ante una red que tiene emisiones asociadas también a los 3 alcances, donde el alcance 3 se dispara ya que, como hemos visto, el combustible de los vehículos de empresas externas, trabajadores/as y gestión de residuos suponen una elevada generación de emisiones de $\mathrm{CO}_{2}$ a la atmósfera.

Tabla 34. Huella de carbono de la red de distribución en alta de la isla de Mallorca en el año 2019 y 2020

\begin{tabular}{|c|c|c|c|c|c|}
\hline Huella d & carbono de la red en alta de Mallorca & 2019 & & 202 & \\
\hline Alcance 1 & & & & & \\
\hline & Emisiones Instalaciones fijas & 16,90 & $\mathrm{t} \infty_{2}$ eq & 31,25 & $\mathrm{t} \infty_{2}$ eq \\
\hline & Vehículos & 0,86 & $\mathrm{t} \infty_{2}$ eq & 0,86 & $\mathrm{t} \infty_{2}$ eq \\
\hline Alcance 2 & & & & & \\
\hline & Emisiones Instalaciones fijas & $1.096,63$ & $\mathrm{t} \infty_{2}$ eq & 784,89 & $\mathrm{t} \infty_{2}$ eq \\
\hline Alcance 3 & & & & & \\
\hline & Vehículos & $10.188,92$ & $\mathrm{t} \infty_{2}$ eq & $10.188,92$ & $\mathrm{t} \mathrm{O}_{2}$ eq \\
\hline Subtotal & & & & & \\
\hline & Alcance 1 & 17,77 & $\mathrm{t} \mathrm{CO}_{2} \mathrm{eq}$ & 32,12 & $t \mathrm{CO}_{2}$ eq \\
\hline & Alcance 2 & $1.096,63$ & t $\mathrm{CO}_{2}$ eq & 784,89 & $t \mathrm{CO}_{2}$ eq \\
\hline & Alcance 3 & $10.188,92$ & $\mathrm{t} \mathrm{CO}_{2}$ eq & $10.188,92$ & $t \mathrm{CO}_{2}$ eq \\
\hline $\begin{array}{l}\text { Huella de } \\
\text { Carbono }\end{array}$ & Total & $11.303,32$ & $\mathrm{t} \mathrm{CO}_{2} \mathrm{eq}$ & $11.005,93$ & $t \mathrm{CO}_{2}$ eq \\
\hline
\end{tabular}




\section{Resultados huella hídrica}

La huella hídrica de la red de distribución de agua potable en alta en la isla de Mallorca queda definida por las pérdidas de agua no registrada de la red que se cifran en un volumen de 785.761,59 m³/año en el 2019 y de $261.765,37 \mathrm{~m}^{3} /$ año en el 2020 , al suponer el agua no registrada de la red entre un 3 y un $5 \%$ del total que circula por ella. 


\section{CONCLUSIONES DEL ESTUDIO}

Una vez estudiado el ciclo integral del agua en las Islas Baleares, se han extraído diversas conclusiones que se exponen a continuación:

Las instalaciones que mayor huella de carbono presentan son las estaciones desaladoras de agua de mar, debido principalmente al gran consumo eléctrico que estas tienen. Además, al no contar ninguna de las instalaciones con una suministradora eléctrica cuyo mix eléctrico sea igual a cero, no se anula el alcance 2 en ninguno de los casos, siendo de notable importancia en las IDAM. Otro de los aspectos que marca la mayor o menor huella de carbono de las IDAM es el alcance 3. Aquellas desaladoras más grandes, como es el caso de la Ciutadella Sud en Menorca, por ejemplo, funcionan también como almacén de repuestos y reactivos, desde donde se reparten al resto de las desaladoras de la zona. Por lo tanto, las empresas proveedoras acuden con mayor regularidad a estas instalaciones, que después repartirán de forma interna los productos entre sí. Además, las instalaciones de mayor entidad cuentan generalmente con un mayor número de trabajadores/ as. Esto es importante debido a que los trayectos realizados por los vehículos de trabajadores y empresas externas (averías, recursos, suministros, gestión de residuos, etc.), se repercuten a la instalación que requiere de dichos servicios y mano de obra, incrementando así el alcance 3 y, por lo tanto, la huella de carbono global de la desaladora.

A continuación, se encontrarían los bombeos de agua potable que extraen agua del acuífero, ya que estos requieren de energía producida por la quema de combustibles fósiles (alcance 1) y/o por la electricidad (alcance 2), para poder llevar el agua hasta la superficie. 
Por su parte, la red de distribución de agua potable en alta también presenta una huella de carbono comparable a la de los bombeos, ya que en algunos tramos de la red se hace necesario impulsar el agua (debido principalmente a las diferencias de cotas existentes a lo largo del recorrido).

Por lo tanto, disminuyendo el uso de combustibles fósiles de la instalación, y contando con empresas suministradoras eléctricas cuyo mix eléctrico sea cero, es posible reducir de manera notable los dos primeros alcances de la huella de carbono. Respecto al alcance 3 hay que tener en cuenta que no son emisiones que dependan directamente de la empresa explotadora, pero deben también considerarse para mejorar la gestión global y la relación de la empresa con su entorno.

Con respecto a las depuradoras de aguas residuales, estas se colocan como las que presentan menores emisiones de $\mathrm{CO}_{2}{ }^{1}$ del ciclo del agua en Baleares. Esto se debe principalmente a un alcance 1 conformado solo por las emisiones asociadas a pequeños recorridos de los vehículos de empresa y un alcance 2 más bajo que el de las desaladoras y bombeos, al tener unos consumos eléctricos las depuradoras de Baleares de entre 50.000 kWh/año y 700.000 kWh/ año (mientras que las desaladoras y bombeos se mueven en un rango entre 1.000 .000 y $3.500 .000 \mathrm{kWh} /$ año).

En España, se han consultado otros estudios de referencia, donde se ha estudiado la huella de carbono del ciclo integral del agua: Islas Canarias $^{2}$ y Murcia (Nevado et al., 2016).

\footnotetext{
1 Hay que tener en cuenta aquí que las emisiones de metano y óxido nitroso de las EDAR de Baleares no se han calculado en este estudio, y podrían elevar significativamente el número de emisiones asociadas a estas instalaciones.

2 Los resultados de este informe son aún inéditos, y estarán a disposición del público en el año 2021 con el título de «La Huella Ecológica del Agua en las Islas Canarias, España» (Cruz-Pérez, et al., n.d.)
} 
En Murcia, los valores de huella energética calculados en las EDAR presentan también una correlación entre el caudal tratado y la huella obtenida (a mayores caudales, en general, mayores valores de huella energética). Sin embargo, se observan en las EDAR de Murcia unos valores de huella ecológica más elevados debido a que el valor medio de los caudales tratados supera al valor de los caudales de las Islas Baleares, a que han incluido en el cálculo el valor del metano y óxido nitroso de las plantas, y a que tienen consumos de combustibles fósiles asociados al alcance 1 debidos a la depuración y a bombeos (mientras que en Baleares no hay consumo de combustibles fósiles en ese aspecto, solo en vehículos).

Por otra parte, si comparamos los dos archipiélagos españoles entre sí obtenemos las siguientes diferencias:

- Los kg de $\mathrm{CO}_{2 \mathrm{eq}}$ por metro cúbico de agua desalada son inferiores en Canarias que en Baleares, pero esto se debe a que los caudales desalados en las IDAM que se han estudiado en Canarias son inferiores a los de Baleares. Sí se observa, sin embargo, que en aquellas desaladoras que manejan caudales elevados y son comparables entre sí, los valores de la huella de carbono permanecen inferiores en Canarias frente a los de las Islas Baleares

- Los valores de las EDAR presentan mucha similitud entre sí, obteniéndose los mismos rangos de emisiones para los mismos caudales tratados

- También los pozos y sondeos presentan valores muy similares de huella de carbono en los dos archipiélagos

- En relación con la eficiencia de las redes de abastecimiento en alta, sí es clara la diferencia entre los archipiélagos, siendo aquí el balear el que tiene unas pérdidas considerablemente menores (valores inferiores al 10\%) frente al archipiélago canario (valores de hasta $35 \%$ en algunas islas) 
Con respecto a la huella hídrica, son las desaladoras de agua de mar las que tienen una huella hídrica menor, al no contemplarse el agua de mar dentro del cálculo por considerarse una fuente inagotable del recurso. Para el resto de las instalaciones, es la red de distribución la que presenta una mayor huella hídrica, al circular por ella un caudal de abastecimiento constante y contar con unas pérdidas de aproximadamente el $5 \%$. Los pozos, por su parte, presentan una huella hídrica menor debido a que trabajan con caudales inferiores a los de la red de distribución y proviene de las pérdidas de la instalación, que se encuentran entre el 1 y el $4 \%$.

Según un estudio realizado en España por Sotelo Navalpotro et al. (2012), «El abastecimiento urbano de agua representa el $4.5 \%$ de la huella hídrica de España, valor inferior al de Italia y Estados Unidos, y ligeramente superior al de India. El 14,7\% del consumo total de agua corresponde al sector industrial, pero el $47 \%$ se debe al agua virtual procedente de las importaciones. El porcentaje restante (81,7\%) corresponde a la producción de alimentos, del cual, las dos terceras partes se producen con recursos hídricos propios».

Por lo tanto, para disminuir la huella hídrica de las instalaciones estudiadas es clave reducir al mínimo las pérdidas de cada una de ellas, debido a que es un volumen de agua potable que se extrae del acuífero y que nunca llega a ser utilizada por los/as usuarios/as finales.

En relación con la huella hídrica gris, se ha estudiado esta para las depuradoras de aguas residuales, al ser las únicas instalaciones que gestionan aguas residuales y que, por lo tanto, contienen contaminantes que es necesario eliminar o reducir su concentración, para poder devolverlas a torrente, mar, lagunas o pozos de infiltración. En las Islas Canarias se han obtenido valores similares de la huella hídrica gris, al depender este valor de la carga contaminante de las aguas (que se ha asumido que es la misma para los dos archipiélagos). 


\section{RECOMENDACIONES}

La descarbonización del mix energético y la apuesta por las energías renovables deben ser uno de los pilares de la lucha contra el cambio climático. Por ello se recomienda que toda la energía que se use para el funcionamiento de las infraestructuras hidráulicas provenga de un contrato que implique el uso fuentes de energías renovables.

En relación con la reducción de la huella de carbono, tendríamos las siguientes medidas específicas para los diferentes procesos que conforman el ciclo del agua:

- Captación: utilización de bombas de alta eficiencia que cuenten con variadores de frecuencia; uso de filtros con una menor pérdida de carga

- Desalación: empleo de paneles solares para aumentar la autosuficiencia energética de la instalación; uso de membranas "Low Energy» en las IDAM; Recuperación por sistema de cámaras isobáricas; Concentrador de salmuera

- Distribución: recuperación mediante empleo de turbinas en aquellas zonas de la red donde se produzca un cambio de cota que se pueda aprovechar energéticamente; uso de variadores de frecuencia en las bombas

- Depuración: empleo de paneles solares para aumentar la autosuficiencia energética de la instalación; uso de variadores de frecuencia en las bombas; recuperación energética de los lodos para aprovechamiento de biogás y abonos

- Rechazo: aprovechamiento de la salida al mar mediante turbina de recuperación de energía 
Por otra parte, y de forma general, se proponen las siguientes medidas para reducir la huella de carbono:

- Potenciar el uso del transporte público entre los trabajadores de la instalación

- Minimizar el uso de papel y otros consumibles, de tal manera que se pueda reducir también la cantidad de proveedores 0 , al menos, que se logren espaciar sus visitas en el tiempo

- Fomentar la contratación de distribuidores con flotas de transporte eficiente (vehículos eléctricos o con bajas emisiones)

- Evitar desplazamientos laborales innecesarios y minimizar los viajes de trabajo que se puedan sustituir por reuniones online

- Facilitar el teletrabajo al personal de la instalación en la medida de lo posible, para minimizar los recorridos asociados al alcance 3 de la huella de carbono

- Contratar electricidad que provenga enteramente de fuentes renovables, lo que generaría que el Alcance 2 quedase compensado (suministradoras con $\mathrm{GdO}$ ) $^{3}$

- Tratar de producir energía eléctrica dentro de las instalaciones, para reducir la dependencia del exterior y la economía circular. En el caso de las depuradoras de aguas residuales puede aprovecharse la energía procedente del biogás (en aquellas que traten los fangos de forma interna y no mediante gestor autorizado). En todas las instalaciones pueden emplearse placas solares para autoconsumo y excedentes

\footnotetext{
3 Se ha puesto en conocimiento de los/as autores/as que, en noviembre de 2020, ABAQUA firma un Contrato Marco en el que se garantiza que el suministro eléctrico a partir de ese momento será con energía $100 \%$ renovable. De esta manera, se reducirá la huella de carbono de las instalaciones de manera muy significativa, al conseguir que el alcance 2 de aquellas instalaciones que consumen electricidad, será cero.
} 
- Comunicar internamente a los/as trabajadores/as de la organización los conceptos asociados al cálculo de la huella de carbono, así como los resultados de esta. Una concienciación interna en la compañía puede ayudar a un uso más consciente de la energía y los recursos

- Continuar realizando el cálculo de la huella de carbono en los años venideros, para poder ver la evolución respecto al año base calculado y poder cuantificar si las medidas de reducción han funcionado

Para lograr una reducción de la huella hídrica, se propone considerar los siguientes aspectos:

- Reutilización del agua en los procesos industriales en los que sea posible. Es decir, cerrar el círculo del agua dentro de cada instalación de tal manera que el agua se recircule y se reutilice todo lo posible, para usos como refrigeración, por ejemplo. Considerar el agua de lluvia como fuente para estos usos también.

- En las instalaciones de depuración de aguas residuales, se propone reutilizar la mayor cantidad posible de agua depurada, en lugar de desviar los caudales tratados al medio (torrente, mar, o laguna)

En cuanto a la recuperación de metano, existen numerosas alternativas que ya están en funcionamiento en el territorio nacional, dentro de las que encontramos las siguientes:

- Instalación de digestores anaeróbicos de lodo: se utilizan para procesar los biosólidos de las aguas residuales y producir biogás, el cual puede utilizarse para compensar el empleo de combustible.

- Instalación de dispositivos de desgasificación por oxidación: a través de la desgasificación se busca transformar el metano 
disuelto en el efluente del agua residual, en dióxido de carbono y oxígeno.

- Utilización de digestores de gas para la generación de calor y/o electricidad: consiste en utilizar el metano generado en el sistema como combustible para la producción de calor y/o electricidad dentro de la propia instalación, minimizando la compra de energía y, por ende, las emisiones asociadas al segundo alcance de la huella de carbono. 


\section{REFERENCIAS Y BIBLIOGRAFÍA RECOMENDADA}

Arvizu, D.; Bruckner, T.; Chum, H.; Edenhofer, O.; Estefen, S.; Faaij, A.; Fischedick, M.; Hansen, G.; Hiriart, G.; Hohmeyer, O.; Hollands, K.; Huckerby, J.; Kadner, S.; Killingtveit, A.; Kumar, A.; Lewis, A.; Lucon, O.; Matschoss, P.; Maurice, L.; Mirza, T. (2011). IPCC Special Report on Renewable Energy Sources and Climate Change Mitigation (p. 1088). Cambridge University Press. https://www.ipcc.ch/report/renewableenergy-sources-and-climate-change-mitigation

Cabrera, E.; Estrela, T.; Lora, J. (2019). Pasado, presente y futuro de la desalación en España. Ingeniería Del Agua, 23(3), 199-214.

CEPAL. (2008). Metodologías de cálculo de la huella de carbono y sus potenciales implicaciones para América Latina.

Doorn, M. R. J., Towprayoon, S., Manso Vieira, S. M., Irving, W., Palmer, C., Pipatti, R., \& Wang, C. (2006). Tratamiento y eliminación de aguas residuales. In Directrices del IPCC de 2006 para los inventarios nacionales de gases de efecto invernadero (pp. 1-31).

Ercin, A. E., Aldaya, M. M., \& Hoekstra, A. Y. (2011). Corporate Water Footprint Accounting and Impact Assessment: The Case of the Water Footprint of a Sugar-Containing Carbonated Beverage. Water Resources Management, 25(2), 721-741. https://doi. org/10.1007/s11269-010-9723-8

García, C.; Amengual, A.; Homar, V.; Zamora, A. (2017). Losing water in temporary streams on a Mediterranean island: Effects of climate 
and land-cover changes. Global and Planetary Change, 148, 139152.

García C.; Rodríguez-Lozano, P. (2020). Cinco aspectos clave en la gestión del agua de las Islas Baleares. In Colegio Oficial de Ingenieros de Montes (Ed.), Los procesos de planificación hidrológica en la península ibérica e islas en un contexto de cambio climático.

Govern de les Illes Balears. (2015). Plan Hidrológico de las Illes Balears 2015-2021 (p. 497). http://observatoriaigua.uib.es/repositori/ phib_2015_memoria.pdf

Hoekstra, A.Y.; Chapagain, A.K.; Aldaya, M.M.; Mekonnen, M. M. (2012). The Water Footprint Assessment Manual. Earthscan.

IDAE. (2008). Manual de Geotermia. In 3C Tecnología_Glosas de innovación aplicadas a la pyme (Vol. 4, Issue 3). https://doi. org/10.17993/3ctecno.2015.v4n3e15.96-108

IPCC. (2014). Climate Change 2014: Impacts, Adaptation and Vulnerability.

Navalpotro, J. A. S., Cantos, J. O., Quiroga, F. G., \& Pérez, M. S. (2012). Huella hídrica de España y su diversidad territorial. Estudios Geograficos, 73(272), 239-272. https://doi.org/10.3989/estgeogr. 201209

Nevado, S., Gomis, A., Mena, E., \& Castro, M. (2016). Cálculo de la huella de carbono del ciclo urbano del agua. La experiencia de Emuasa. TecnoAqua, 19, 58-65.

Pellicer-Martínez, F. (2014). La evaluación de la Huella Hídrica Gris en una Demarcación Hidrográfica. Congreso Nacional Del Medioambiente, 26. www.conama2014.org

WFN. (2002). Manual de Evaluacion HH. 44. http://waterfootprint. org/media/downloads/ManualEvaluacionHH.pdf

World Bank. (2015). Electricity production from hydroelectric sources. https://data.worldbank.org/indicator/EG.ELC.HYRO.ZS 


\section{ACRÓNIMOS}

CH4: Metano

CO2eq: Dióxido de carbono equivalente

CO2: Dióxido de carbono

COVID-19: Coronavirus

FAO: Organización de las Naciones Unidas para la Alimentación y la Agricultura

GEI: Gases de efecto invernadero

ha: Hectárea

IPCC: Grupo Intergubernamental de Expertos sobre el Cambio Climático

ISO: Organización Internacional de Normalización

kWh: kilovatio hora

N2O: Óxido nitroso

ODS: Objetivos de Desarrollo Sostenible

OMS: Organización Mundial de la Salud

ONU: Organización de las Naciones Unidas

PIB: Producto Interior Bruto 


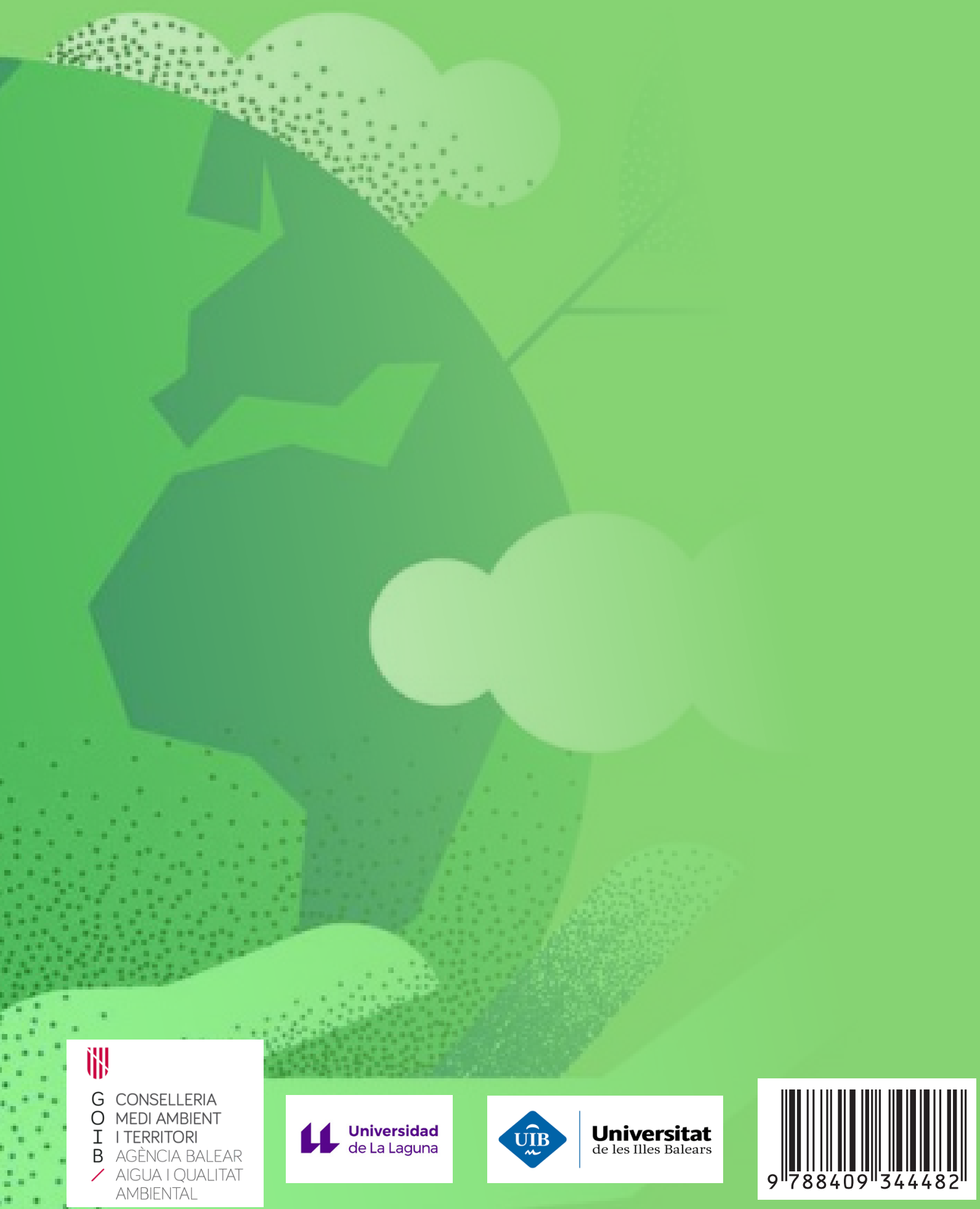

